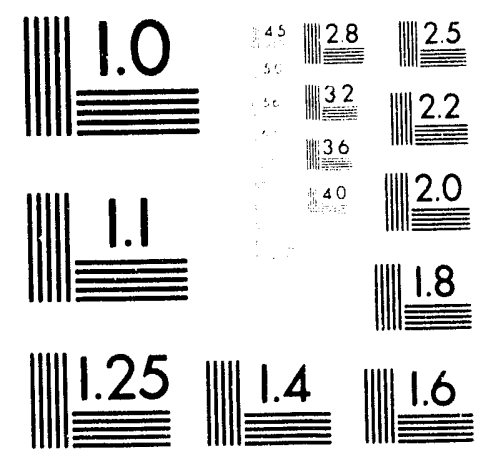



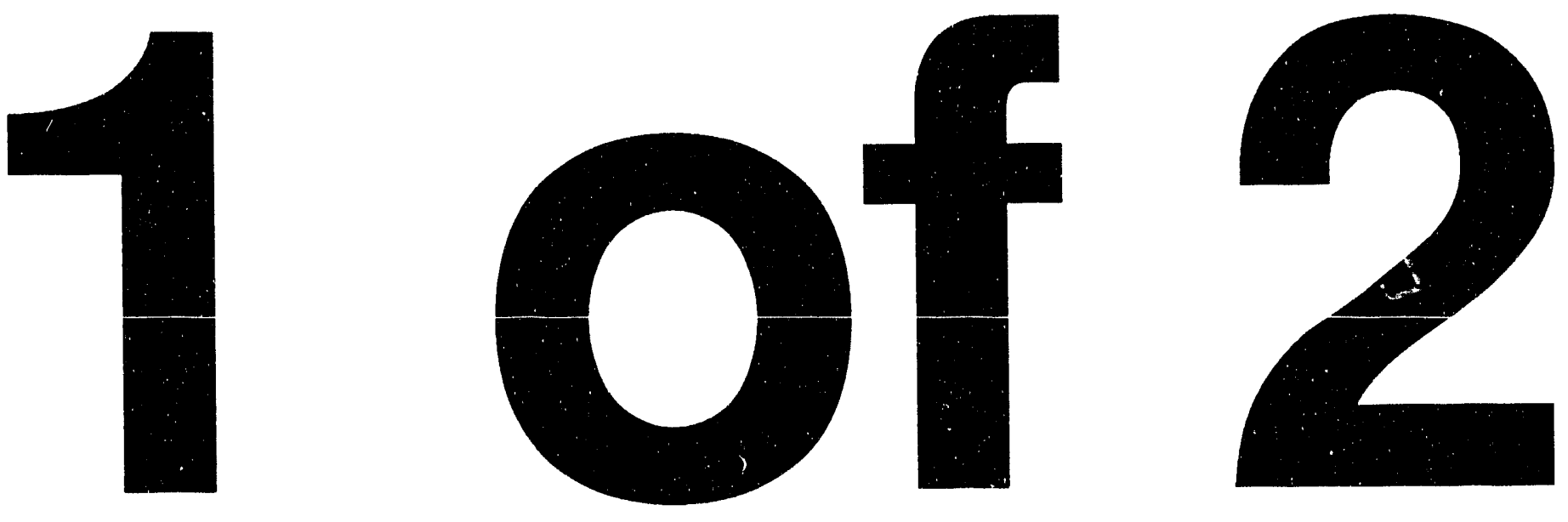


\title{
Electricity End-Use Efficiency: Experience with Technologies, Markets, and Policies throughout the World
}

\author{
M.D. Levine, ${ }^{1}$ H. Geller, ${ }^{2}$ J. Koomey, ${ }^{1}$ S. Nadel, ${ }^{2}$ and L. Price ${ }^{1}$ \\ ${ }^{1}$ Energy and Environment Division \\ Lawrence Berkeley Laboratory \\ University of California \\ Berkeley, California 94720 \\ 2American Council for an Energy-Efficient Economy, \\ Washington, DC 20036
}

March 1992

This work was funded by the Deputy Undersecretary of the Office of Policy, Planning, and Analysis of the U.S. Department of Energy under Contract No. DE-AC03-76SF00098, and Oak Ridge National Laboratory, Contract No. DE-AC05-840R21400. 
In its August meeting in Geneva, the Energy and Industry Subcommittec (EIS) of the Policy Response Panel of the Intergovemmental Panel on Climate Change (IPCC) identified a series of reports to be produced. One of these reports was to be a synthesis of available information on global electricity end-use efficiency, with emphasis on developing nations. The repon will be reviewed by the IPCC and approved prior to the U.N. Conference on Environment and Development (UNCED), Brazil, June 1-12, 1992.

A draft outline for the report was submitted for review at the November 1991 meeting of the EIS. This outline, which was accepted by the EIS, identified three main topics to be addressed in the repor:

- status of available technologies for increasing electricity end-use efficiency

- review of factors currently limiting application of end-use efficiency technologies

- review of policies available to increase electricity end-use efficiency

The United States delegation to the EIS agreed to make arrangments for the writing of the report. The U.S. Department of Energy then agreed to support the project and requested Dr. Mark D. Levine of the Lawrence Berkeley Laboratory to be the lead author.

This report is the result. The analysis and conclusions are those of the authors, until the report is adopted by the EIS and the IPCC. The conclusions of the report are contained in the executive summary. A very brief statement of them is:

A substantial fraction of increased anthropogenic carbon emissions over the next several decades is likely to come from electricity generation. Increases in end-use efficiency improvements beyond those expected to occur under current policies could cut the growth of electricity use and associated growth in projected carbon emissions significantly. There is sufficient experience among industrialized countries in the technologies, programs, and policies to have confidence that significant increases in electricity end-use efficiency are possible. It appears that many of these increases can be achieved in a cost-effective manner. Making these efficient electricity end-use technologies widely available to developing countries is an essential part of a successful strategy to curtail growth in carbon dioxide emissions. 
The authors wish to thank a number of individuals who have contributed to this report. This work would not have happened if the members of the Energy and Industry Subcommittee of the Intergovernmental Panel on Climate Change had not decided to produce a report on this subject. Similarly, we are grateful to Edward R. Williams for agreeing to have us produce the report.

The authors of the report have contributed in different ways. The lead author, Mark D. Levine, was responsible for organizing the overall effort and for the substantive editing of the whole report. He also was the lead author of the Executive Summary, Chapter $1^{*}$ (Introduction), 4 (Policy) and 5 (Conclusions). Howard Geller and Steven Nadel wrote Chapter 2 (Technology). Lynn Price and Jonathan G. Koomey wrote Chapter 3 (Barriers).

Chapter 4 (Policy) was organized so as to gain inputs from a large number of individuals who are experts in their fields. Individuals who provided very useful information for this Chapter include Ed Vine ${ }^{1}$ (information programs), Lawrence J. Hill ${ }^{2}$ (electricity pricing), Isaac Turiel ${ }^{1}$ (appliance standards), Michael L'Ecuyer ${ }^{3}$ and James E. McMahon ${ }^{1}$ (financial incentives to appliance manufacturers), Katy Janda ${ }^{1}$ (commercial building standards), Joe Eto ${ }^{1}$ (integrated resource planning), David Wolcott ${ }^{4}$ (private sector delivery of demand-side management services), Evan Mills ${ }^{1}$ (European demand-side programs), Alain Streicher ${ }^{5}$, John Armstrong 5 and Ignacio Rodriguez ${ }^{5}$ (programs in developing countries). Howard Geller contributed the section of Chapter 4 on DSM programs. Lynn Price edited and wrote various sections of the chapter.

Ned Helme ${ }^{6}$, Mark Popovich ${ }^{6}$ and Rich Howarth ${ }^{1}$ produced ideas and written material relating to policy approaches and scenarios that could serve as a basis for future work. All of these individuals gave very generously of their time, producing information that was valuable to the effort.

We thank Ted Gartner and Kristen Nickel for able assistance preparing the report for production while learning the vagaries of new software.

The report has benefited from reviews by many individuals. In particular, we wish to thank Edward R. Williams and Howard Gruenspecht of the U.S. Department of Energy for their thorough and thoughtful reviews of the entire report. Several of our colleagues have also reviewed the report. We particularly wish to mention Jeff Harris (of Lawrence Berkeley Laboratory), Michael Totten (of the International Institute for Energy Conservation), and Professor Marc Ross (of the University of Michigan).

\footnotetext{
* with Steven Meyers of Lawrence Berkeley Laboratory

1 Lawrence Berkeley Laboratory, Berkeley, California

2 Oak Ridge National Laboratory, Oak Ridge, Tennessee

3 U.S. Environmental Protection Agency, Washington, D.C.

4 N.Y. Energy Research and Development Agency, Albany, N.Y.

5 RCG/Hagler Bailly, Inc., Washington, D.C.

6 Center for Clean Air Policy, Washington, D.C.
} 
EXECUTIVE SUMMARY

1.0 IMPORTANCE OF ELECTRICITY END-USE EFFICIENCY ............... i

2.0 TECHNOLOGIES TO INCREASE ELECTRICITY END-USE EFFICIENCY iii

3.0 FACTORS LIMITING ACCEPTANCE OF EFFICIENT TECHNOLOGIES iii

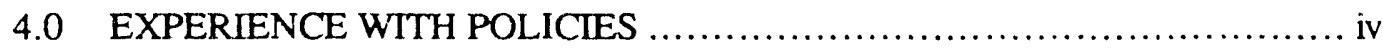

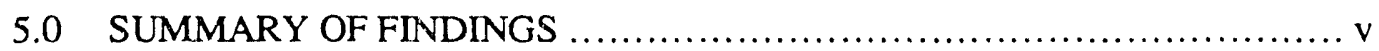

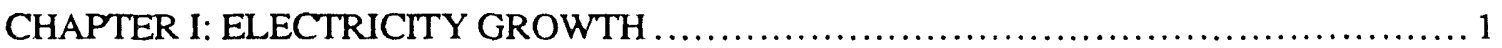

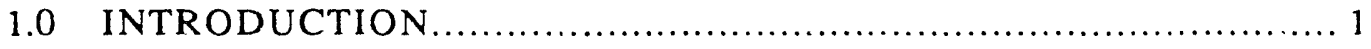

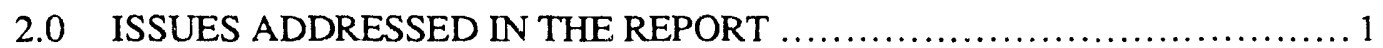

3.0 TRENDS IN WORLD ELECTRICTTY CONSUMPTION ................... 2

3.1 Overall Electricity Growth................................................... 2

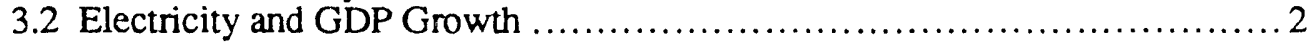

3.3 Electricity Use Per Capita ............................................. 5

3.4 Change in Energy Sources for Electricity Generation ......................... 5

3.5 Patterns of Electricity Consumption ..................................... 5

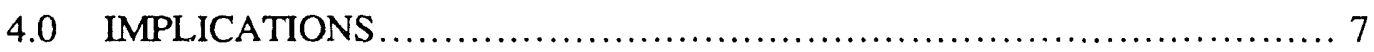

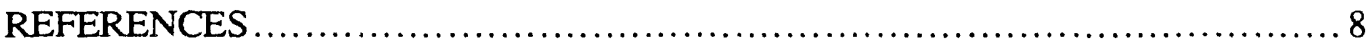

CHAPTER 2: TECHNOLOGIES TO ACHIEVE GREATER ELECTRICITY END-USE

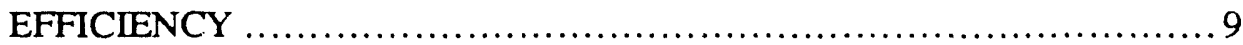

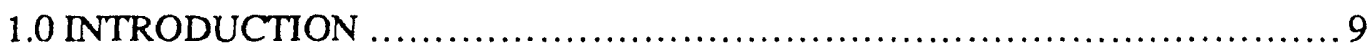

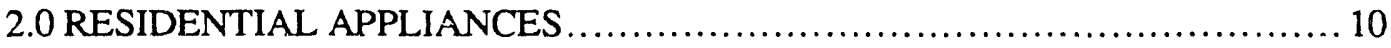

2.1 Refrigerators and Freezers................................................. 11

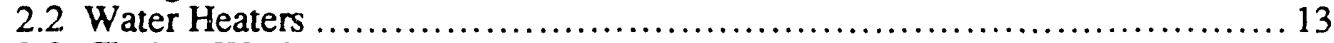

2.3 Clothes Washers ............................................................. 13

2.4 Clothes Dryers ..................................................... 14

3.0 HEATING, VENTILATION, AND AIR CONDITIONING (HVAC) ............ 15

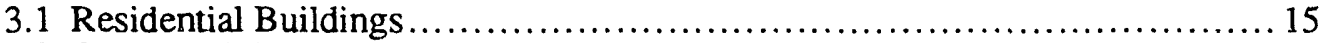

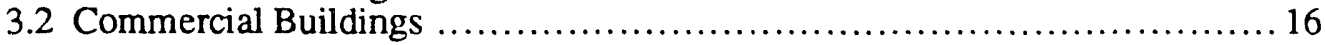

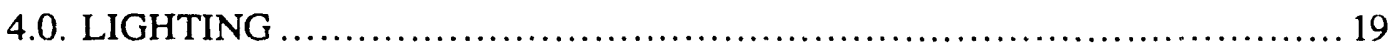

4.1 Incandescent and Incandescent Substitutes ................................. 19

4.2 Fluorescent Lamps .............................................................. 23

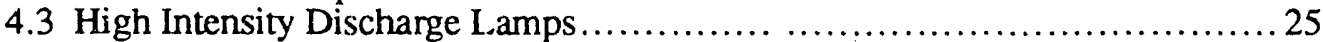

4.4 Lighting Design and Controls ......................................... 26

4.5 Summary of Lighting Savings Potential ........................................... 27 


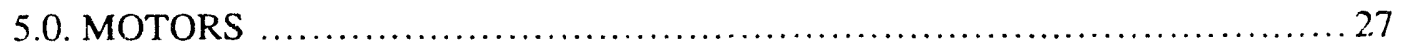

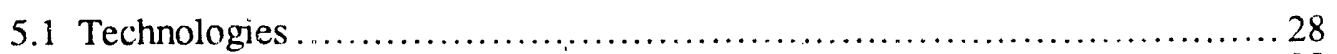

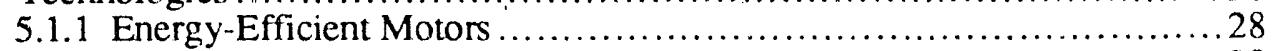

5.1 .2 Variable Speed Drives ......................................... 28

5.1 .3 Power Qualiiy................................................... 28

5.1.4 Specifying and Maintenance Practices ............................... 29

5.1 .5 Drivetrain Components ......................................... 29

5.2 Economics and Savings Potential .........................................?99

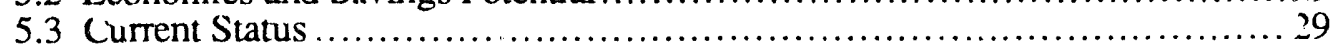

6.0 ELECTRICITY-INTENSIVE INDUSTRIAL PROCESSES ................... 30

6.1 Aluminum Production .................................................... 31

6.2 Chlor-Alkali Production .............................................. 31

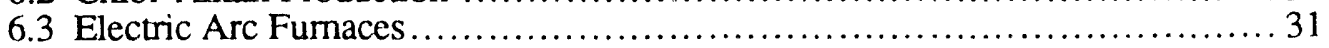

7.0 ELECTRICITY CONSERVATION SUPPLY CURVES ....................... 33

7.1 United States .............................................................. 33

7.2 Europe and Developing Countries.............................................. 34

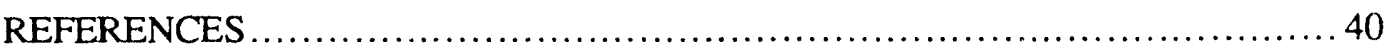

CHAPTER 3: FACTORS LIMITING ADOPTION OF TECHNOLOGIES FOR

INCREASING ELECTRICITY END-USE EFFICIENCY ................47

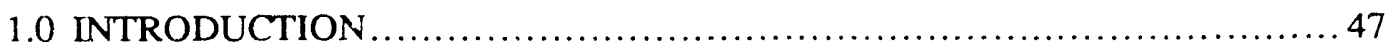

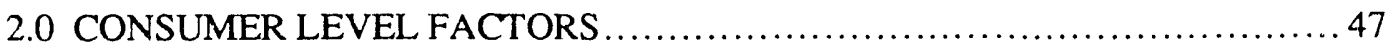

2.1 Information Costs and Related Issues..................................... 48

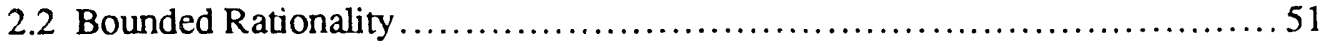

2.3 Capital Constraints ................................................................... 51

2.4 Split Incentives............................................................... 52

2.5 Differences in Produict Attributes ......................................5 52

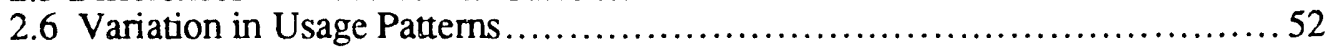

3.0 NATIONAL LEVEL BARRIERS ....................................... 53

3.1 Lack of Adequate Institutional Capability ..................................53

3.2 Supply-Oriented, Centralized Utilities ...................................5 53

3.3 Lack of Cost-based Electricity Prices ........................................ 54

3.4 Lack of Energy-Efficient Products ..................................... 55

4.0 INTERNATIONAL LEVEL FACTORS ................................ 56

4.1 Lack of Funding ..................................................... 56

4.2 Lack of Effective Collaboration Between Industrialized and Developing Countries .............................................................. 57

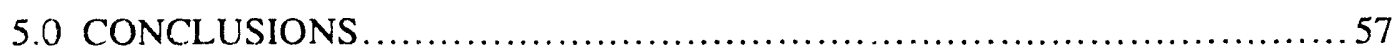

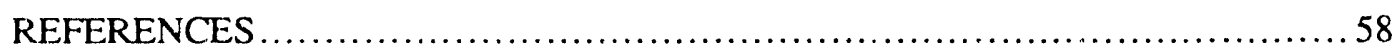


CHAPTER 4: EXPERIENCE WITH POLICIES AND PROGRAMS ........................61

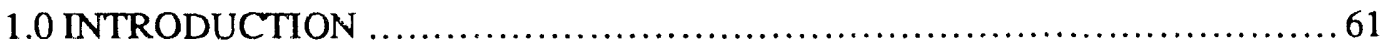

2.0 ELECTRICITY PRICING .............................................. 62

3.0 PROGRAMS IN THE UNITED STATES AND OTHER INDUSTRIALIZED

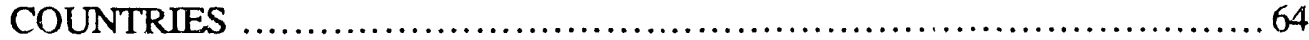

3.1 Information Programs.............................................. 64

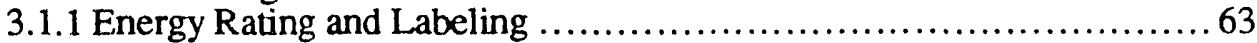

3.1.2 Technical Informnation for Non-Energy-Efficient Buildings...............65

3.2 Appliance Efficiency Standards .........................................66 66

3.3 Financial Incentives to Appliance Manufacturers .........................6 69

3.4. Commercial Building Energy Standards ..................................... 69

3.5 Integrated Resource Planning and Utility Demand-Side Program

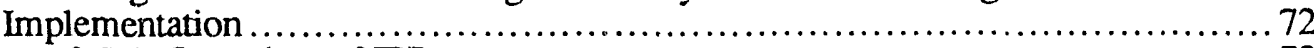

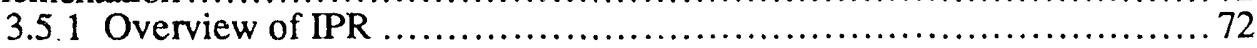

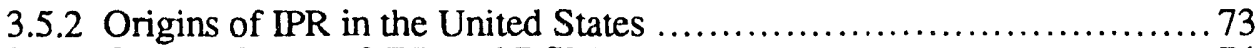

3.5.2 Current Status of IPR and DSM ..................................74

3.5.4 Utility Demand-Side Managements (DSM) Programs ................... 76

3.5.5 Significance of These Developments

3.6 Private Sector Delivery of (DSM) Programs .................................79

3.7 Research and Development ........................................... 80

4.0 ELECTRICITY CONSERVATION PROGRAMS AND POLICIES IN

DEVELOPING COUNTRIES ............................................. 81

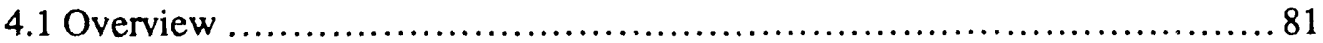

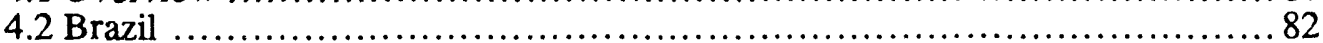

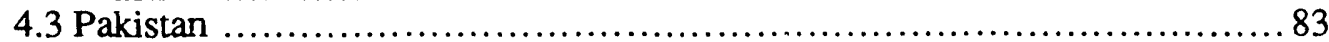

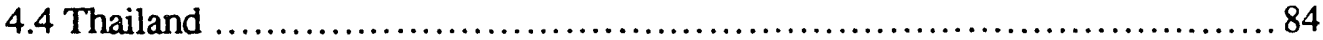

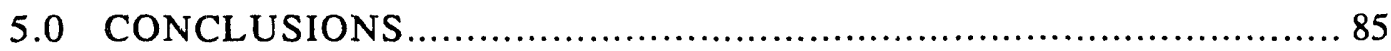

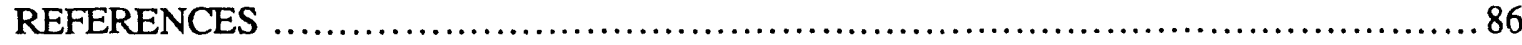

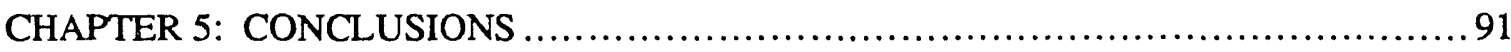

1.0 IMPORTANCE OF ELECTRICITY END-USE EFFICIENCY .................91

2.0 TECHNOLOGIES TO INCREASE ELECTRICITY END-USE EFFICIENCY ........................................................... 91

3.0 FACTORS LIMITING ACCEPTANCE OF EFFICIENT TECHNOLOGIES....... 92

4.0 EXPERIENCE WITH POLICIES ........................................ 93

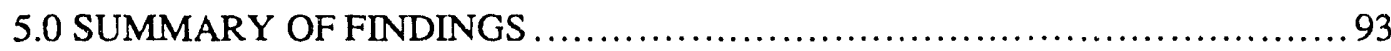




\section{LIST OF FIGURES}

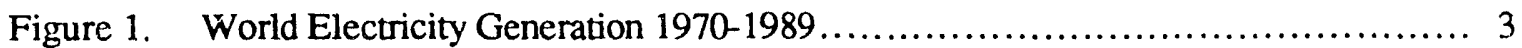

Figure 2. Average Annual Growth Rates, 1970-1989: Electricity Generation ............... 3

Figure 3. Electric Generation \& GDP ......................................... 4

Figure 4. Electricity Generation per Capita $1971 \& 1989$.............................. 6

Figure 5. Electricity Generation by Source (Share ofTotal) ............................ 6

Figure 6. Electricity Consumption by Sector (Share of Total) ......................... 7

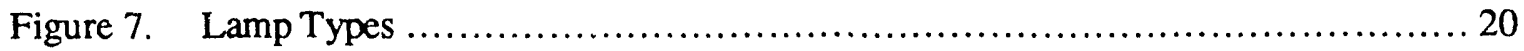

Figure 8. U.S. Electricity Conservation Supply Curves............................... 33

Figure 9. Electricity Conservation Supply Curve; New York State-6\% Discount Rate...... 35

Figure 10. Integrated Electricity Resource Supply Curve for Sweden.............................. 36

Figure 11. Electricity Conservation Supply Curve for Brazil in 2010, Improved-

Technology Scenario ................................................. 37

Figure 12. Supply Curve for Conserved Electricity in India.............................. 37

Figure 13. Maximum AcceptablePayback Time for Investments in Energy Efficiency..........49

Figure 14. Average New Refrigerator Annual Electricity Use (1947-1988) ................. 68 


\section{LIST OF TABLES}

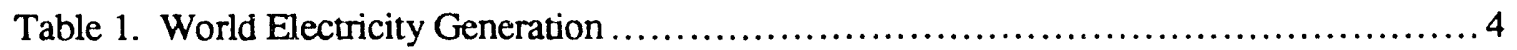

Table 2 Energy Consumption and Conservation Potential with Major Residential

Electrical Equipment.................................................................. 10

Table 3. Electricity Savings Potential and Cost Effectiveness of Increasing the Efficiency of a U.S.-style Refrigerator/Freezer............................ 12

Table 4. HVAC equipment Efficiency and Cost Comparison .............................. 17

Table 5. Lamp Efficiency and Cost-Effectiveness Analysis ............................. 21

Table 6. Summary of Savings Potential for Electric Motors .................................. 30

Table 7. Measures to Improve Electric Arc Furnace Efficiency in India....................... 32

Table 8. Cost-Effective Electricity Conservation Potential in New York State................... 35

Table 9. Selected Cost-Effectiveness Calculations for the Swedish Efficiency Scenario.......... 36

Table 10. Electricity Conservation Supply Curve in 2010, Improved-Technology Secenario (Brazil) ........................................................... 38

Table 11. Cost-Effective Savings Potential for India ........................................ 39

Table 12. Comparisons of Average Revenues and Long-Run Marginal Costs of Electricity in Selected Countries........................................... 55

Table 13. DSM Program Expenditures and Savings Goals of Utilities Recognized as Leaders in Energy Efficiency in the United States ............................ 75

Table 14. Results from New York State Electric and Gas Corporation's Pilot Refrigerator Rebate Program . .77 


\subsection{IMPORTANCE OF ELECTRICITY END-USE EFFICIENCY}

Electricity generation is responsible for more than 30 percent of energy-related global carbon dioxide emissions to the atmosphere. Significantly, more than 50 percent of all increases in carbon dioxide emissions due to increased energy use during the past twenty years are from electricity. There is strong reason to believe that the factors that have led to electricity increasing its share of total energy demand will continue. A large fraction of growth in electricity generation will take place in the developing world.

There are three major ways of reducing the growth of these emissions from electricity that avoid cutting the growth of electricity services: (1) increasing the efficiency of electricity use, (2) using less carbon-intensive fuels to generate electricity, and (3) improving the thermal efficiency of converting fossil energy to electricity. This paper addresses the first of these three approaches. More specifically, the paper provides an in-depth review of three topics:

- status of available technologies for increasing electricity end-use efficiency,

- factors that limit the application and widespread deployment of these technologies, and

- policies that have been implemented to increase the efficiency of electricity use.

\subsection{TECHNOLOGIES TO INCREASE ELECTRICITY END-USE EFFICIENCY}

Worldwide, industry uses about 50 percent of all electricity and buildings consume almost as much (45 percent). Technologies to significantly improve electricity efficiency exist for virtually all buildings and industrial end-uses. For industry, the greatest savings in electricity can often be achieved by process changes that require less energy input to produce a final product rather than by retrofits of existing processes.

Examples of some technologies for buildings include efficiency improvements for residential appliances, lighting, air conditioners, heating systems, and thermal integrity of building envelopes. In the United States, the average new refrigerator consumes half as much electricity as a comparable refrigerator purchased twenty years ago. In Japan, the efficiency improvement has been even greater (fourfold), primarily because the older refrigerators were much less efficient than U.S. models. The doubling of refrigerator efficiency in the United States (using foam instead of fiberglass insulation, thicker insulation, more efficient motors and compressors, and larger heat exchangers) has been highly costeffective, typically paying back the added first cost in about one year.

Compact fluorescent lamps are presently available and have been selling briskly throughout the world in the past few years. Compared with incandescents, these lamps consume 25 to 40 percent as much electricity per lumen output. The compact fluorescent lamps, if used an average of four hours per day, typically pay back their higher cost in about three years, at an average electricity price of $\$ 0.08$ to $\$ 0.10$ per kilowatt hour.

A typical central air conditioner in the United States purchased in 1990 was 36 percent more efficient than a 1976 model. Heat pumps, installed in 25 percent of U.S. houses, consume on average half as much electricity as electric resistance heating. The major electricity-using appliance that has not seen large increases in electricity end-use efficiency in the United States is the electric water heater. However, heat pump water heaters are commercially available and can reduce electricity use for water heating by 50 to 70 percent.

The largest users of electricity in commercial buildings are air conditioning and lighting. Compared with standard fluorescent lamps, energy-saving fluorescent lamps typically save 15 
percent of electricity for lighting, and have captured an estimated 30 to 40 percent of the U.S. market. Efficient lamps with electronic ballasts consume about 35 percent less electricity than a standard fluorescent. The addition of a specular reflector is estimated to cut electricity use by an additional 40 percent. All of these measures pay back to the purchaser in one to three years, if the lamp is used 3000 hours per year or more.

The typical air conditionirg system for commercial buildings purchased today is 10 to 30 percent more energy efficient than the system purchased ten to twenty years ago. Efficient air conditioning systems for commercial buildings presently consume from 25 to 38 percent less electricity than this typical system, with a payback to the purchaser of 1.5 to 5 years in the United States. In addition, control systems for air conditioners (e.g., energy management systems and, where applicable, economizers) and for lighting systems (e.g., motion detectors) can reduce electricity requirements 10 to 20 percent in many buildings.

The largest portion of industrial electricity is used by motors to power pumps, fans, compressors, and machine tools. In the United States, 60 percent of industrial electricity use is by motors; in many developing nations, the percentage is even higher. The largest other uses are industrial buildings (lighting and air conditioning), primary metals processing and fabrication, and chemicals. Improvements applied tu motor systems in the United States could yield savings of 16 to +0 percent with paybacks of one to three years. The measure that has the largest potential impact but the largest uncertainty is the variable speed drive (VSD). VSDs were commercialized in the early 1970s as a means of better matching the output of the motor to varying loads. Traditionally, varying loads are met either by cycling the motor on and off or mechanically adjusting the motor speed. The latter approach is very wasteful of electricity. VSD; modify the power going into the motor, allowing the speed to be varied in proportion to the amount of motor power needed. The overall penetration of efficient motors, including controls, into markets in industrialized or developing countries is relatively low. In the United States, about 20 percent of motor sales are high-efficiency motors. In India and Brazil, less than 1 percent of motor sales are high-efficiency. Variable speed drive sales have been steadily increasing in the United States, but many costeffective applications remain untapped.

Research and development (R\&D) is expected to result in advanced technologies that will further improve efficiency of electricity use. For example, U.S.-sized refrigerators with evacuated panels and without CFCs are under development that are expected to consume 200 to 500 kilowatt hours per year, compared with an average of 900 kilowatt hours per year today. Similar technology applied to freezers would cut electricity use from 600 to between 200 and 300 kilowatt hours per year. Research on integrated appliances can lead to heat pumps for two or more applications, increasing the benefit of heat pumps to the consumer. More efficient lighting technologies, such as multiple photon phosphors, surface wave lamps, and diodes as a light source, are under development. These technologies, compared with the most efficient lighting systems available today, can cut lighting electricity requirements in half. Of particular importance in the industrial sector is $R \& D$ directed at substituting one process for another. Such substitutions, often sought for reasons other than energy, can lead to very significant reductions in energy use.

Information on cost and performance of electricity-efficient technologies can be summarized in a conservation supply curve, in which potential electricity savings are plotted against cost of conserved electricity. The curves are generally applied to a future date, so that a sizeable portion of the existing stock of energyusing equipment is replaced. For our purposes, we refer to conservation supply curves for the time period 2005 to 2010 . We have reviewed various conservation supply curves, and have chosen those that, in our view, represent mainstream estimates. These curves, evaluated at a social discount rate of 6 to 10 percent with costs o? conserved electricity below current electricity 
prices, typically show potential savings of 30 to 40 percent for the United States in 2010, and 20 to 30 percent for developing nations. The lower savings in developing nations may be the result of the less detailed studies performed to date for these countries. These are savings relative to a baseline with efficiencies fixed at today's levels. A portion of the potential efficiency improvements will take place simply as a result of market forces, in the absence of policy reforms.

\subsection{FACTORS LIMITING ACCEPTANCE OF EFFICIENT TECHNOLOGIES}

Many of these technologies have been accepted only slowly in the market, in spite of their apparent advantages. Some of the factors limiting market acceptance result from limitations of the technologies themselves or are intrinsic to the environment in which the technology is applied. Other factors are the result of market barriers or distortions. Policies designed to promote electricity end-use efficiency are generally most effective, and cause the least unwanted impacts, if they are designed to directly address the factors that distort the market and inhibit the acceptance of efficient technologies.

Some of the factors relating to the technology and its environment include (1) attributes that affect performance or may be perceived by consumers as affecting performance (e.g., lower temperatures for clothes washing), (2) physical barriers that impede the introduction of the technology (e.g., difficulty in retrofitting insulation in the walls of existing houses), or (3) instances where lower than average usage of the product causes the economics of the investment to be unfavorable. To the extent possible, the estimates of potential savings described above attempt to keep amenity levels constant. Nonetheless, variations in usage and physical barriers to installation of a device will affect market acceptance.

Numerous market factors limit the acceptance of efficient electricity end-use technologies. Probably the most important involves the fact that the investment in efficiency is usually made by the end-user, who typically requires a high return on investment (a short payback period), while the investment in electricity generation is made by the electric utility, which accepts a much lower retum on investment (longer payback time). If a typical consumer requires 25 to 50 percent retum on an investment in efficiency but a utility requires a 6 percent return on nev supply (in constant dollars), then electricity will be produced at 7 cents per kilowatt hour but end-use investments producing savings at 2 cents per kilowatt hour will be rejected. This is an extremely important factor that strongly favors investments in supply over end-use efficiency.

Other market factors inhibit the acceptance of energy-efficient technologies. High costs of credible information on efficient technologies, and uncertainty about the actual savings, are important factors. The difficulty of measuring electricity savings (which are obscured in utility bills) plays a role in consumers' reluctance to invest. The difficulty of finding efficient products, and the time necessary to evaluate the information about the products, often discourages purchase of efficient technolggy. Unavailability of capital, or its high cost, renders otherwise sound investments in efficiency (and other products) unaffordable. Different parties being the beneficiary or the investor (as when a landlord pays for the efficiency measure but the tenant profits) results in rejection of energy-efficient technologies.

There are additional factors that operate especially in developing countries. Not only do many developing countries lack the trained people and industrial infrastructure for significant investments in efficiency, but the international institutions that could assist (with training or capital) have traditionally directed their efforts at electricity supply. There are often no institutions in developing countries for formulating or implementing policies to promote energy efficiency; if they do exist, they generally have little authority. Moreover, efficient products may not be available in developing countries. Assistance from industrialized countries that includes training programs can play a significant role in supporting developing countries to design and implement electricity end-use efficiency 
programs. Because a very large portion of futum electricity growth is expected to take place in developing countries, attention to factors limiting the introduction of efficient technologies using electricity in these countries is important.

\subsection{EXPERIENCE WITH POLICIES}

With rising electricity prices and problems associated with building new power plants in many areas, some industrialized countries have in recent years begun to implement policies to promote electricity conservation. The United States has been particularly active in implementing many of these policies. Appliance efficiency standards have been established for refrigerators, freezers, room aur conditioners, water heaters, clothes washers and dryers, dishwashers, and fluorescent lighting ballasts. These standards, which address end-uses that presen:'y consume 35 percent of U.S. electricity, are estimated to save 21 quadrillion Btus of resource energy (more than 90 percent electricity) from 1990 to 2015 . These savings result in estimated reductions in the growth of residential energy demand in the United States of 20 to 40 percent over this time period. These estimated savings include standards for refrigerators and freezers that will take effect in 1993, but do not include the mandated updates for all products that take place roughly every five to ten years. The appliance standards in the United States have been based on technical/economic studies showing an average payback of five years or shorter on the incremental first cost of the more efficient appliance.

While standards can eliminate inefficient products or raise the efficiency of an average unit, thev do not directly encourage the development and introduction of new, more efficient technologies. An innovative approach to this problem is being tried in Sweden and the United States. This involves offering mailufacturers incentives, often called "golden carrots," for bringing to market more efficient products than are currently available. Sweden has done this for more efficient refrigerators. An effort is underway to establish a similar program in the
United States, first for refrigerators and later for other products.

Efficiency standards for commercial buildings, aimed at reducing electricity used for lighting and air conditioning, are in place in a large number of countries, including Sweden, Germany, France, the United Kingdom, the United States, Singapore, and Japan among the industrialized countries and Jamaica, the Philippines, Pakistan, and Kuwait. These standards can be mandatory (such as Singapore), voluntary (e.g., Pakistan) or intermediate (e.g., the United States with standards established by a consensus process within industry and then adopted by many states). Using Singapore and the United States as examples, it is likely that the standards can reduce elcctricity consumption in new commercial buildings by 25 to 50 percent.

Integrated Resnirce Planning (IRP) addresses a basic factor limiting the choice of efficient technology discussed earlier, namely that the lower cost of capital to the utility favors supply investments that have much longer payback periods than are acceptable to the enduser, the investor in efficiency. Many electric utilities in the United States, with the encouragement of their state regulatory agencies, are now investing directly in end-use efficiency measures that will be installed by their customers. The investments that utilities have made in DSM have been typically well below the cost of equivalent supply investments per unit of electricity saved or supplied. The utilities are often assured a profit on these investments and recovery of earnings from lost sales. In some locations utilities also receive an incentive payment for aggressive implementation of DSM programs.

As a result of these policy reforms, a number of utilities are investing in end-use efficiency technologies for their customers and these utilities anticipate the majority of projected demand to be met by these investments. The leading efforts to date have been in New England and Califomia, where utilities typically invest 2 to 4 percent of operating revenues, receive financial incentives for the pursuit of DSM, and expect to reduce electricity growth considerably. For the United 
States as $\mathfrak{a}$ whole, utilities spend about $\$ 2$ billion per year (1 percent of total operating revenues) on DSM programs. It should also be noted that there are complex issues involved in the design and implementation of these programs, including faimess in allocation of costs and benefits among different ratepayer classes and the potential for some of these programs to lead to economically inefficient investments in conservation.

Numerous other important policy approaches have been tried to increase electricity end-use efficiency. Information programs, in which highly credible data are presented to consumers (e.g. appliance efficiency labeling; energy-rating systems for houses) or persuasion has been applied (e.g., programs to induce large companies to set good examples by installing highly efficient lighting systems), have been instituted in many rountries. These programs have served an educational value. Often they are most effective in achieving savings when combined with complementary policies and programs, such as technical assistance and financial incentives.

There have been efforts to involve private firms more actively in the delivery of electricity efficiency. The development of energy service companies (ESCOs) in several industrialized countries is an example. They have been most active to date when utilities, through the development of DSM programs, create a substantial market for the services of ESCOs. Research and development, supported by governments, has been used to assure the continued development of new, efficient technologies.

Several developing nations actively promote more efficient electricity use. Brazil and Pakistan were among the first to focus on electricity conservation. Brazil has the most extensive set of electricity conservation programs, organized through a national program (PROCEL) based at the federally-owned utility. PROCEL has carried out specific programs (e.g., a major effort to improve efficiency of public street lights), technology R\&D and demonstrations (e.g., efficient appliances), education about energy saving and promotion of efficient technologies, and development of standards. To date, PROCEL has invested about $\$ 20$ million in electricity conservation. The PROCEL programs have spurred investments by manufacturers and consumers that have achieved savings equivalent to the output of 280 to $650 \mathrm{MW}$ of generating capacity.

Pakistan has been active in retrofits of industrial facilities and agricultural pumps to save electricity. A pilot program to improve the power factor in five industrial plants has led to a new effort to implement the program nationwide. A five million dollar (U.S.) loan from the Asian Development Bank will support this program.

Mexico and Thailand are two developing countries that have recently become involved in electricity conservation programs. Mexico has set up an entity at the national utility to carry out enduse efficiency programs. The activity is funded by a tax on electricity, and has an initial budget of about $\$ 7$ million per year. Thailand has recently (November 1991) decided to invest $\$ 183$ million (U.S.) over five years to purchase 225 Megawatts of new capacity through utility DSM programs.

These examples, in both industrialized and developing countries, indicate that policy efforts can be successful in promoting more efficient use of electricity. Many of these policies nave been initiated in recent years, however, and only early results are known. These policies and others have the potential to increase significantly the market acceptance of technologies that provide a given end-use service with lower input of electricity.

\subsection{SUMMARY OF FINDINGS}

In very brief sumnary form, the basic conclusions of this review of electricity end-use efficiency are:

- Half of the increases in energy-related carbon dioxide emissions in the last two decades came from electricity production. A comparable share is likely to come from electricity generation in the future.

- Increases in electricity end-use efficiency beyond those expected to occur under current 
policies van cut the growth of electricity use and associated carbon emissions significantly.

- There has been sufficient experience among industrialized countries in both technologies and policies to have confidence that significant increases in electricity end-use efficiency are possible.

- Many end-use efficiency investments are more cost-effective than new electricity supply investments when eyaluated using common criteria (e.g., using the same discount rate).

- Policies such as utility DSM programs, information and labeling programs, voluntary and mandatory appliance and building standards, and "golden carrot" financial incentives have been successful in accelerating investments in end-use efficiency. Policies that remove market distortions serve to promote both economic and end-use efficiency. Policies that try to compensate for market distortions indirectly can sometimes promote economically inefficient investments as well as economically efficient ones.

- Making these efficient electricity end-use technologies widely available in developing countries could contribute in important ways to a global effort to increase electricity end-use efficiency, thus reducing growth in electricity supply and in greenhouse gas emissions. 


\section{CHAPTER 1}

\section{ELECTRICITY GROWTH}

\subsection{INTRODUCTION}

In this chapter, we observe some major features of electricity growth during the past two decades:

- global electricity generation and use have more than doubled

- growth has been fastest in the developing world, where electricity consumption has quadrupled

- unlike commercial energy consumption, which has grown more slowly than GDP worldwide, electricity consumption has increased more rapidly than GDP in industrialized countries and twice as fast as GDP in developing nations

- in spite of the rapid increase in electricity consumption in developing nations, the per capita consumption levels in these countries are less than 8 percent of those in the OECD

- the largest share (about 50 percent) of worldwide electricity use goes to industrial activity; however, the fastest growth is in buildings, which presently consume about 45 percent of all electricity

- carbon dioxide emissions to the atmosphere per unit electricity have declined by about 15 percent largely because of the increase in nuclear generation; total carbon dioxide emissions from electricity have nonetheless doubled because of the rapid growth of electricity

- as a result, 50 percent of the increase in energy-related carbon dioxide emissions is from increased generation and consumption of electricity.

Further information is presented in Section 3.0 below.

\subsection{ISSUES ADDRESSED IN THIS REPORT}

The reason for the impurtance of electricity end-use efficiency in t'ie context of greenhouse gas emissions is evident: half of all increases in energy-related carton dioxide emissions come from electricity. This report discusses the opportunities to reduce growth in these emissions.

Chapter 2 describes technologies that permit an increase in electricity end-use efficiency. Data are presented in the chapter that describe experiences throughout the world with these technologies. Chapter 3 discusses factors that limit the widespread adoption of electricityefficient technologies. This chapter pays particular attention to the developing world, where new approaches will likely be needed to achieve high penetrations of efficient technologies. Chapter 4 describes experience with policies and programs to promote the more rapid or widespread adoption of end-use efficiency technologies. Because a great deal of this experience has been in the United States, U.S. programs receive considerable attention in this chapter. Chapter 5 presents the major conclusions, particularly with respect to the possible role of efficiency technologies in reducing growth of carbon dioxide emissions in various regions of the globe. 


\subsection{TRENDS IN WORLD ELECTRICITY CONSUMPTION ${ }^{1}$}

\subsection{Overall Electricity Growth}

Since 1970 , world electricity generation has grown more than two-fold from 5000 Terawatt hours (TWh) ${ }^{2}$ to over $11,000 \mathrm{TWh}$ in 1989. Electricity consumption and generation have risen in all regions, but growth has been much faster in developing countries ( 8.2 percent per year) than in the OECD countries ( 3.5 percent per year) or the countries with economies in transition (CET), including Central and Eastern Europe and the former USSR (4.4 percent per year). As a result, the share of the OECD countries has fallen from 69 percent to 58 percent, while that of the developing countries has increased from 11 percent to 21 percent (Figure 1). The share of the CET has remained at around 20 percent.

Among the developing countries, the growth has been fastest in Asia and China (Figure 2). ${ }^{3}$ Generation in Latin America and Africa has grown somewhat slower, but still much faster than the world average. Among the OECD countries, growth has been faster in the Pacific countries (especially Japan) than in North America and Europe. North America still accounted for over half of total OECD electricity

1 The data source for this section is the United Nations Energy Statistics Yearbooks. The data include self-production by industry as reported by countries or estimated by the UN $(1981,1982,1989$, 1991).

2 TWh $=$ trillion $\left(10^{12}\right)$ watt hours = billion kilowatt hours

3 For purposes of the figures in this chapter we include most of the Middle East and developingcountry portions of Oceania in Asia. China is treated as a separate region. Developing countries include all nations that are not in the OECD or the former East Bloc (those countries with economies in transition or CET). The newly industrialized countries are included as developing countries; their electricity consumption is such a small portion of the developing country total that this allocation has little effect on the figures. generation in 1989, however, while the OECD shares by Europe and the Pacific countries were 33 percent and 15 percent respectively (Table 1). Among the developing countries, 39 percent of total generation in 1989 was in Asia, 24 percent was in China, 25 percent was in Latin America, and 12 percent was in Africa. The Soviet Union accounted for three-fourths of generation in the Former East Bloc.

In all regions, growth in electricity generation was slower in the 1980s than in the 1970s (Table 1). The main reason for this is the lower economic growth in the 1980 s, but higher electricity prices and improvements in efficiency also played a role in reducing growth in the 1980 s in the OECD countries and in some developing countries. The lower growth rate in the 1980 s was much more evident in the OECD and the CET than in most developing country regions. Average growth in Asia was only slightly lower in the 1980s than in the 1970s.

\subsection{Electricity and GDP Growth ${ }^{4}$}

Faster economic growth in the developing countries was one reason that electricity generation grew there more rapidly than in the rest of the world. More important, however, was the fact that generation in these countries rose much faster than Gross Domestic Product (GDP). While total GDP in the developing countries (in U.S. doilars) increased slightly over two-fold between 1970 and 1989 , electricity generation grew more than four-fold (Figure 3). In the OECD countries, on the other hand, electricity generation grew only slightly faster than GDP. Many factors account for the increase in

\footnotetext{
4 The source for GDP (in 1985 dollars) for the OECD countries is the International Energy Agency (IEA, $1989,1991)$. For the developing countries, the GDP series were derived from the Asian Development Bank (ADB , 1983, 1986, 1990) the Inter-American Development Bank (IADB 1987, 1990), the International Monetary Fund (IMF, 1989, 1990) and the World Bank Report World Tables (World Bank, 1991).
} 


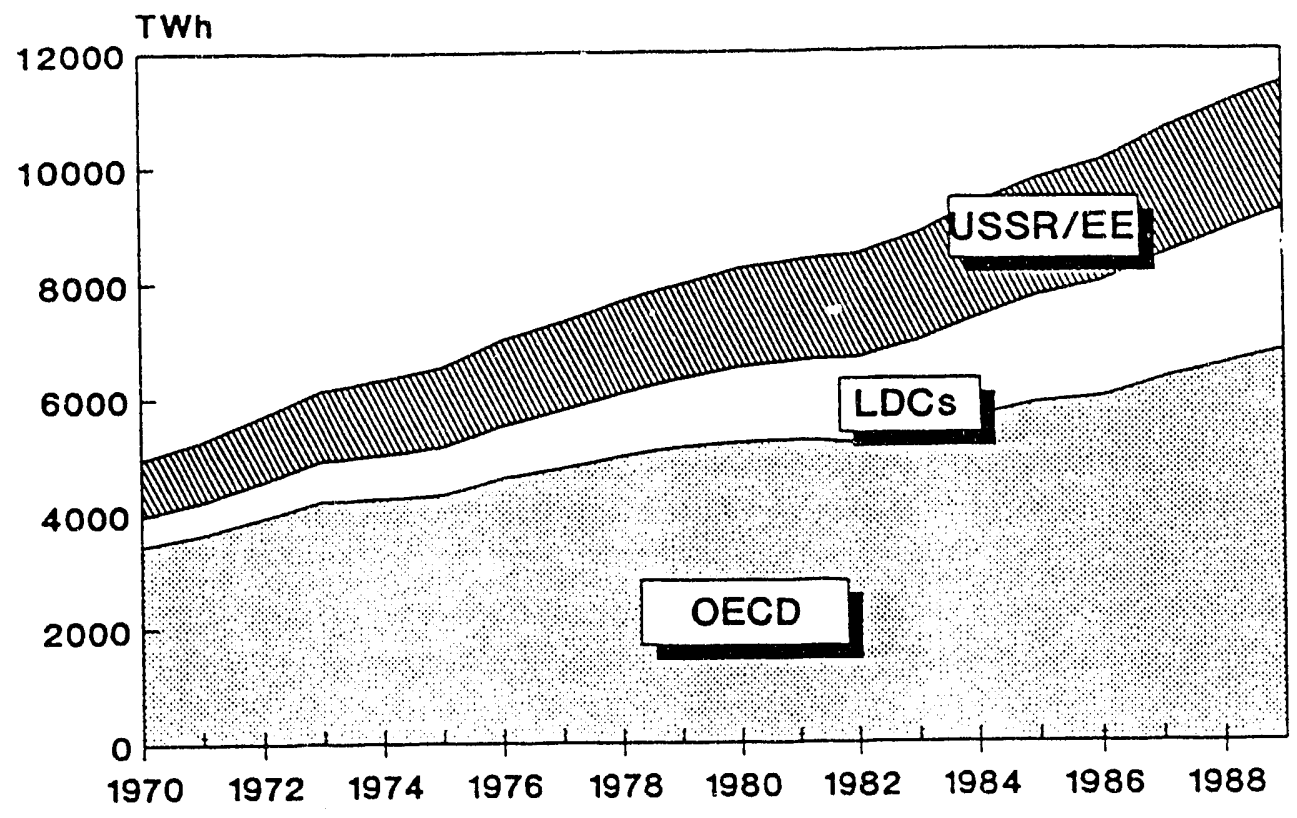

Figure 1. World Electricity Generation 1970-1989.

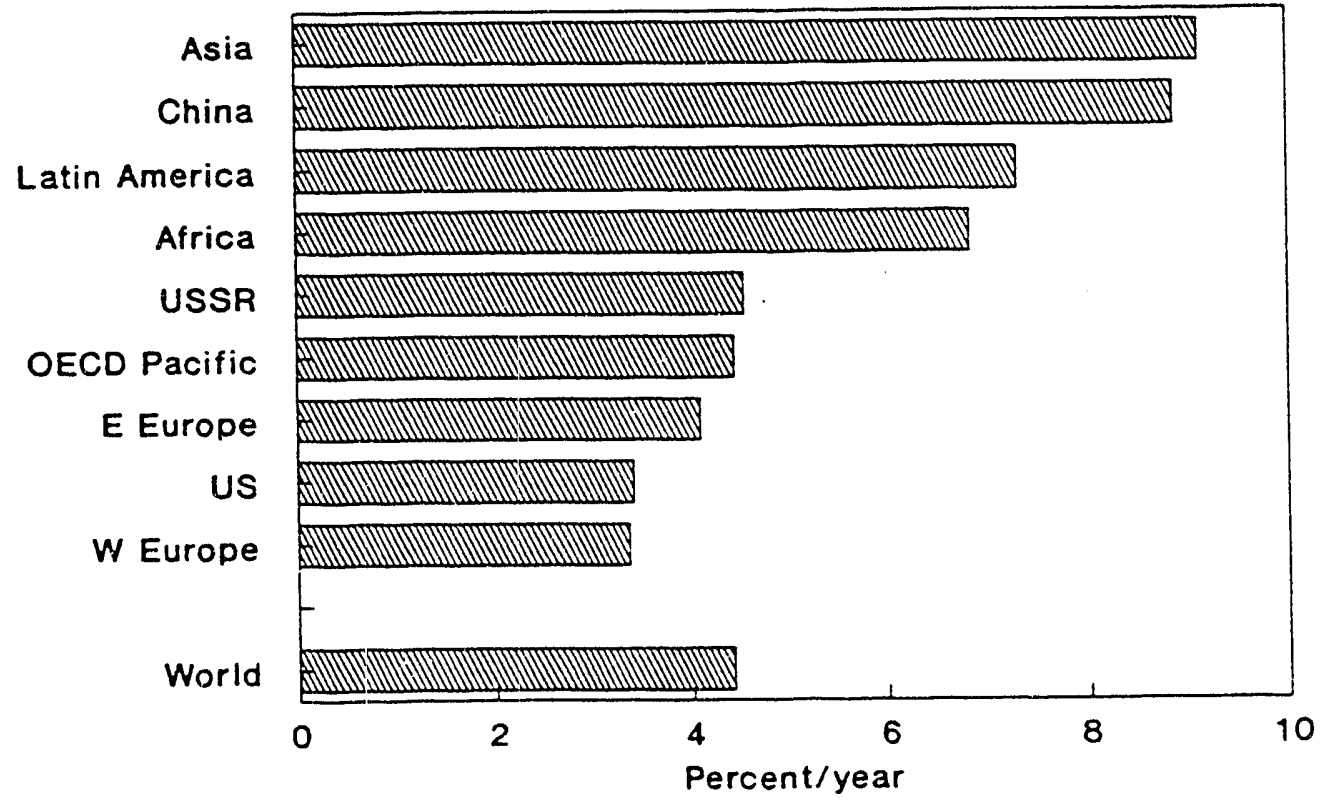

Figure 2. Average Annual Growth Rates, 1970-1989:

Electricity Generation. 
Table 1. World Electricity Generation, 1970-1989

\begin{tabular}{crrr|rr} 
& Generation (TWh) & \multicolumn{3}{c}{ Avg. Growth (\%/year) } \\
\cline { 2 - 6 } & $\mathbf{1 9 7 0}$ & $\mathbf{1 9 8 0}$ & $\mathbf{1 9 8 9}$ & $\mathbf{1 9 7 0 - 8 0}$ & $\mathbf{1 9 8 0 - 8 9}$ \\
\hline OECD Countries & 3459 & 5249 & 6674 & 4.3 & 2.7 \\
North America & 1845 & 2732 & 3480 & 4.0 & 2.7 \\
Europe & 1160 & 1764 & 2172 & 4.3 & 2.3 \\
Pacific & 428 & 696 & 977 & 5.0 & 3.8 \\
Developing Countries & 541 & 1323 & 2434 & 9.4 & 7.0 \\
Asia & 179 & 452 & 938 & 9.7 & 8.4 \\
China & 116 & 300 & 582 & 10.0 & 7.6 \\
Latin America & 159 & 385 & 609 & 9.3 & 5.2 \\
Africa & 87 & 186 & 306 & 7.9 & 5.7 \\
Former East Bloc & 1014 & 1773 & 2306 & 5.7 & 3.0 \\
Soviet Union & 741 & 1294 & 1722 & 5.7 & 3.2 \\
E. Europe & 273 & 479 & 584 & 5.8 & 2.2 \\
World & 5014 & 8345 & 11,414 & 5.2 & 3.5 \\
\hline
\end{tabular}

Figure 3. Electricity

Generation \& GDP
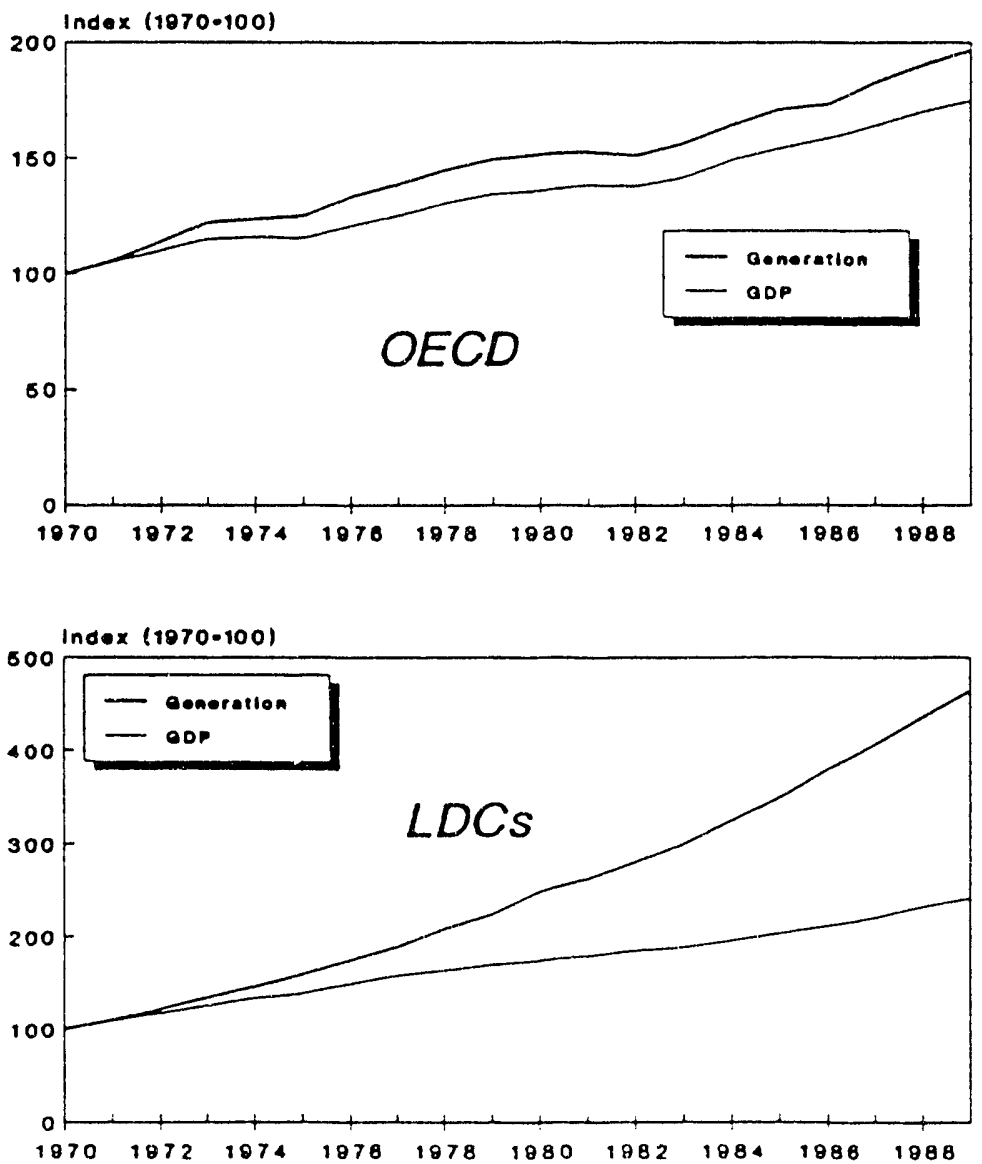
the electricity/GDP ratio in the developing countries. They include growth in rural electrification and ownership of household appliances, the rise of the manufacturing sector, development of electricity-intensive industries in some countries, growth in water pumping for agriculture, and rapid increase in the construction of modern commercial buildings. In addition, subsidized electricity prices contributed to growth in demand and inefficient electricity use in many countries. Increase in transmission and distribution (T\&D) losses was yet another factor increasing requirements for electricity generation.

Electricity generation also grew faster than economic output in the CET. The size of the difference depends on the data used to represent output, however. Average growth in Soviet electricity generation between 1970 and 1985 was 5.0 percent per year. Estimates of annual economic growth range from the official value for Net Material Product of 4.5 percent, an unofficial estimate of 3.8 percent, and the U.S. Central Intelligence Agency's estimate of 2.7 percent for GDP.

\subsection{Electricity Use Per Capita}

Despite the faster growth in the developing countries, generation per capita remains over 13 times low'r than in the OECD countries and nine times lower than in the CET (Figure 4). While lower economic output per capita is the main reason, many households in developing countries still do not have electricity or possess few appliances. The level of energy services in the commercial sector is also relatively low in the developing countries. If the equipment and processes in the developing countries were more modem and energy-efficient and transmission and distribution losses were less, the per capita generation would be even lower than it is.

\subsection{Change in Energy Sources for Electricity Generation}

The share of fossil fuels in world electricity generation declined from 74 percent in 1971 to 63 percent in 1989 (Figure 5). Nuclear power grew considerably in share from 2 percent in 1971 to 17 percent in 1989. Among fossil fuels, the share of coal declined slightly from 40 percent to 38 percent, while the share of oil fell by almost half from 21 percent to 12 percent. The share of gas remained at 13 percent. While total carbon dioxide emissions from electricity generation doubled in this period, the emissions per $\mathrm{kWh}$ declined.

The change in patterns varied somewhat among the three groups of countries. In the OECD countries, coal grew in share, while oil fell substantially. Nuclear power grew from 3 percent to 24 percent. In the developing countries, coal grew slightly in share, but the decline in oil and rise in use of nuclear power was less than in the OECD countries. Hydro power declined in share, but is still more important in the developing countries than elsewhere. The CET saw a decline in the share of coal as the use of gas and nuclear power rose significantly. Thus, the power sector's carbon intensity declined more in the CET than in the rest of the world.

\subsection{Patterns of Electricity Consumption}

Industry accounts for just under half of world electricity consumption, but its share has fallen since 1971 (Figure 6). The commercial sector grew in share from 17 percent to 21 percent, while the residential sector share remained at about 25 percent. Although industry's share declined in the developing countries and CET, it continued to account for around 60 percent of 


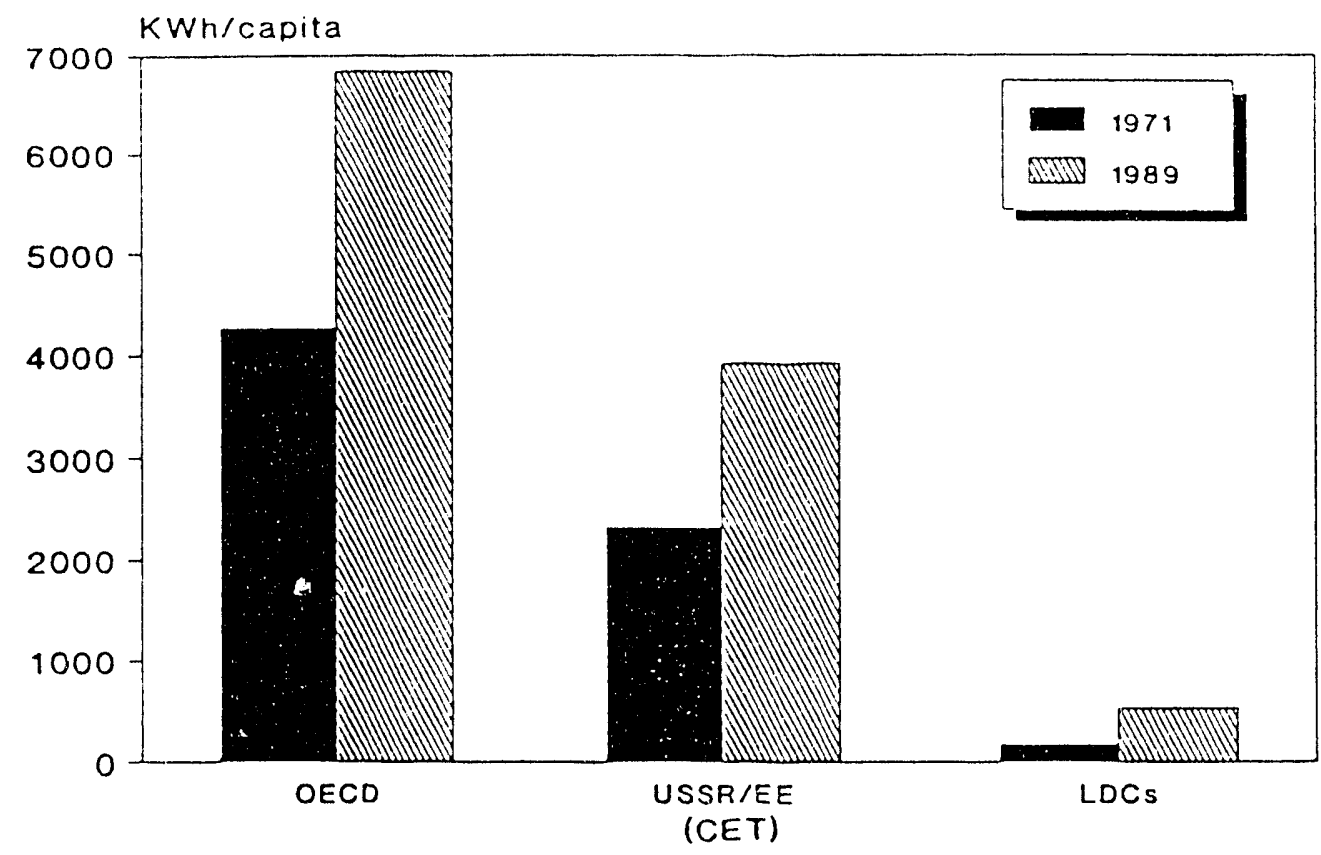

Figure 4. Electricity Generation per Capita 1971 \& 1989.

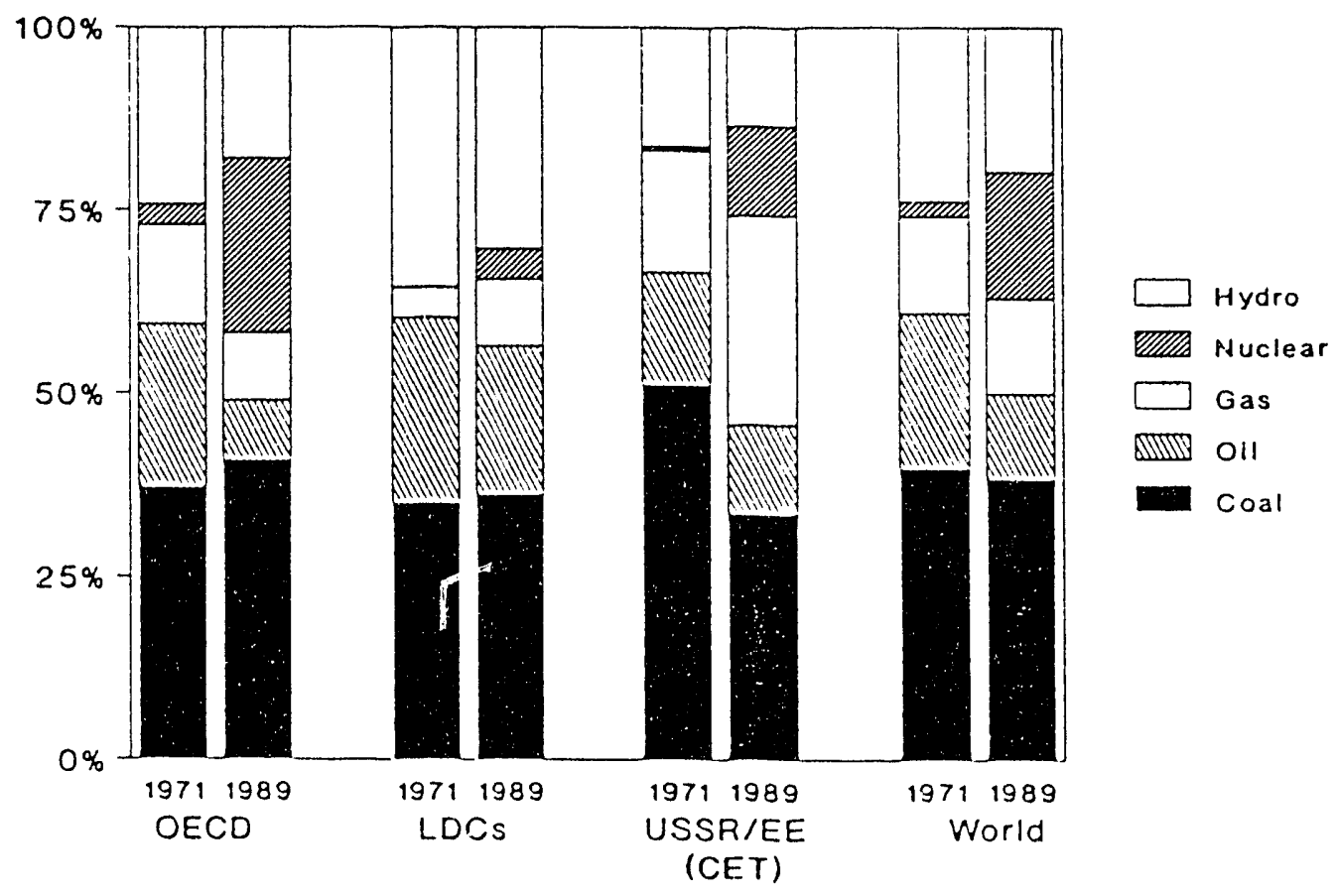

Figure 5. Electricity Generation by Source (Share of Total). 
total consumption. In the OECD countries, on the other hand, the share of industry in 1989 was only 41 percent. This difference reflects the more electricity-intensive character of the residential and commercial sectors in the OECD countries. The share of the commicrial sector rose from 19 percent to 25 percent in the OECD countries. Agriculture and transport are minor consumers of electricity on a world scale, but the share of agriculture grew in the developing countries as pumping for irrigation became more common.

\subsection{IMPLICATIONS}

The growth of electricity generation and consumption during the past two decades has been rapid. Despite increased use of nuclear power and improvements in conversion efficiency, carbon emissions from electricity generation increased from about 900 to 1800 million tonnes. Significantly, half of all increases in carbon dioxide emissions from energy during the two decades came from electricity production, even as the carbon intensity of a kilowatt hour declined. There are a variety of ways to reduce the growth of carbon dioxide emissions from electricity. The three foremost approaches involve increasing the efficiency of electricity use, changing fuel from carbon intensive to carbon non-intensive sources, and improving the thermal efficiency of conversion of fossil energy to electricity. This paper addresses only the first of these approaches. 


\section{REFERENCES}

ADB. 1983. "Key Indicators of Developing Asian and Pacific Countries," Manila: Asian Development Bank.

ADB. 1986. "Key Indicators of Developing Asian and Pacific Countries," Manila: Asian Development Bank.

ADB. 1990. "Key Indicators of Developing Asian and Pacific Countries," Manila: Asian Development Bank.

IADB. 1987. "Economic and Social Progress in Latin America," Washington, DC: InterAmerican Development Bank.

IADB. 1990. "Economic and Social Progress in Latin America," Washington, DC: InterAmerican Development Bank.

IEA. 1989. Energy Balances of OECD Countries, Paris: International Energy Agency.

IEA. 1991. Energy Balances of OECD Countries, Paris: Intemational Energy Agency

IMF. 1989. "International Monetary Statistics," Washington, DC: International Monetary Fund.

IMF. 1990. "International Monetary Statistics," Washington, DC: International Monetary Fund.

United Nations. 1981. Energy Statistics Yearbook, New York: United Nation:.

United Nations. 1982. Energy Statistics Yearbook, New York: United Nations.

United Nations. 1989. Energy Statistics Yearbook, New York: United Nations.

United Nations. 1991. Energy Statistics Yearbook, New York: United Nations.

World Bank. 1991. World Bank Tables, Washington, DC: World Bank. 


\section{CHAPTER 2}

\section{TECHNOLOGIES TO ACHIEVE GREATER ELECTRICITY END-USE EFFICIENCY}

\subsection{INTRODUCTION}

A wide range of energy-efficient products and system modifications has been developed and commercialized throughout the world during the past 20 years. These technologies can provide increased electricity efficiency in virt:ally every end-use.

Technologies for increasing electricity enduse efficiency originated primarily in the United States and in other industrialized countries. However, in recent years, electricity-conserving products and processes have begun to appear in developing countries. Since energy services and electricity demand are growing rapidly in developing countries, there is wide potential for electricity savings if energy efficiency is stressed when new industries, buildings, and appliances are built. The following discussion of clectricity savings opportunities pertains to both industrialized and developing countries. Technologies and applications in the United States are emphasized because more information is available for this country.

In discussing efficient technologies, wherever data permit, we provide information on the cost-effectiveness of each technology. Technology cost-effectiveness is assessed in terms of either cost of saved energy (CSE) or simple payback period. CSE is the levelized cost of saving energy over the lifetime of the conservation measure. CSE is expressed in terms of cost per $\mathrm{kWh}$. Unless otherwise indicated, a real discount rate of 6 percent is used to calculate CSE in this chapter. It is also assumed that the level of electricity service demand remains constant.

The cost-effectiveness of energy-efficiency measures from the perspective of the user can be judged by comparing the CSE of a measure to the (levelized) retail electricity price. Costeffectiveness from the national economic perspective can be judged by comparing the CSE of a measure to the marginal cost of electricity. For example, in the United States, the average price of electricity is approximately $\$ 0.07 / \mathrm{kWh}$. The U.S. Department of Energy projects that electricity prices will shange little over the next 20 years, and hence the marginal cost of electricity is similar to the current average cost (EIA 1991a). In Brazil, on the other hand, the average price of electricity was $\$ 0.04-0.05 / \mathrm{kWh}$ in recent years, much less than the marginal cost of about $\$ 0.07 / \mathrm{kWh}$ (World Bank 1990).

The sections below cover major residential appliances, electrical heating and air conditioning equipment, lighting, motors, and electricityintensive industrial processes. These end-uses represent a large fraction but certainly not all of the opportunities for greater efficiencies. Other end-uses in which electricity savings are possible include commercial refrigeration systems and office equipment.

Our review of electricity savings potential emphasizes technologies for using electricity more efficiently. These technologies apply to mass-produced equipment such as residential appliances and lighting equipment, building envelopes and site-assembled building systems, and major industrial processes. Thus, the implementation process and the number of decisionmakers involved varies from technology to technology. Futhermore, studies show that non-hardware strategies such as proper building commissioning and operation are also important mechanisms for achieving electricity savings. Quantitative evaluations of non-hardware strategies are relatively limited, however. 


\subsection{RESIDENTIAL APPLIANCES}

Residential appliances (i.e., end-uses other than space heating, cooling, and lighting) account for $15 \%$ of total electricity use in Japan, $20 \%$ in Germany, $23 \%$ in the United States, and $27 \%$ in the United Kingdom (IEA 1989). Residential appliances typically account for a smaller fraction of total electricity use in developing countries as compared to industrialized countries, but residential electricity demand is growing faster than total demand in developing countries.

Table 2 shows the overall progress in improving the efficiency and reducing the energy consumption of major residential electrical appliances in the United States. These are national average values, assuming that the level of "energy service" per household (e.g., the refrigeration or heating delivered by the systems) has not changed over time. The substantial improvement in efficiency is clearly seen by comparing estimates of the energy use of today's average and best new products with that for typical models in the 1986 or 1991 housing stock. Table 2 also provides estimates of the energy use of advanced technologies that could become widely available during the 1990s. Progress towards the levels of efficiency indicated by the advanced technologies is occurring throughout the world. In some cases, prototype models within these performance ranges already exist.

\begin{tabular}{|c|c|c|c|c|c|}
\hline $\begin{array}{l}\text { Table 2. Ene } \\
\text { Elec }\end{array}$ & $\begin{array}{l}\text { Consumptio } \\
\text { cal Equipme }\end{array}$ & and Con & tion Pot & al with Maj & Residential \\
\hline Product & $\begin{array}{l}1986 \text { Stock } \\
\text { UEC a } \\
\end{array}$ & $\begin{array}{c}1991 \text { Stock } \\
\text { UEC }\end{array}$ & $\begin{array}{l}1991 \text { New } \\
\text { UECC } \\
\end{array}$ & $\begin{array}{l}1991 \text { Best } \\
\text { UEC d }\end{array}$ & $\begin{array}{c}\text { Advanced } \\
\text { Technology }\end{array}$ \\
\hline Refrigerator & 1450 & 1200 & 900 & 710 & $200-500$ \\
\hline Freezer & 1050 & 810 & 600 & 430 & $200-300$ \\
\hline Central AC & 3500 & 3000 & 2750 & 1600 & $1200-1400$ \\
\hline Room AC & 1200 & 1000 & 850 & 590 & $300-400$ \\
\hline $\begin{array}{l}\text { Electric water } \\
\text { heating }\end{array}$ & 4000 & 3800 & 3300 & 1200 & $800-1000$ \\
\hline Electric range & 800 & 770 & 740 & 700 & $400-500$ \\
\hline $\begin{array}{l}\text { Electric clothes } \\
\text { dryer }\end{array}$ & 1120 & 1090 & 1060 & 920 & $250-500$ \\
\hline
\end{tabular}

Source: American Council for an Energy-Efficient Economy

a Estimate of unit energy consumption per typical installation in the 1986 housing stock. All UECs are in kilowatt hours per year.

b Estimate of the unit energy consumption per typical installation in the 1991 housing stock.

c Unit energy consumption for the typical model produced in 1991.

d Unit energy consumption for the best model mass-produced in 1991.

e Unit energy consumption possible in new models during the 1990s if further cost-effective improvements in energy efficiency are made. 


\subsection{Refrigerators and Freezers}

The efficiency of refrigerators and freezers increased substantially throughout the world during the past 20 years. In the United States, the average efficiency of new refrigerators (measured in terms of refrigerated volume per unit of electricity consumption) increased by 112 percent during 1972-1990; the average efficiency of new freezers increased by 95 percent during this period (AHAM 1991). In Japan, the average efficiency of new refrigerators increased by around 400 percent between 1972 and 1987 while efficiency gains in Europe were similar to those achieved in the United States (Schipper and Hawk 1989).

Efficiencies were improved through a combination of measures, including shifting from fiberglass to polyurethane foam insulation, increasing insulation thickness, use of more efficient motors and compressors, use of larger heat exchangers, and removal or reduction of electric resistance heaters (Geller 1985). The large increase in the efficiency of refrigerators and freezers occurred without any major technological innovations or radical product redesign.

Improving the efficiency of refrigerators and freezers is very cost-effective. The top-rated models produced in the United States in recent years were about 5 to 10 percent more expensive than their counterparts of average efficiency (Geller 1988a). The operating savings generally provide a simple payback period of three years or less.

Refrigerators used in developing countries are relatively small (typically 100-300 liters). If a freezer is included, it is usually defrosted manually. Nonetheless, there is great potential to increase energy efficiency. In South Korea, it is estimated that the electricity consumption of a typical 200 liter refrigerator declined from 670 $\mathrm{kWh} / \mathrm{yr}$ in 1980 to $240 \mathrm{kWh} / \mathrm{yr}$ by 1987 (Meyers et al. 1990). In Brazil, the most efficient model in the 250-300 liter size range consumes 30 percent less electricity than the typical model manufactured there in recent years (Geller 1991).

There is tremendous potential to further improve the efficiency of both large refrigerator/freezers and small refrigerators typically used in developing countries. Regarding the latter, a highly efficient 200-liter refrigerator (without a freezer compartment) has been produced on a limited scale in Denmark. This model, whirh contains heavy insulation, an efficient compressor, and enlarged heat exchangers, consumes only about $90 \mathrm{kWh} / \mathrm{yr}$ based on the European test procedure, about 180 $\mathrm{kWh} / \mathrm{yr}$ less than the typical equivalent-sized model sold in Europe as of 1988 (Nørgård 1989). With an incremental first cost of about $\$ 25$, the simple payback period is 21 months assuming an electricity price of $\$ 0.08 / \mathrm{kWh}$ and the cost of saved energy is only $\$ 0.011 / \mathrm{kWh}$.

Regarding U.S.-style refrigerator/freezers, Table 3 shows an analysis sponsored by the U.S. Department of Energy of the potential for increasing the efficiency of an 18-cubic foot U.S.-style refrigerator/freezer with automatic defrost. Applying all conservation measures considered reduces electricity use to $490 \mathrm{kWh} / \mathrm{yr}$, 46 percent below the baseline, which is representative of U.S. refrigerators manufactured in the late-1980s. The total retail cost for all eight measures is estimated to be $\$ 272$, yielding an average cost of saved energy of $\$ 0.051 / \mathrm{kWh}$. If consideration is limited to the measures with a cost of saved energy under $\$ 0.08 / \mathrm{kWh}$, the electricity savings potential is $40 \%$, the average cost of saved energy is $\$ 0.031 / \mathrm{kWh}$, and the simple payback period is 4.4 years using the U.S. average residential electricity price. Many of the conservation measures included in this analysis are already commercially available; others, such as evacuated panel insulation, are still under development. 
Various types of evacuated panels are being developed including very thin metal panels containing a hard vacuum, silica aerogel, and plastic panels containing a soft vacuum and powder material. Evacuated parels have the potential to provide much greater insulating value than polyurethane foam without using chlorofluorocarbons (CFCs). The issues of durability (maintaining a vacuum for many years), mass production techniques, and cost must be resolved before evacuated panel insulation is widely implemented (Turiel and Levine 1989).

Another efficiency option for refrigerator/freezers is to shift from one to two compressors. This improves thermodynamic efficiency and results in less dehydration of food in the refrigerator compartment. Refrigeratorfreezers with dual compressors are already manufactured in Europe. Danish researchers have built a prototype 18-cubic foot, two-door automatic defrost model with two compressors and high levels of insulation. This model consumes about $520 \mathrm{kWh} / \mathrm{yr}$ using the American testing procedure (Pedersen et al. 1986), about 40 percent less than typical U.S. refrigerators of similar size and style.

Another example that demonstrates the possibility to greatly increase the efficiency of refrigerators is a 450 liter, manual defrost refrigerator/freezer custom-made by a small company in Califomia for use with photovoltaic power systems. This model features heavy insulation, separate compressors and condensor coils for each compartment, and mounting of the compressors above the refrigerated space. J' consumes only about $240 \mathrm{kWh} / \mathrm{yr}$ (Shepard 1990).

\begin{tabular}{|c|c|c|c|}
\hline \multicolumn{4}{|c|}{$\begin{array}{l}\text { Electricity Savings Potential and Cost } \\
\text { U.S.-Style Refrigerator/Freezer }\end{array}$} \\
\hline Conservation Measure & $\begin{array}{c}\begin{array}{c}\text { Electricity use } \\
(\mathrm{kWh} / \mathrm{yr})\end{array} \\
\end{array}$ & $\begin{array}{c}\text { First cost } \\
(1987 \quad \$) \\
\end{array}$ & $\begin{array}{c}\text { Cost of saved } \\
\text { energy } \mathbf{b}(\$ / k W h)\end{array}$ \\
\hline Baseline & 955 & 512.70 & - \\
\hline Enhanced heat transfe: & 878 & 521.90 & 0.001 \\
\hline Foam refrigerator door & 787 & 525.10 & 0.005 \\
\hline 5.05 EER compressor & 763 & 532.30 & 0.007 \\
\hline $2^{\prime \prime}$ foam in doors & 732 & 540.60 & 0.030 \\
\hline More efficient fans & 662 & 559.50 & 0.053 \\
\hline Evacuated panel insulation & 577 & 656.20 & 0.054 \\
\hline Two-compressor system & 508 & 760.70 & 0.132 \\
\hline Adaptive defrost & 490 & 794.00 & 0.161 \\
\hline All measures & - & - & 0.051 \\
\hline Measures $<\$ 0.08 / \mathrm{kWh}$ & - & - & 0.031 \\
\hline
\end{tabular}

Source: US DOE 1988.

\footnotetext{
a Based on an 18-cubic foot, automatic defrost, top freezer model.

b The cost of saved energy is the annual capital charge for the measure divided by the annual electricity savings, where the annual capital charge is determined using a $6 \%$ real discount rate and a 20 -year lifetime.
} 


\subsection{Water Heaters}

Storage-type electric water heaters are used in about 20 percent of households in Germany and the United Kingdom, $30 \%$ of households in Sweden, $36 \%$ of households in the United States and $45 \%$ of households in Italy (IEA 1989). The average efficiency of new storage water heaters increased only about 5 to 10 percent during the past 20 years through use of better insulation and "heat traps"-devices that prevent heat flow into the water lines when hot water is not being drawn. Upgrading the efficiency of a new electric resistance storage water heater from 82 percent to 90 percent through better insulation and use of heat traps is estimated to cost $\$ 36$ at the retail level and saves about $300 \mathrm{kWh} / \mathrm{yr}$ in a typical U.S. residence (Miller et al. 1989). The simple payback period at average U.S. electricity prices is 1.5 years and the cost of saved energy is about $\$ 0.013 / \mathrm{kWh}$. The most efficient new electric resistance water heaters produced in the United States in 1991 had efficiency ratings as high as 98 percent (ACEEE 1991).

Significant energy savings also are possible by adding an insulation blanket and/or by installing heat traps on an existing water heater. Metering studies performed in the United States show that an insulation wrap can be very costeffective with payback in less than one year (Brown et al. 1987).

A leap in the efficiency of a storage electric water heater is possible by using a heat pump rather than electric resistance heating. Heat pump water heaters (HPWHs) were first introduced in the United States in the early 1980s. They consume about 50 to 70 percent less electricity than electric resistance water heaters (Geller 1986 ). With a first cost around $\$ 800$ to $\$ 1200$, four times that of a conventional electric water heater, the HPWH typically pays back its extra initial cost through electricity savings in about six years (Geller 1988a). Álso, a heat pump can be used to provide hot water as well as space heating and cooling, and a few systems are available that provide all of these functions.

HPWHs can be operated together with a mechanical ventilation system in tight (i.e., low infiltration) housing. The heat pump removes heat from the exhaust air stream during the heating season and from the incoming air stream during the cooling season. Such systems are commonly installed in new homes in Scandanavia and were introduced in North America in the late1980s (Gehring 1986). The ventilation air streams are a very efficient source of heat for the HPWH.

In some European and developing countries, point-of-use electric water heaters are widely used. These water heaters are directly installed in a shower, faucet, or other end-use device and are used without a storage tank. The point-of-use water heater is relatively efficient since there are no storage or distribution losses. Some electricity savings may be possible through better conirol, however. In Brazil, for example, it has been estimated that addition of a variable power control could save up to 20 percent of the electricity used by a typical point-of-use shower water heater (Geller 1991). Tine variable power control enables the user to selict the appropriate power level at any particular flow rate.

\subsection{Clothes Washers}

The typical clothes washer produced in the United States in 1990 consumed $2.7 \mathrm{kWh} /$ cycle (including electricity required for water heating), compared to $3.8 \mathrm{kWh} /$ cycle for the average new clothes washer produced in 1972 (AHAM 1991). These efficiency gains were achieved mainly by reducing hot water use through lower wash and rinse temperatures (Geller 1988a).

Consumer behavior significantly affects clothes washer energy consumption. For example, selecting "warm wash" rather than "hot 
wash" reduces enerey consumption per cycle by about 50 percent (Levins 1980). Likewise, using "cold rinse" rather than "warm rinse" will reduce energy use. Consumer surveys indicate that changes in washing habits have resulted in significant energy savings during the past 15 years (US DOE 1989). Nonetheless, it is estimated that eliminating the warm rinse option on clothes washers in the United States would cut average energy use by 20 percent without adversely affecting performance (US DOE 1989).

Clothes washers produced in the United States arc predominantly vertical axis, whereas European clothes washers are usually horizontal axis. Horizontal-axis washers are inherently more efficient because they use much less water. Tests show that horizontal-axis washers are nearly three times as energy-efficient as verticalaxis washers of comparable size (Lebot 1990).

Regarding new technologies, one European manufacturer has introduced an innovative horizontal-axis washer that eliminates filling the clothes tub with hot or warm water during the wash cycle. Instead, hot detergent solution is continuously circulated and sprayed on the spinning clothes. This technique significantly reduces hot water, detergent, and energy use compared to standard European clothes washers (Abbate 1988; Nørgård 1989).

Another recent advance developed in Japan is the use of "fuzzy logic" control for computerized systems. A fuzzy logic control develops and responds to a more complex picture of reality than a conventional control. When applied in a clothes washer, the control can vary the quantity of detergent, agitation speed, and wash time based on measurements of the load size and dirt in the wash water. Ten percent energy and water savings are reported (IRM 1991). Fuzzy logic controls can also be used to reduce electricity use in industrial processes, building HVAC systems, and subway systems.

\subsection{Clothes Dryers}

Limited information is available regarding trends in the efficiency of clothes dryers during the past 20 years. One study estimates that the average electricity use of new U.S. clothes dryers declined about 5 percent during the 1980s (US DOE 1989). In Europe, it was estimated that a typical new clothes dryer produced in 1988 consumed about 15 percent less electricity than the average for existing dryers in the same year (Nørgård 1989).

Clothes dryer efficiency can be improved with automatic termination controls and improved insulation. The termination control senses dryness and automatically shuts off the dryer (or initiates a cool-down cycle). U.S. studies show that termination controls and improved insulation can reduce electricity use by around 15 percent (US DOE 1989). With a retail cost estimate of $\$ 29$, these measures have a simple payback of 2.5 years and a cost of saved energy of $\$ 0.018 / \mathrm{kWh}$ (US DOE 1989).

One way to reduce electricity consumption for clothes drying is to increase the spin cycle speed of the clothes washer. Typical North American washers have spin speeds of about 550 rpm, while several European washers spin above $1000 \mathrm{rpm}$ without excessive noise or wrinkling. Increasing from $550 \mathrm{rpm}$ to $1300 \mathrm{rpm}$ reduces the water content of clothes by about 50 percent (Turiel et al. 1990b). Nearly a 50\% reduction in energy consumption for clothes drying would result since mechanical water removal is about 70 times less energy-intensive than thermal removal (US DOE 1989).

Advances in clothes dryers are on the horizon. A prototype heat pump clothes dryer (HPCD) has been developed in the United States. Tests of the HPCD show electricity savings of 50 to 60 percent relative to a conventional electric clothes dryer (Lewis 1983). The HPCD has a 
drain pipe rather than an exhaust vent (advantageous in apartment buildings), and is reported to produce less static and less wear on clothes. It is estimated that the HPCD will have a retail price of $\$ 600$ to $\$ 700$, about twice that of a conventional electric dryer (Geller 1988a). The simple payback period is approximately seven years at typical usage rates and electricity prices and the cost of saved energy is about $\$ 0.053 / \mathrm{kWh}$.

Microwave clothes dryers also are under development. One prototype tested in the United States provided 26 percent electricity savings compared to a standard clothes dryer (Turiel et al. 1990b). This microwave dryer is estimated to cost only 20 to 25 percent more than a conventional dryer (US DOE 1990).

\subsection{HEATING, VENTILATION, AND AIR CONDITIONING (HVAC)}

Improved building design is one way to reduce energy consumption for heating and cooling in both residential and commercial buildings. Air conditioning needs can be cut by shading windows, insulating roofs and walls, reducing air infiltration, using reflective surfaces, using natural ventilation, and reducing artificial lighting. A study of different commercial building designs in Brazil found that by employing a combination of these measures, air conditioning electricity use could be reduced by 60 to 75 percent (Geller 1991).

\subsection{Residential Buildings}

Electricity use for space conditioning (heating and cooling) in residences varies from country to country. As of 1986, electricity was the principal source for residential space heating in 5 percent of households in Italy, 8 percent of households in the former West Germany, 11 percent of households in the United Kingdom, 19 percent of households in the United States, and 36 percent of households in Sweden (IEA 1989). Air conditioning is negligible in Europe, but it was used in 58 percent of households in the United States and 76 percent of households in Japan as of 1986 (IEA 1989). Electrical space heating or cooling of residences is uncommon in developing countries.

The typical central air conditioner produced in the United States in 1990, a "split system" with about $36,000 \mathrm{Btu} / \mathrm{hr}$ or 3 "tons" of cooling capacity, was about 35 percent more efficient than the typical model produced in 1976 (ARI 1992). The efficiency of a typical room air conditioner produced in the United States rose about the same amount during this period (AHAM 1991). In Japan, the average efficiency of room air conditioners and heat pumps increased around 60 percent between 1973 and 1985 (Tsuchiya 1988).

The most efficient central and room air conditioners produced in the United States in 1991-92 had energy-efficiency ratios of over 16.0 and 12.0, respectively (ACEEE 1991). These values are 30 to 40 percent greater than the efficiency of average new air conditioners (see Table 2). The technologies used to increase efficiency include larger and/or improved heat exchangers, higher evaporator coil temperatures, more efficient motors, and improved compressors (Geller 1985). In addition, some highly efficient air conditioners utilize two-speed compressors or variable speed control (Geller 1988a). Variable speed controls are used for capacity modulation, increasing efficiency at part-load operation.

High efficiency air conditioners are economical for residential consumers in the United States as long as annual operating hours and the price of electricity are average or above average. Table 4 includes cost-effectiveness estimates for high-efficiency room and central air conditioners assuming 750 hours per year of operation for the room air conditioner and 1000 hours per year for the central air conditioner (national average usage levels in the United 
States), and an electricity price of $\$ 0.08 / \mathrm{kWh}$. The high-efficiency units have an initial cost that is 15 to 30 percent greater than units of average efficiency, with the operating savings paying back this cost in about seven years. Highefficiency air conditioners and heat pumps are more cost-effective from a utility or societal perspective because air conditioners contribute disproportionately to peak load in most regions.

In Japan and Southeast Asia, some residential air conditioners and heat pumps contain inverterbased variable speed controls (Ushimaru 1987). Japanese systems condition a number of rooms or zones by running refrigerant lines to separate fancoil units. Both zonal control and capacity modulation provide electricity savings.

In residences with electric space heating, heat pumps typically consume about half as much electricity for heating as electric resistance-based systems (Koomey et al. 1991). Furthermore, high-efficiency heat pumps are available which are about 25 percent more efficient than standard heat pumps based on field tests (Schaper et al. 1990 ). As of 1987 , heat pumps are used in about 25 percent of U.S. homes where electricity is the primary space-heating fuel (EIA 1989).

Switching from electric resistance heating to a heat pump can be extremely cost-effective. One study (using a 7 percent real discount rate) estimates a typical cost of saved energy of $\$ 0.003$ to 0.006 per $\mathrm{kWh}$ if the heat pump is installed in new single-family homes at the time of construction in the United States (Koomey et al. 1991). If a heat pump replaces electric resistance heating in an existing house with a forced-air distribution system, the cost of saved energy is estimated to be $\$ 0.01$ to $\$ 0.02 / \mathrm{kWh}$.

\subsection{Commercial Buildings}

HVAC systems account for 40 to 50 percent of electricity use in commercial buildings in some industrialized countries, such as the United States and Germany (IEA 1989). In other industrialized countries such as Japan and in many developing countries, HVAC represents less than 25 percent of electricity use in the services sector.

For commercial buildings, there have been moderate improvements in the efficiency of larger air conditioning systems produced in the United States during the past 15 years. In the late $19 \%$ ios, the efficiency of air-cooled chillers (measured in terms of the coefficient of performance or $\mathrm{COP}$ ) was typically around 2.2 and the COP for watercooled chillers was typically around 3.2 to 3.8 (Usibelli et al. 1985). In the early 1990s, the minimum efficiency standards adopted by ASHRAE and incorporated in building codes by some states requires a COP of at least 2.5 for aircooled chillers and at least 3.8 to 5.2 for watercooled chillers (ASHRAE 1990).

Larger air conditioning systems (greater than about 50 tons of cooling capacity) utilize reciprocating, centrifugal, rotary, or absorption chillers. Large air conditioning systems utilizing rotary or centrifugal compressors are typically more efficient than systems based on reciprocal compressors or smaller air conditioning units. The most effecient products available in the marketplace in the U. S. have efficiencies that are 10 to 50 percent higher than that of standard equipment (Usibelli et al. 1985).

Table 4 includes three examples of the energy savings and cost-effectiveness of more efficient air conditioning equipment for commercial buildings. The "base" system efficiency is typical of equipment recently produced in the U.S.. The analysis is based on a national average commercial electricity price and estimated average operating hours. The efficiency improvement in the three examples ranges from 25 to 38 percent. The incremental cost between the base and highefficiency systems ranges from 17 to 44 percent, with the simple payback period on the incremental cost ranging from 1.5 to 5 years. 
Table 4. HVAC Equipment Efficiency and Cost Comparison.

\section{RESIDENTIAL SYSTEMS}

\section{BTU/HR Room Air Conditioner}

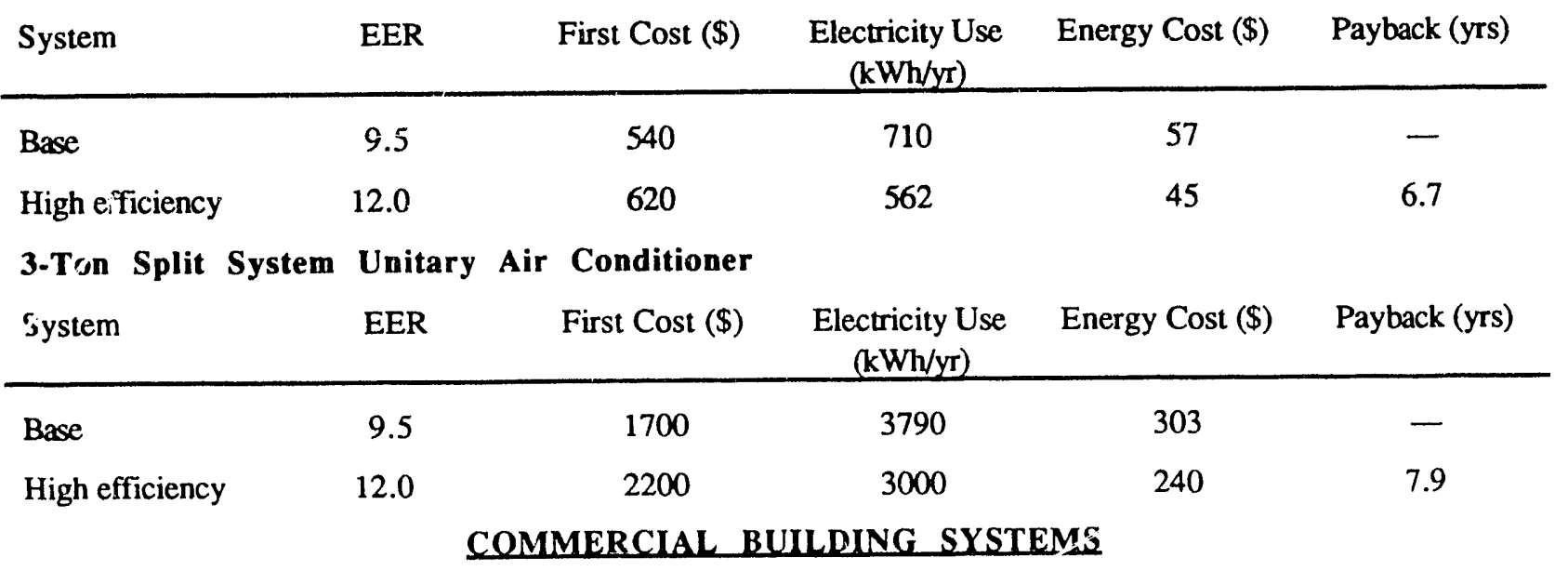

\section{5-Ton Single Package Rooftop Air Conditioner}

\begin{tabular}{lccccc} 
System & EER & First Cost (\$) & $\begin{array}{r}\text { Electricity Use } \\
(\mathrm{kWh} / \mathrm{yr})\end{array}$ & Energy Cost (\$) & Payback (yrs) \\
\hline Base & 7.0 & 5775 & 25,730 & 2060 & - \\
High efficiency & 9.0 & 6750 & 19,980 & 1600 & 2.1
\end{tabular}

100-Ton Reciprocating Chiller, Air-Cooled

\begin{tabular}{lccccc} 
System & COP & First Cost $(\$)$ & $\begin{array}{c}\text { Electricity Use } \\
(\mathrm{kWh} / \mathrm{yr})\end{array}$ & Energy Cost (\$) & Payback (yrs) \\
\hline Base & 2.34 & 27,000 & 150,300 & 12,020 & - \\
High efficiency & 2.93 & 39,000 & 120,030 & 9600 & 5.0 \\
$\begin{array}{l}\text { 100-Ton Reciprocating Chiller, } \\
\text { System }\end{array}$ & COP & Fiter-Cooled & & & \\
\hline Base & 3.20 & 19,000 & 109,910 & 8790 & Payback (yrs) \\
High efficiency & 4.40 & 22,500 & $\begin{array}{c}\text { Electricity Use } \\
(\mathrm{kWh} / \mathrm{yr})\end{array}$ & Energy Cost $(\$)$ & - \\
\hline
\end{tabular}

Source: American Council for an Energy-Efficient Economy. 
Energy management and control systems (EMCSs) automatically regulate the operation of HVAC, lighting, and possibly other systems in buildings. EMCSs range from simple point-ofuse timers to complex microprocessor-based systems. It is estimated that computerized EMCS equipment typically provides a 10 to 20 percent energy savings (Geller 1988b). EMCSs can minimize unnecessary equipment operation and provide other functions such as economizer cycling (see below) or varying supply air/water temperatures defending on climatic conditions. Also, EMCSs are used to limit peak electrical loads by selectively switching off or cycling certain loads.

In the United States, about 22 percent of all commercial buildings floorspace contained computerized control of HVAC systems as of 1989 (EIA 1991b). However, such systems are much more common in large buildings. About 50 percent of buildings with floor areas greater than 20,000 square meters contained computerized EMCSs as of 1989. Application of EMCS technology is expanding rapidly-the fraction of buildings with EMCSs roughly doubled between 1983 and 1989 (EIA 1985; EIA 1991b).

Economizer and variable air volume controls are two specific add-on features for HVAC systems that can save considerable amounts of energy. An economizer brings in outdoor air when it is cool and dry enough, thereby reducing the use of mechanical chillers. Studies for various regions in California show that economizers can reduce electricity use for air conditioning in commercial buildings by 40 to 75 percent (Usibelli et al. 1985). Actual savings depend on climatic conditions and HVAC system design.

Variable air volume systems respond to changes in heating or cooling load by reducing the amount of conditioned air. This can substantially reduce electricity consumption for ventilation. The savings, which depend on the control techniques and the systems to which they are applied. can range from 25 to 80 percent (Usibelli et al. 1985). One very efficient way to operate variable air volume systems is to use an electronic adjustable speed drive instead of more conventional inlet vane controls.

Installing economizers and variable air volume controls as part of air conditioning systems in commercial buildings can be highly economical. A study of electricity conservation potential in New York state found that the cost of saved energy for adding economizers and variable air volume controls is less than $\$ 0.03 / \mathrm{kWh}$ for most types of commercial buildings (Miller et al. 1989). A similar study of electricity conservation potential in Texas estimated a similar costeffectiveness for economizer controls, but an even lower cost of saved energy for conversion to variable air volume (Hunn et al. 1986).

Thermal energy storage systems can be used to reduce peak power demand in electrically heated and/or cooled buildings. Thermal storage involves heating or cooiing the infrastructure of the building (e.g., concrete floors) at night, storage of ice or chilled water produced during off-peak hours, or storage of heat in a medium such as ceramic brick. In so-called "full storage" systems, peak electrical demand is typically reduced by 80 to 90 percent while in "partial storage" systems the reduction is typically 40 to 50 percent (Piette et al. 1988). Thermal storage systems used for reducing cooling requirements during peak load periods in large commercial buildings typically reduce peak electrical demand at a cost of around $\$ 500 / \mathrm{kW}$ to $\$ 850 / \mathrm{kW}$ (Piette et al. 1988). Partial storage systems tend to be more cost-effective than full storage systems.

Implementing a combination of HVAC efficiency measures can have a large impact on total electricity use. For example, it is estimated that new commercial buildings in Sweden 
typically consume $40 \mathrm{kWh} /$ square meter annually for operation of HVAC systems. If a variety of energy-efficiency measures are implemented, annual HVAC electricity use drops to about 20 $\mathrm{kWh} /$ square meter (Abel 1989). Likewise, the New York study found that HVAC conservation measures can reduce electricity use for space cooling in commercial buildings by over one-half (Miller et al. 1989).

\subsection{LIGHTING}

Lighting accounts for a significant portion of electricity use in all countries, and in all sectors. For example, in the United States, lighting accounts for approximately 18 percent of electricity use, including approximately 11 percent of residential sector electricity use, 31 percent of commeicial sector use, and 10 percent of industrial sector use (IEA 1989). Similarly, in India, lighting accounts for an estimated 13 percent of electricity use, including approximately 28 percent of residential sector use, 50 percent of commercial sector use, and 9 percent of industrial sector use (Nadel et al. 1991b).

Throughout the world, three types of lighting systems are widely used-incandescent, fluorescent, and high-intensity discharge (HID). The allocation of lighting energy use among these different lamp types varies primarily from sector to sector-differences between countries are generally not pronounced. In must countries, incandescent lamps account for the vast majority of residential sector lighting energy use (e.g., 95 percent in Brazil and India-(Jannuzzi et al. 1991; Nadel et al. 1991b), while fluorescent lamps account for the majority of commercial and industrial lighting (e.g., approximately 70 percent in the United States and 75 to 80 percent in India -(Nadel et al. 1989; Nadel et al. 1991b). HID lamps are primarily used for industrial and outdoor lighting.

For all three types of lamps, there are generally large opportunities to conserve energy using improved-efficiency technologies that are now sold in many countries. In addition, lighting energy use can be reduced through us? of lighting controls and improved luminaires (lighting fixtures). Promising opportunities are discussed in the sections below.

\subsection{Incandescent and Incandescent Substitutes}

Two types of incandescent lamps are in widespread use in most countries: general service lamps and reflector lamps (see Figure 7). General service lamps predominate in the residential sector and are also used in many commercial and industrial applications. Reflector lamps are commonly used in retail display lighting and recessed ceiling fixtures in commercial buildings. For both types of incandescent lamps, several types of energysaving substitutes are available including "energysaver," halogen, halogen infrared reflecting (IR), and compact fluorescent lamps.

"Energy-saver" lamps are similar to standard lamps except they may feature improved filament design, reflectors, and fill-gases. Relative to standard incandescent lamps, energy-saver lamps use 5 to 20 percent less electricity, although some of these savings come at the expense of reduced light output (data on the performance and economics of products discussed in this section are summarized in Table 5). 


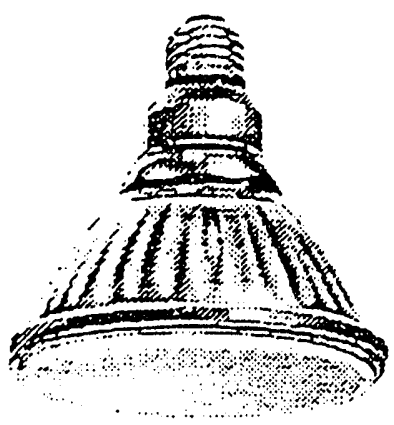

Reflector lamp

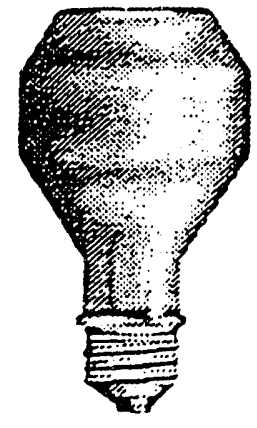

Halogen general service lamp

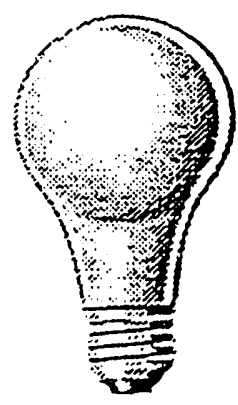

Standard general service lamp

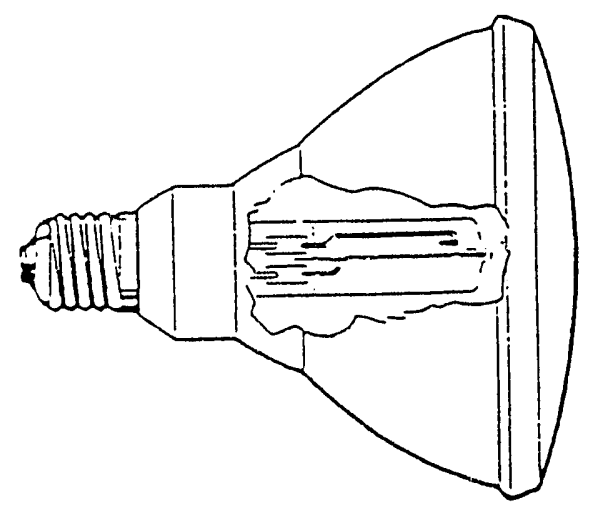

Cut-away view showing tungsten hologen capsule within a reflector lamp

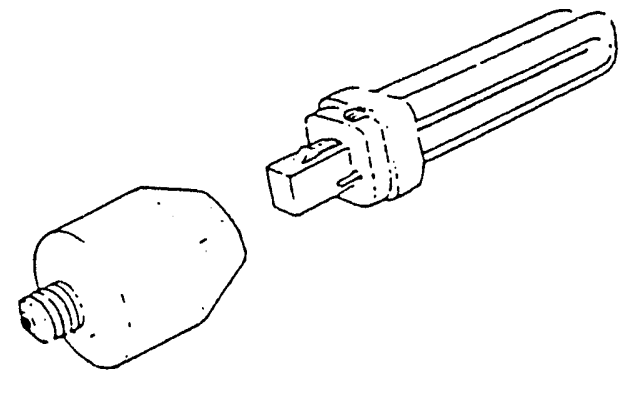

Compact fluorescent limp with screw-in ballast

Sources: General Electric, 1990; CEC, 1990.

Figure 7. Lamp types 
Table 5. Lamp Efficiency and Cost-Effectiveness Analysis.

\begin{tabular}{|c|c|c|c|c|c|c|c|c|}
\hline Lamp type & $\begin{array}{l}\text { Lamp } \\
\text { Watts } \\
\end{array}$ & $\begin{array}{c}\text { Lamp + } \\
\text { ballast } \\
\text { Watts } \\
\end{array}$ & Lumens & $\begin{array}{c}\text { Lumens } \\
/ \mathbf{W a t t}^{2}\end{array}$ & $\begin{array}{c}\text { Life } \\
\text { (hours) } \\
\end{array}$ & $\begin{array}{c}\text { Lamp } \\
\text { cost } \\
\end{array}$ & $\begin{array}{c}\text { Ballast } \\
\text { cost }\end{array}$ & $\begin{array}{c}\mathrm{CSE} \\
(\$ / \mathbf{k W} \mathbf{h}) \\
\end{array}$ \\
\hline \multicolumn{9}{|l|}{ General service incandescent: } \\
\hline Standard & 60 & NA & 883 & 14.7 & 1000 & $\$ 0.52$ & NA & - \\
\hline Energy-saving & 52 & NA & 800 & 15.4 & 1000 & $\$ 0.62$ & NA & $\$ 0.012$ \\
\hline Halogen & 52 & NA & 885 & 17.0 & 3500 & $\$ 2.41$ & NA & $\$ 0.029$ \\
\hline Compact fluorescent & 13 & 16 & 860 & 53.8 & 10,000 & $\$ 15.00$ & NA & $\$ 0.027$ \\
\hline \multicolumn{9}{|l|}{ Reflector incandescent: } \\
\hline Standard & 150 & Nr. & 1740 & 11.6 & 2000 & $\$ 3.60$ & NA & 一 \\
\hline Energy-saving & 120 & NA & 1450 & 12.1 & 2000 & $\$ 3.89$ & NA & $\$ 0.003$ \\
\hline Halogen & 90 & NA & 1270 & 14.1 & 2000 & $\$ 4.98$ & NA & $\$ 0.006$ \\
\hline Infrared reflecting & 60 & NA & 1200 & 20.0 & 2000 & $\$ 6.23$ & NA & $\$ 0.008$ \\
\hline \multicolumn{9}{|l|}{ Fluorescent } \\
\hline Standard lamp \& ballast & 40 & 44 & 1538 & 34.9 & 20,000 & $\$ 1.52$ & $\$ 5.00$ & 一 \\
\hline ES lamp/standard ballast & 34 & 39 & 1399 & 35.9 & 20,000 & $\$ 2.10$ & $\$ 5.00$ & $\$ 0.006$ \\
\hline ES lamp \& ballast & 34 & 35 & 1399 & 40.0 & 20,000 & $\$ 2.10$ & $\$ 7.00$ & $\$ 0.026$ \\
\hline $\begin{array}{l}\text { Cathode cutout lamp/ES } \\
\text { ballast }\end{array}$ & 32 & 32 & 1333 & 41.7 & 20,000 & $\$ 2.33$ & $\$ 7.00$ & $\$ 0.021$ \\
\hline 26mm lamp \& ES ballast & 32 & 33 & 1590 & 48.2 & 20,000 & $\$ 2.45$ & $\$ 7.50$ & $\$ 0.026$ \\
\hline $26 \mathrm{~mm}$ lamp \& elec ballast & 32 & 28 & 1590 & 56.8 & 20,000 & $\$ 2.45$ & $\$ 7.50$ & $\$ 0.026$ \\
\hline Same as above + reflector & 16 & 14 & 1193 & 85.2 & 20,000 & $\$ 2.45$ & $\$ 18.75 \#$ & $\$ 0.010$ \\
\hline \multicolumn{9}{|l|}{ High-intensity discharge: } \\
\hline Self-ballasted mercury & 750 & 750 & 15,000 & 20.0 & 16,000 & $\$ 146.73$ & $\$ 0.00$ & - \\
\hline External ballasted mercury & 400 & 454 & 17,500 & 38.5 & 24,000 & $\$ 16.16$ & $\$ 126.25 \#$ & $(\$ 0.002)$ \\
\hline Metal halide & 250 & 295 & 16,000 & 54.2 & 10,000 & $\$ 32.86$ & $\$ 126.25 \#$ & $\$ 0.004$ \\
\hline High-pressure sodium & 200 & 240 & 19,800 & 82.5 & 24,000 & $\$ 37.83$ & $\$ 126.25 \#$ & $\$ 0.001$ \\
\hline Low-pressure sodium & 135 & 165 & 22,500 & 136.4 & 18,000 & $\$ 49.27$ & $\$ 126.25 \#$ & $\$ 0.003$ \\
\hline
\end{tabular}

- Fluorescent lamp lumens include ballast and fixture efficiency factors and hence are not comparable to lumen figures for other lamp types.

- Reflector and HID fixtures costs are included under "ballast cost" where applicable, as discussed in the text. These instances are noted with the "\#" symbol.

- Ballast, reflector, and HID fixture costs are prorated over the life of the lamp. Ten-year life assumed for magnetic ballasts, and 20-year life assumed for electronic ballasts, reflectors, and new HID fixtures (Gordon et al., 1988).

- CSE relative to standard lamp assuming a 6 percent real discount rate and further assuming 2000 operating hours/yr for incandescent lamps, 3500 hours/yr for fluorescent and HID.

Source: Based on data in Nadel et al., 1989; supplemented with data from lighting manufacturers and distributors. 
Halogen lamps enclose the filament in a glass capsule filled with halogen gas. As a result the filament burns hotter and more efficiently. Relative to standard general service incandescent lamps, halogen lamps reduce energy use by approximately 10 percent. Halogen reflector lamps can save up to 40 percent relative to standard reflector lamps. The additional savings are made possible with improved reflector designs which take advantage of the fact that light output is more concentrated in halogen lamps than in standard incandescent lamps.

Halogen infrared reflecting (IR) lamps are similar to halogen lamps, but the glass capsule is lined with a special coating that reflects infrared energy back onto the filament, causing the filament to burn even more efficiently. Presently, halogen IR lamps are only available in reflector versions. Relative to standard reflector lamps, energy savings of up to 60 percent can be achieved.

Compact fluorescent lamps feature multiple short fluorescent tubes, resulting in products that are nearly the same size as incandescent lamps, yet use 60 to 75 percent less electricity per unit of light output. Like other types of fluorescent lamps, compact fluorescent lamps require a ballast to operate. These ballasts come in two major forms: (1) screw-in adaptors that fit into standard incandescent fixtures and (2) separate ballasts that are incorporated into new fixtures and retrofit kits specifically designed for compact fluorescent lamps. Compact fluorescent lamps are available in a wide variety of general service and reflector sizes and shapes. This wide variety of products allows compact fluorescent lamps to be used in place of many, though not all, incandescent lamps. Compact fluorescent lamps are available in colors that closely match the output of incandescent lamps and that are free from the humming noise that is common with straight tube fluorescent lamps, thus providing a light source and amenity that closely matches the incandescent lamp.

In addition to these technologies, which are already commercialized, a number of new technologies are now being developed. For example, in the late-1980s a small American manufacturer, Durotest, developed and marketed a halogen IR general service lamp. The lamp was eventually withdrawn from the market due to technical problems and poor sales (the lamp was very expensive), but commercially viable products are expected in the future. For example, General Electric is conducting extensive research in this area (McGowen 1992). Several European manufacturers are working on compact fluorescent lamps that are more compact than existing products, and hence can be used in more applications (Lees 1991). Similarly, Philips Lighting recently introduced an "induction lamp" (radio waves induce light output in a fill gas, with the resulting light converted into usable form by phosphors). The lamp uses about the same amount of energy as a compact fluorescent but lasts six times as long (IRT 1991). Finally, researchers in the United States are working on screw-in HID lamps that can reduce energy use by 75 percent when incandescent lamps are replaced (Weijo et al. 1991).

The economics of the incandescent and compact fluorescent products discussed above are summarized in Table 5. Costs are in U.S. dollars, although costs tend to be similar in other countries. For each product we calculate the CSE. The analysis shows that all of the measures have a CSE of less than $\$ 0.03 / \mathrm{kWh}$ for typical hours of lamp use, and hence all measures are likely to be cost-effective for many applications in most countries.

"Energy-saver" lamps are widely available in the United States, Canada, and Brazil. A recent study for the Commonwealth of Massachusetts in the United States estimated that energy-saver 
lamps account for approximately 40 percent of general service incaridescent lamp sales and 20 percent of reflector lamp sales to commercial and industrial customers, with a lower but undeterminable sales share in the residential sector (Nadel et al. 1989). In Brazil, "energysaver" lamps account for approximately 20 percent of lamp sales in the 50-100 watt category (Geller 1991). To the best of our knowledge, energy-saver lamps are not sold in Europe or Asia, most likely because European and Asian lamps put out fewer lumens of light output per watt input than lamps in the Americas and hence the reduced light output of energy-saver lamps is noi a viable option. (European and Asian manufacturers reduce light output in order to get longer lamp life than in the Americas.)

Halogen reflector lamps are produced in most industrialized countries in the world (Philips Lighting 1988) and some developing countries such as Brazil (Geller 1991). In the U.S. Commonwealth of Massachusetts, in 1989, these lamps accounted for nearly 10 percent of reflector lamp sales, with the sales share increasing significantly each year (Nadel et al. 1989). General service halogen lamps are produced in both the United States and Europe. Halogen IR lamps are available only in the United States. Sales of general service halogen lamps have been modest. Halogen IR lamps have been very successful in the market; the manufacturer, General Electric, could not at first keep up with the demand, but presently supplies are adequate (McGowen 1992). Other manufacturers are expected to enter the field in the next few years (Gallien 1990).

Compact fluorescent lamps have been selling briskly throughout the world. In 1990, shipments in the United States were estimated at 25 million (Johnson and Unterwurzacher 1991; EPRl, forthcoming). Demand for compact fluorescent lamps in North America, Europe, and Asia exceeds supply, with the result that some purchasers frequently have to wait many months to receive their orders (Johnson and Unterwurzacher 1991); (Arthur D. Little Company 1991); (Nadel 1990a). Compact fluorescent lamps are now being produced in Europe, the United States, Brazil, Mexico, Japan, Taiwan, Korea, China, and Sri Lanka.

\subsection{Fluorescent Lamps}

Lighting manufacturers developed and introduced a number of improved fluorescent lamps in the past 15 years. In the United States and other countries with 115-volt electrical service, the first generation of energy-saving fluorescent lamps (developed in the mid-1970s) s'sbstituted krypton for argon as the inert gas in the lamps. Power consumption dropped from 40 to $34 \mathrm{~W}$ for a standard four-foot $(120 \mathrm{~cm})$ lamp, but light output also fell by 10 to 12 percent (Marbek Resources Consultants Limited 1986). Lamp efficacy (lumens of light output per watt of power input) increased about 3 percent. Another improvement in some energy-saving lamps is disconnection of the cathode after the arc is struck, providing an additional 5 percent of electricity savings (General Electric 1990).

In European and Asian countries with 220- to 240-volt electrical service, the first generation of energy-saving fluorescent lamps were thinner in diameter than standard fluorescent lamps $(26 \mathrm{~mm}$ versus $38 \mathrm{~mm}$ ). The small diameter reduced energy losses, with the result that the energy use of a four-foot $(120 \mathrm{~cm})$ fluorescent lamp fell from 40 to $36 \mathrm{~W}$, with no change in light output (Philips Lighting 1988).

A second generation of improved fluorescent lamps was introduced in the early-1980s. These lamps contain improved phosphors that result in a 5 to 15 percent increase in efficacy along with very good color rendition (improvements are at the high end of this range in Europe and at the low end in the U.S) (Philips Lighting 1988; General Electric 1990). 
A lamp ballast is needed to provide a suitable starting voltage, thereafter limiting current flow during operation of fluorescent lamps. Ordinary ballasts dissipate about 20 percent of the total power entering a fixture (Geller and Miller 1988). In some developing countries, poor quality ballasts may disipate as much as 30 percent of the energy entering the fixture (Turiel et al. 1990a). More efficient electromagnetic ballasts (also known as core/coil ballasts), introduced in the mid-1970s, make use of better materials including copper windings and high-grade steel to reduce ballast losses by 50 to 60 percent. Solid-state electronic ballasts, introduced during the early1980s, cut ballast losses even further and alsn increase lamp efficacy due to high-frequency operation. Total power savings are approximately 20 to 25 percent relative to use of a standard ballast (Geller and Miller 1988).

In addition, special ballasts were introduced in the 1980s which optimize the efficiency of 26$\mathrm{mm}$ (one inch) fluorescent tubes (standard ballasts optimize the efficiency of $38-\mathrm{mm}$ [ 1.5 inch] tubes). These $26-\mathrm{mm}$ ballasts (called $\mathrm{T} 8$ ballasts in the United States) come in both electromagnetic and electronic versions. Relative to electromagnetic and electronic ballasts designed for 38-mm lamps, they reduce energy use of the lamp/ballast system by approximately 10 percent (Philips Lighting 1988).

An optical reflector (also known as a specular reflector) can be placed in a fluorescent light fixture in order to increase the amount of light emitted from the fixture. Three types of reflectors are produced in the United States-polished anodized aluminum, aluminum film, and silver film. Use of an optical reflector typically increases useful light output by 75 to 100 percent, thereby permitting removal of one or two lamps from three or four lamp fixtures (Marbek Resources Consultants Limited 1986). Optical reflectors can be retrofit into existing fixtures, or they can be designed into new fixtures.

In addition to products presently on the market, a number of advanced technologies are now being developed including advanced phosphor materials, isotopically enriched fill gases, surface wave lamps, and two-photon phosphors. These measures have the potential to more than double the efficacy of fluorescent lamps (EAP 1991).

The economics of the different technologies discussed above are summarized in Table 5. For U.S. markets, all of the options examined have a CSE of less than $\$ 0.03 / \mathrm{kWh}$ relative to standard lamps and ballasts for an average usage of 3500 hours per year, and many of the options have a CSE of less than $\$ 0.01 / \mathrm{kWh}$. For the European and Asian markets, most of the options are similar, except that the 34-watt, energy-saving lamp cannot be used, and the 36 Watt $26 \mathrm{~mm}$ lamp should be included instead. The 36-watt 26 $\mathrm{mm}$ lamp costs approximately the same as the 40watt $38 \mathrm{~mm}$ lamp, and hence saves electricity at zero incremental cost (Nadel et al. 1991b).

Level of adoption and market share varies among the different energy-efficient lighting technologies, in part due to the period of time each technology has been commercially available.

Regarding energy-saving fluorescent lamps (all types), estimates of current market share in the Uniied States range from 20 to 60 percent, with 30 to 40 percent being the most commonly reported values (Geller 1988b; Nadel et al. 1989). In Europe, energy-saving fluorescent lamps account for the majority of fluorescent lamp sales. In recent years, energy-saving fluorescent lamps have become popular in many developing countries. For example, in Egypt, of the two major fluorescent lamp manufacturers, one produces only $26-\mathrm{mm}$ lamps, and the other plans to switch exclusively to 26-mm lamps in the nearfuture (Turiel et al. 1990a). A similar situation exists in Thailand where several manufacturers 
sell $26 \mathrm{~mm}$ lamps and one plans to switch exclusively to these lamps in the near future (Busch et al. 1991).

Regarding fluorescent lamp ballasts, in the United States, due to a law passed in 1988, nearly all ballasts produced since 1990 are energy-efficient magnetic ballasts (Geller and Miller 1988). A similar law is expected to take effect in Canada in a few years (Davis 1991). Sales of solid-state electronic ballasts are rapidly increasing in the United States. In 1991, electronic ballasts accounted for an estimated 11 percent of ballast sales, and are projected to reach 39 percent by 1995 (Johnson and Unterwurzacher 1991). Sales of efficient magnetic and electronic ballasti: appear to be much lower elsewhere in the world, although sales of electronic ballasts are starting to pick up. Electronic ballasts are produced by several countries along the Pacific Rim in Asia, and production has begun in Brazil and India (Geller 1991; Nadel et al. 1991b).

Installation of optical reflectors is expanding at the rate of about 30 percent per year in the United States, with estimated sales of 450,000 units in 1987 (Maximum Technology Inc. 1988). However, the fraction of all fluorescent fixtures with reflectors is probably still under one percent.

\subsection{High-Intensity Discharge Lamps}

There are five main types of high-intensity discharge (HID) lamps. In order from least to most efficient these are: self-ballasted mercury vapor, externally ballasted mercury vapor, metal halide, high-pressure sodium, and low-pressure sodium. Table 5 summarizes the efficacy (lumens per watt) of each of these lamp types for an application requiring approximately 18,000 lumens.

There are significant opportunities for energy savings by upgrading from less-efficient to moreefficient lamp types. Generally the most common upgrade will be to move from mercury vapor lamp types to high-pressure sodium. Highpressure sodium lamps can provide a similar quality of light as mercury vapor lamps; standard high-pressure sodium lamps have a somewhat lower color-rendering index (a measure of color distortion) than standard mercury vapor lamps, but deluxe high-pressure sodium lamps are superior to mercury vapor lamps in this regard (General Electric 1987). In applications where high color rendering is important, metal halide lamps can be used. In applications where color rendering is unimportant, low-pressure sodium lamps can be used.

To replace a self-ballasted mercury vapor lamp with another HID lamp type requires a new fixture. If an externally-ballasted mercury vapor lamp is being replaced, some metal halide and high-pressure sodium lamps will operate on the mercury vapor ballast, albeit with some sacrifice in performance. In most cases, to optimize performance, a new ballast designed for that lamp type should be installed.

Electronic ballasts for HID lamps are just now entering the market, offering the opportunity for additional energy savings. Higher efficacy products are also being developed. For example, in Europe Philips recently introduced a lowpressure sodium lamp with an efficacy of over 200 lumens/watt (Philips Lighting 1988). In the United States, research is taking place on electrodeless HID lamps that have the potential to reduce energy use by 50 percent (Weijo et al. 1991).

The economics of the different types of HID lamps are summarized in Table 5. Relative to the self-ballasted mercury vapor lamp, all of the options have a CSE of less than $\$ 0.01 / \mathrm{kWh}$, even thnugh all of the options involve purchasing a new fixture. Thus, all of the options should be highly cost-effective in most situations.

In the United States, high-pressure sodium 
lamps are the most commonly used HID lamp type, although approximately 35 percent of applications still use extemally-ballasted mercury vapor lamps (Nadel 1990b). Very few lowpressure sodium lamps are in use in the United States. In Europe, both high- and low-pressure sodium lamps are in widespread use. In many developing countries, mercury vapor lamps, both internally and exiernally ballasted, are the predominant HID lamp type. For example, in India, approximately 60 percent of HID energy use is by mercury lamps (Nadel et al. 1991b). In Brazil, approximately 65 percent of HID lamps sold are self-ballasted mercus y lamps, 30 percent are extemally-ballasted mercury lamps, and only 5 percent are of the more efficient types (Geller 1991). Production of high-pressure sodium lamps has recently begun in a number of the larger developing countries such as Brazil and India (Geller 1991; TERI 1990). However, in many other developing countries, these lamps are not produced and must be imported.

\subsection{Lighting Design and Controls}

While more efficient lighting equipment can be used to reduce the amount of energy lights use when they are on, additional czergy can be saved by controlling lights so they are on less often. A number of energy-saving lighting controls are now on the market including multilevel switches, timers, photocell controls, occupancy sensors, and daylight dimming systems. In addition, "task lights" (small lights which illuminate only the work surface) can be used, so that general lighting levels can be reduced.

Multilevel switches allow light levels to be adjusted manually so that the number of lamps in use match the need for lighting, since, generally, maximum lighting levels are not needed at all times. For example, one control option is to install three-lamp fluorescent fixtures and a muit'evel switch that turns on one, two, or three lights, depending on the need. Timers automatically tum off lights during periods a building is unoccupied, thereby reducing labor costs and saving energy in situations where staft did not tum off lights. Savings of 15 percent can be achieved with these systems in large office buildings (CEC 1990). Photocell controls turn lights on at night and off at sunrise.

Occupancy sensors use infrared or ultrasonic sensors to determine when people enter a room and automatically turn the lights on. Lights are turned off a few minutes after people leave. When used in individual offices, bathrooms, and conference rooms, savings of up to 30 percent can result. When used in large open office areas, savings of up to 15 percent can result (CEC 1990).

Daylighting controls automatically reduce lamp output when daylight is sufficient to maintain or supplement required illumination levels. The systems combine a photocell sensor with a dimmable lighting system such as a fluorescent lighting system employing dimmable ballasts. This technology is applicable to perimeter zones of buildings as well as interior zones if skylights are installed. Savings of 50 percent are typical in areas within approximately 15 feet (5 meters) of windows and skylights (Verderber and Rubinstein 1983).

Use of task lights allows general area lighting levels to be reduced. For example, lighting guidelines prepared by the Illuminating Engineering Society specify a recommended lighting level of 750 lux (a unit of light intensity) for detailed work (such as accounting), but only 150 lux for filing and, 300 lux for reading most printed material (IES 1985). Many offices are designed to provide 750 to 1000 lux throughout the workspace, which would typically require 20 to 30 watts/square meter of lighting (General Electric 1988). If a task light is installed at each work area that provides $750 \mathrm{lux}$ and the general lighting levels reduced to 200 lux, lighting loads 
can be reduced by approximately 70 to 80 percent.

The economics of lighting controls and task lights are highly application-specific, but are often very attractive. For example, an occupancy sensor for a private office typically costs $\$ 65$ (Miller et al. 1989). Assuming 30 percent savings with standard fluorescent lamps and ballasts, and a 10-year sensor life, the cost of saved energy is $\$ 0.024 / \mathrm{kWh}$. A daylight dimming system typically costs $\$ 0.20 /$ watt controlled assuming standard lamps and ballasts (Xenergy Inc. 1991). Assuming 50 percent energy savings in the fixtures controlled and a control life of ten years, the cost of saved energy is $\$ 0.016 \mathrm{kWh}$. Thus, advanced lighting controls are likely to be cost-effective in most countries.

In the United States, use of lighting controls is generally limited. For example, a national survey of commercial buildings conducted by the U.S. Department of Energy indicated that about 6 percent of commercial floor area is served by some type of automatic lighting control (EIA 1991b). A field study of new commercial buildings in several northeastern states found that only one out of 18 buildings studied used automatic lighting controls, and only two emplined task lights to a significant degree (Nade. et al. 1989). In most developing countries, use of sophisticated lighting controls is extremely rare (see, for example, TERI 1990).

\subsection{Summary of Lighting Savings Potential}

Each of the lighting efficiency measures discussed above is appropriate for some buildings, but not all buildings. Several studies have looked at the applicability of each measure and estimated the total potential for savings from all cost-effective measures. For example, Lawrence Berkeley Laboratory and the American Council for an Energy-Efficient Economy have looked at the cost-effective savings potential in the residential, commercial, and industrial sectors and estimated that lighting energy use in these sectors can be reduced by 47 percent, 69 percent, and 36 percent respectively (Nadel et al. 1991a). In Europe, several studies have estimated that total lighting energy use can be reduced by more than 50 percent (Fickett et al. 1990). A review of opportunities to save energy in commercial buildings in Thailand concluded that costeffective measures could reduce lighting energy use by 70 percent (Busch et al. 1991). In Brazil Jannuzzi et al. (1991) have concluded that application of cost-effective efficiency measures can reduce lighting energy use by 22 percent. In India, a recent analysis prepared for the World Bank estimated that cost-effective measures could reduce lighting energy use by 35 percent (Nadel et al. 1991b). Differences in savings estimates are partly due to differences in the number of efficiency measures included in the analysis-in studies with low savings estimates, generally only a limited number of measures are examined.

\subsection{MOTORS}

Motors are the largest end-user of electricity in most countries in the world. For example, in the United States an estimated 57 percent of total electricity use is by motors (Nadel et al. 1991c). Approximately 60 percent of this use is in the industrial sector, primarily to power pumps, fans, compressors, and machine tools. The remaining 40 percent is split evenly between the residential sector (primarily to power refrigerators and air conditioners) and the commercial sector (primarily to power cooling, ventilation, and refrigeration systems) (Nadel et al. 1991c). In India, approximately 70 percent of national electricity use is for motors, primarily in the industrial sector (similar end-uses as in the United States) and agricultural sectors (primarily irrigation pumps) (Nadel et al. 1991b). 


\subsection{Technologies}

There are numerous technologies and practices that can reduce motor electricity use, including use of energy-efficient motors, variable speed drives and other controls. Electricity can also be saved with improvements in power quality, specifying and maintenance practices, and drivetrain components. These opportunities are summarized below.

\subsubsection{Energy-Efficient Motors}

In the United States, for the most commonly used motor types, virtually all manufacturers produce two different product lines-a standard efficiency line and a high-efficiency line. A highefficiency motor typically costs 10 to 30 percent more than a standard efficiency motor, and reduces energy use by 2 to 15 percent (depending on the motor size) (Nadel et al. 1991c). However, the operating cost of a motor for a single year often exceeds the purchase price, and thus even small efficiency improvements can quickly pay for themselves. In Japan, motors even more efficient than U.S. "high-efficiency" motors are available (Washington State Energy Office 1990). In developing countries, small motors may be produced by hand, with the resulting products even less efficient than U.S. standard efficiency products (Nadel et al. 1991b). However, a few devcloping countries are now producing high-efficiency motors in limited quantities including Taiwan, Brazil, and India (Washington State Energy Office 1990; Geller 1991; Nadel et al. 1991b).

There are opportunities for additional efficiency gains in the future. In the United States, the National Electrical Manufacturers Association is debating a proposal to develop a new type of motor with efficiencies 1 to 4 percent higher than high-efficiency motors now being produced (NEMA 1991). Even higher efficiency gains are possible with amorphous metal motor cores, permanent magnet motors, and switched reluctance motors. Each of these technologies is entering commercialization, albeit on a limited scale (Baldwin 1989; Comnes and Barnes 1987; Lovins et al. 1989)

\subsubsection{Variable Speed Drives}

In many motor applications, the need for motor power varies over the course of the hour, day, or year. For example, commercial cooling and ventilation systems often need to move more air on hot days than on mild days. Industrial processes need more motor power at times of peak production. Traditionally the need to vary motor power output has been handled in one of two ways: (1) periodically cycling the motor on and off, and (2) varying motor speed with a variety of mechanical devices such as inlet vanes, outlet dampers, and throttling values. Cycling the motor on and off is not possible in continuous processes, and extensive cycling can shorten the life of the motor. Varying motor speed mechanically is analagous to driving a car with the accelerator pushed to the floor while controlling the vehicle's speed with the brake. Such methods yield imprecise control and waste a lot of energy.

In the early-1970s, an alternative control was developed--the variable speed drive (VSD). VSDs modify the power going into the motor, allowing the speed to be varied in proportion to the amount of motor power needed. Savings with VSDs vary depending on the application, but savings of 15 to 40 percent are possible in many cases (Nadel et al. 1991c). Since their development, VSDs have steadily improved in reliability, cost-effectiveness, and the range of applications for which they can be successfully applied. These trends are likely to continue (Greenberg et al. 1988).

\subsubsection{Power Quality}

Motors operate less efficiently when voltages dip and rise, phases are out of balance, and the 
electrical sine wave is distorted. Unfortunately, these problems are common, due either to problems with the electricity generation and transmission system, or problems caused by welders, arc-furnaces, and other power-distorting equipment within customer facilities. Avoiding and correcting such problems requires careful monitoring of power quality, repair of faulty devices, and in some cases, installation of specialized power-conditioning equipment. Savings are highly application-specific. One U.S. study estimated the range of potential savings to be 1 to 15 percent (Lovins et al. 1989).

\subsubsection{Specifying and Maintenance Practices}

Oversized motors, pumps, fans, and compressors operate less efficiently than those that are properly sized. The average efficiency loss has been estimated at 1 percent of all motor energy use, corresponding to an average 5 percent efficiency loss in the estimated 20 percent of motors that are significantly oversized (Nadel et al. 1991c). When power cables are undersized, excess energy losses result. Optimal sizing can reduce these losses by up to 80 percent, reducing electricity use by a few percent. Furthermore, a good maintenance program can reduce motor electricity use by up to 10 to 15 percent (Ibanez 1978). Such a program includes periodic testing of motors to spot problems before they result in motor failure, and proper lubrication. Over- or under-lubrication can harm motor efficiency. Use of premium lubricants can save 3 percent or more (Nadel et al. 1991c). Finally, most motors are periodically rewound (the old wire windings removed and new wire installed). In most of the world, to loosen the glues that hold the old wire in place, the motor is baked in an oven (or an open fire in many developing countries). If baking temperatures are too high the motor core is damaged and efficiency drops by a few percent (Nadel et al. 1991C). Proper temperature regulation and use of a mechanical stripping process can eliminate these losses (Dreisilker 1987).

\subsubsection{Drivetrain Components}

In most applications, motors are connected to the driven equipment through a series of belts, chains, and gears. The efficiency by which different products can transmit motor power varies considerably. For example, the commonly used "V-belt" generally has an efficiency of 90 to 96 percent (4 to 10 percent of the power is lost). "Synchronous" and "flat" belts have efficiencies of 98 to 99 percent (Nadel et al. 1991c). Similarly, worm gears have efficiencies of 55 to 94 percent, significantily less than the 90 to 98 percent efficiency of the slightly more expensive helical and bevel gears (Nadel et al. 1991c).

\subsection{Economics and Savings Potential}

The economics of these different efficiency measures for motors vary from measure to measure and application to application. Still, typical values or ranges can be estimated for many measures. These values are summarized in Table 6. As can be seen in this table, most of the meas". es discussed above have a cost of saved eicrgy of less than $\$ 0.03 / \mathrm{kWh}$, including several measures that can be accomplished at no added cost when existing motors are replaced. If cost-effective incasures are implemented, substantial savings will result. One recent analysis for the United States estimated that electric motor energy use can be reduced by 16 to 40 percent from application of the measures summarized in Table 6 (Nadel et al. 1991c). Another recent study (Lovins et al. 1989) estimated an even higher savings potential-from 44 to 60 percent. Essentially all of the measures examined for the United States are also applicable in developing countries (see, for example, Nadel et al. 1991b).

\subsection{Current Status}

Although all of the measures are 
Table 6. Summary of Savings Potential for Electric Motors.

$\begin{array}{lr}1988 \text { Input to U.S. Drivepower } & 1574 \mathrm{TWh} / \mathrm{yr} \\ \text { Allocated Thus } & \\ \text { Induction } & 1511 \\ \text { Synchronous } & 55 \\ \text { DC } & 8\end{array}$

\begin{tabular}{lccc}
\hline & $\begin{array}{c}\text { Savings } \\
\text { (TWh/yr) }\end{array}$ & $\begin{array}{c}\text { Remaining Input } \\
\text { (TWh/yr) }\end{array}$ & $\begin{array}{c}\text { Cost of Savings } \\
\text { (cents/kWh) }\end{array}$ \\
\hline Induction motors & 59 & 1511 & $1.5-2.6$ \\
Replacement with high E motors & 15 & & 0 \\
Elimination of past rewind damage & 8 & 1429 & 0 \\
Correction of previous oversizing & $14-72$ & $1357-1415$ & $?$ \\
Electrical tune-ups (1-5 percent savings) & $75-298$ & $1059-1340$ & $1-5$ \\
Controls (5.5-21 percentsavings) & & 63 & $<3$ \\
DC and synchronous motors & 3 & 60 & \\
$\quad \begin{array}{l}\text { S percent savings from all measures } \\
\text { Remaining input to all motors }\end{array}$ & & $1119-1400$ & \\
$\begin{array}{l}\text { Drivetrain, lubrication, and maintenance } \\
\text { savings: }\end{array}$ & & & \\
$\quad$ 3-7 percent from all measures on all & $34-98$ & $1021-1366$ & 0 \\
$\quad$ motors & & & 0 \\
Indirect savings & & & \\
$\quad$ Reduced distribution loss & $24-55$ & $966-1342$ & \\
$\quad$ Reduced HVAC effectPRI & $13-24$ & $942-1329$ & \\
Total savings & $245-632$ & & \\
Savings as percent of original input & $16-40$ percent & & \\
Source: Nadel et al. 1991c & & &
\end{tabular}

used to some degree, none are widely practiced. In the United States, approximately 20 percent of motor sales are high-efficiency motors (Nadel et al. 1991c). In India and Brazil, less than 1 percent of motor sales are high-efficiency (Nadel et al. 1991b; Geller 1991). Variable speed drive sales in the United States have been steadily increasing in recent years (Miller and Rupnow 1991). VSDs are also produced in some developing countries such as India and Brazil. Approximately 1700 VSDs were sold in Brazil in 1989, with sales increasing about 30 percent per year (Geller 1991). A recent study on motor rewind practices in the northwestern United States found that half of the motors are heated above 650 degrees F (350 C) (Seton Johnson and Odell Inc. 1987) and thus efficiency degradation is likely. The current status of the other efficiency measures is much harder to measure. In the United States, discussions with knowledgable parties indicate that all measures are practiced by only a small minority of firms. In Japan, motor maintenance practices are reportedly very advanced, so most of the savings from improved maintenance have probably been captured (Johnston 1990) .

\subsection{ELECTRICITY-INTENSIVE INDUSTRIAL PROCESSES}

Electricity-intensive processes such as electrolysis and electric arc furnaces are major consumers of electricity in the aluminum, steel, and chemicals industries. The fraction of industrial electricity use corisumed by these 
processes varies significantly from country to country and depends on natural resource availability, industrial mix, electricity prices, and other factors. For example, electrolysis and electric fumaces account for about 39 percent of industrial electricity use in Brazil (Geller 1991), about 20 percent of industrial electricity use in the United States (Faruqui et al. 1990), and about 14 percent of industrial electricity use in India (Nadel et al. 1991b).

\subsection{Aluminum Production}

Electrolytic reduction for aluminum production requires large amounts of electricity and accounts for a substantial portion of the total cost of aluminum. The energy efficiency of aluminum production has been undergoing steady improvement. New energy-efficient smelters consume about $13 \mathrm{kWh} / \mathrm{kg}$, about half the level typical of smelters installed 50 years ago (Streicher and Geller 1990). In Brazil, recently installed aluminum smelters use 10 to 20 percent less electricity per unit of output as compared to smelters installed in the early-1970s (Geller 1991). The payback period for better process controls and other measures that reduce the electricity intensity of aluminum production is typically one to four years (Gamba et al. 1986).

A number of advanced technologies, including the Alcoa reduction process, inert anodes, and wettable cathodes, may become available during the 1990s. These advances could provide further efficiency improvements. One U.S. study estimates that a 30 to 50 percent reduction in electricity use per unit of aluminum production will be possible by 2000 compared to present practices, although this is an estimate of "maximum technical potential" (Faruqui et al. 1990).

Increasing aluminum recycling is another way to reduce electricity use since producing secondary aluminum requires only about 5 percent of the energy necessary to produce aluminum from bauxite (EPRI 1988). The production of secondary aluminum (using fabricators' scrap as well as post-consumer scrap) grew from 25 percent to 50 percent of total production in the United States between 1970 and 1985 (Williams et al. 1987).

\subsection{Chlor-Alkali Production}

The chlor-alkali industry uses electrolysis to produce chlorine and caustic soda. In chlor-alkali production, selective membrane cells consume 15 to 30 percent less electricity than conventional mercury or diaphragm cells (EPRI 1988). Also, membrane cells improve product quality and reduce adverse environmental and health impacts. Furthermore, improved ion exchange membranes have been developed in Japan that are 10 to 15 percent more efficient than standard selective membranes (Tsuchiya 1988).

In some industrialized countries, the membrane process is widely used because the mercury process was banned due to environmental and health concerns. Switching to the membrane process also can be cost-effective based on the energy savings. In India, for example, it is estimated that replacing existing mercury and diaphragm cells with membrane cells would have a CSE of about $\$ 0.018 / \mathrm{kWh}$ (considering capital costs only) (Nadel et al. 1991b).

In many developing countries, mercury and diaphragm cells are still the predominant processes used in chlor-alkali production. In India, for example, the mercury process accounts for about 90 percent and the diaphragm process for about 7 percent of total output. Thus, there is wide potential to reduce electricity use through installation of selective membrane cell production facilities.

\subsection{Electric Arc Furnaces}

Electric arc furnaces (EAFs) are used to 
produce raw steel either from scrap metal or directly from iron ore in so-called "minimills." Minimills are smaller in scale, require lower investment costs, and are faster to construct than conventional steel plants. Some developing countries (e.g., Argentina, Indonesia, and Thailand) already produce most of their steel using minimills. In the United States, minimills accounted for about 35 percent of steel production in 1985 (EPRI 1988). EAFs also are used to produce specialty steel alloys such as silicon steel.

In industrialized countries, electric minimills in use in the early-1980s typically consumed 0.55 $\mathrm{kWh} / \mathrm{kg}$ when using scrap steel and about 0.74 $\mathrm{kWh} / \mathrm{kg}$ when iron ore is directly reduced (Meunier and Kops 1984). These electricity intensities are four to six times greater than that for conventional coke-based steel processes. But overall energy consumption and energy costs are considerably lower for minimills (EPRI 1988).

Various technologies are available to improve the efficiency of EAFs including preheating scrap using waste gases, the use of oxygen lancing to assist melting, the use of improved electrodes, computerized control, continuous steelmaking, and ultra-high power furnaces. Table 7 lists a variety of measures that can improve the efficiency of EAFs in India, where EAFs typically consume 600 to $900 \mathrm{kWh} /$ metric ton. Not all of these measures can be implemented in every EAF but an average savings potential of 30 percent has been estimated at a CSE of around $\$ 0.01 / \mathrm{kWh}$ (Nadel et al. 1991b)

Case studies show that implementing a combination of efficiency measures can significantly reduce EAF electricity consumption. In Brazil, for example, one large steel company reduced its purchased electricity per unit of steel

Table 7. Measures to Improve Electric Arc Furnace Efficiency in India

\begin{tabular}{lcl} 
Savings Measure & $\begin{array}{c}\text { Electricity } \\
\text { Savings } \\
\text { (kWh/tonne) }\end{array}$ & Notes \\
\hline $\begin{array}{l}\text { Oxygen assisted melting } \\
\text { Oxyfuel burner }\end{array}$ & $\begin{array}{l}\text { up to } 75 \\
\text { up to } 50\end{array}$ & $\begin{array}{l}\text { Needs water-cooled panels and computer controls } \\
\text { for best results. } \\
\text { Best suited for a shop with more than one } \\
\text { furnace since cost can be spread among several } \\
\text { furnaces. }\end{array}$ \\
$\begin{array}{l}\text { Scrap preheating } \\
\text { Use burnt lime }\end{array}$ & $\begin{array}{l}\text { Needs installation of a lime kiln or purchase of } \\
\text { burnt lime. Some energy is consumed in the } \\
\text { process to make burnt lime. }\end{array}$ \\
$\begin{array}{l}\text { Power factor correction \& control } \\
\text { Ladle furnace }\end{array}$ & $\begin{array}{c}\text { NA } \\
10-15\end{array}$ & Also improved product quality and productivity. \\
$\begin{array}{l}\text { Eccentric bottom tapping } \\
\text { Foaming slag practices } \\
\text { Computerized control \& automation }\end{array}$ & $\begin{array}{l}10-15 \\
\text { up to } 40\end{array}$ &
\end{tabular}

Source: National Productivity Council, 1991, Report on Review of Power End-Use Efficiencies, prepared for the World Bank, New Delhi, India. Cited in Nadel, Kothari and Gopinath, 1991b. 
output by 30 percent between 1981 and 1989 (Geller 1991). In Germany, the BSW plant managed to reduce its electricity intensity from over $0.60 \mathrm{kWh} / \mathrm{kg}$ in 1979 to under $0.45 \mathrm{kWh} / \mathrm{kg}$ by 1986 (Eketorp 1989).

A promising new technology for producing steel or steel alloys is the "plasmamelt" processusing electricity to generate a plasma, which is injected into a furnace along with iron ore or scrap steel and coal powder. If scrap metal is used, the plasma-based process consumes only about one-third as much electricity as a normal scrap-based EAF (Eketorp 1989). A full-scale plasma-based steel alloy plant is operating in Sweden.

\subsection{ELECTRICITY CONSERVATION SUPPLY CURVES}

The overall technical potential for electricity savings in a particular country or region can be displayed in a "conservation supply curve." A conservation supply curve indicates the maximum savings potential and the cost of saved energy for a discrete number of conservation measures (or groups of measures). The measures are ranked from most to least economical. The conservation supply curves described below refer to efficiency improvements that can be achieved over a 15- to 20-year time period relative to current efficiency levels.

\subsection{United States}

Major studies performed in the United States generally identify a technical potential for electricity savings in the range of 25 to 75 percent. Figure 8 shows two electricity conservation supply curves for the United States at either end of this range (Fickett et al. 1990). The first curve, developed by the Electric Power Research Institute, indicates a potential savings of about 30 percent at an average cost of around $\$ 0.025 / \mathrm{kWh}$. The second curve, developed by the Rocky Mountain Institute, indicates a savings potential of over 70 percent at an average cost of

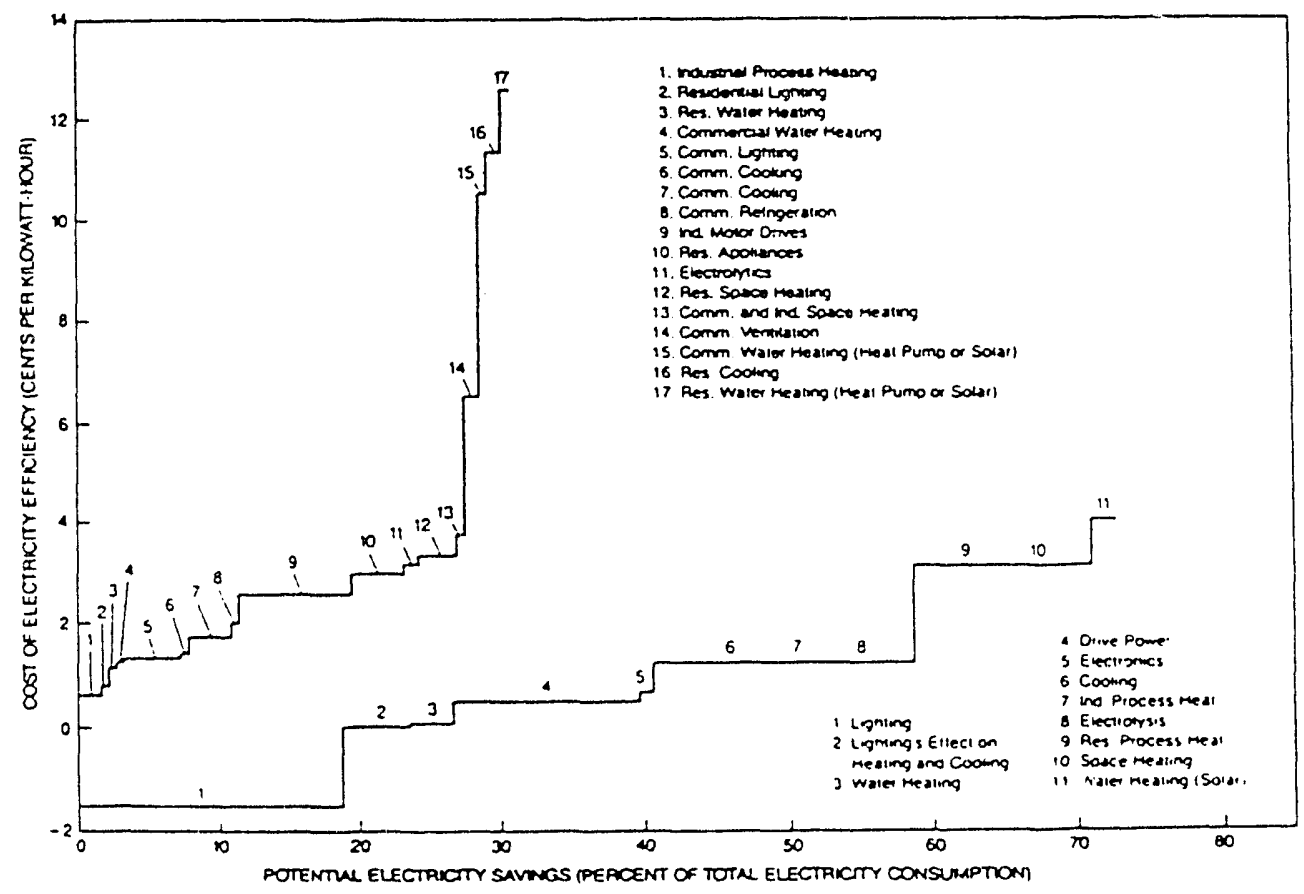

Source: Fickett et al. 1990

Figure 8. U.S. electricity conservation supply curves. 
only $\$ 0.006 / \mathrm{kWh}$. The variation between these estimates is due to differences in the number of technologies considered, differences in assumptions about technology performance, applicability, and cost, and differences in analytical factors. But as the authors state, "The differences between these estimates are less important than thcir agreement that substantial amounts of electricity can be saved in a costeffective manner" (Fickett et al. 1990).

Table 8 and Figure 9 present a conservation supply curve developed for New York state during the late-1980s (Miller et al. 1989). The table includes conservation measures with a cost of saved energy of $\$ 0.07 / \mathrm{kWh}$ or less. This analysis, which is based primarily on commercially available conservation measures but includes some near-term advanced measures, found a 38 percent overall electricity savings potential at an average cost of saved energy of about $\$ 0.025 / \mathrm{kWh}$. The savings potential is highest in the commercial sector (50 percent), followed by the residential sector ( 37 percent), and the industrial sector (22 percent). Measures which offer the largest savings include more efficient refrigerators, installation of reflectors in fluorescent light fixtures, variable speed motor drives, conversion of HVAC systems to variable air volume, energy-efficient fluorescent lamps and ballasts, and compact fluorescent lamps.

The results of other electricity conservation potential studies in the United States are similar to those of the New York study. A recent assessment of nationwide electricity conservation potential in the residential sector, for example, estimated a 40 percent savings potential at a CSE of $\$ 0.076 / \mathrm{kWh}$ or less (Koomey et al. 1991) An assessment of the electricity conservation potential in all buildings in the Sacramento, California, area estimated a 35 percent savings potential at an average cost of about $\$ 0.035 / \mathrm{kWh}$ saved (Xenergy Inc. 1990).

\subsection{Europe and Developing Countries}

Only a few conservation supply curves have been developed outside of the United States. Perhaps the most comprehensive effort was undertaken by researchers in Sweden. For this project the savings available from a wide array of efficiency measures were assessed (see Table 9) and a supply curve constructed that combined efficiency measures with the least-cost sources of power supply (Figure 10). All told, the technical potential for efficiency measures was estimated to be $43 \%$ of projected electricity use in 2010 relative to a frozen efficiency scenario (assuming equipment and building efficiency is frozed at 1987 levels).

Several supply curves have been put together for developing countries. In general these analyses examine fewer measures than comprehensive studies in the United States, and hence cumulative savings estimates are lower. For example, one study examined 20 cost-effective efficiency measures for Brazil and concluded that these measures can reduce electricity use in 2010 by 24 percent relative to an equivalent base case scenario that did not include extensive efforts to promote efficiency improvements (see Table 10 and Figure 11) (Geller 1991). Similarly, another study examined 26 cost-effective efficiency measures for India and estimated that successful application of these measures will reduce electricity use in 2005 by 21 percent below forecasted levels (see Table 11 and Figure 12) (Nadel et al. 1991b).

In summary, work done in the United States, Europe, Brazil, and India indicates electricity use can be reduced by 20 to 40 percent with measures that have already been commercialized and that are cost-effective to consumers and society. As new measures become commercialized, even greater savings become possible. 
Table 8. Cost-Effective Electricity Conservation Potential in New York State

\begin{tabular}{|c|c|c|}
\hline Conservation Measures & $\begin{array}{l}\text { Savings Potential } \\
\text { (GWh/ry) }\end{array}$ & Cost of Energy \\
\hline Reflectors for fluorescent fixtures & 4140 & 0.010 \\
\hline High-efficiency refrigerators and freezers & 5280 & 0.011 \\
\hline Residential infiltration reduction & 590 & 0.017 \\
\hline HVAC retrofits in commercial buildings & 6850 & 0.020 \\
\hline Commercial building variable speed drives & 3473 & 0.024 \\
\hline Energy saving incandescent lamps & 880 & 0.028 \\
\hline High-efficiency industrial lighting & 470 & 0.028 \\
\hline Occupancy sensors in commercial buildings & 500 & 0.033 \\
\hline $\begin{array}{l}\text { High-efficiency commercial fluorescent } \\
\text { lighting }\end{array}$ & 2190 & 0.036 \\
\hline Industrial variable speed drives & 2550 & 0.040 \\
\hline Compact fluorescent lamps & 2020 & 0.040 \\
\hline Infrared reflecting lamps & 810 & 0.044 \\
\hline Daylighting in commercial buildings & 1660 & 0.047 \\
\hline Heat-pump clothes dryer & 860 & 0.065 \\
\hline Other measures & 2070 & - \\
\hline All measures & 34,340 & 0.025 \\
\hline
\end{tabular}

Notes:

1. Savings potential excludes measures already implemented.

2. Total electricity use in base year-99,000 GWh.

3. Cost of saved energy is based on a 6 percent real discount rate.

Source: Miller et al. 1989

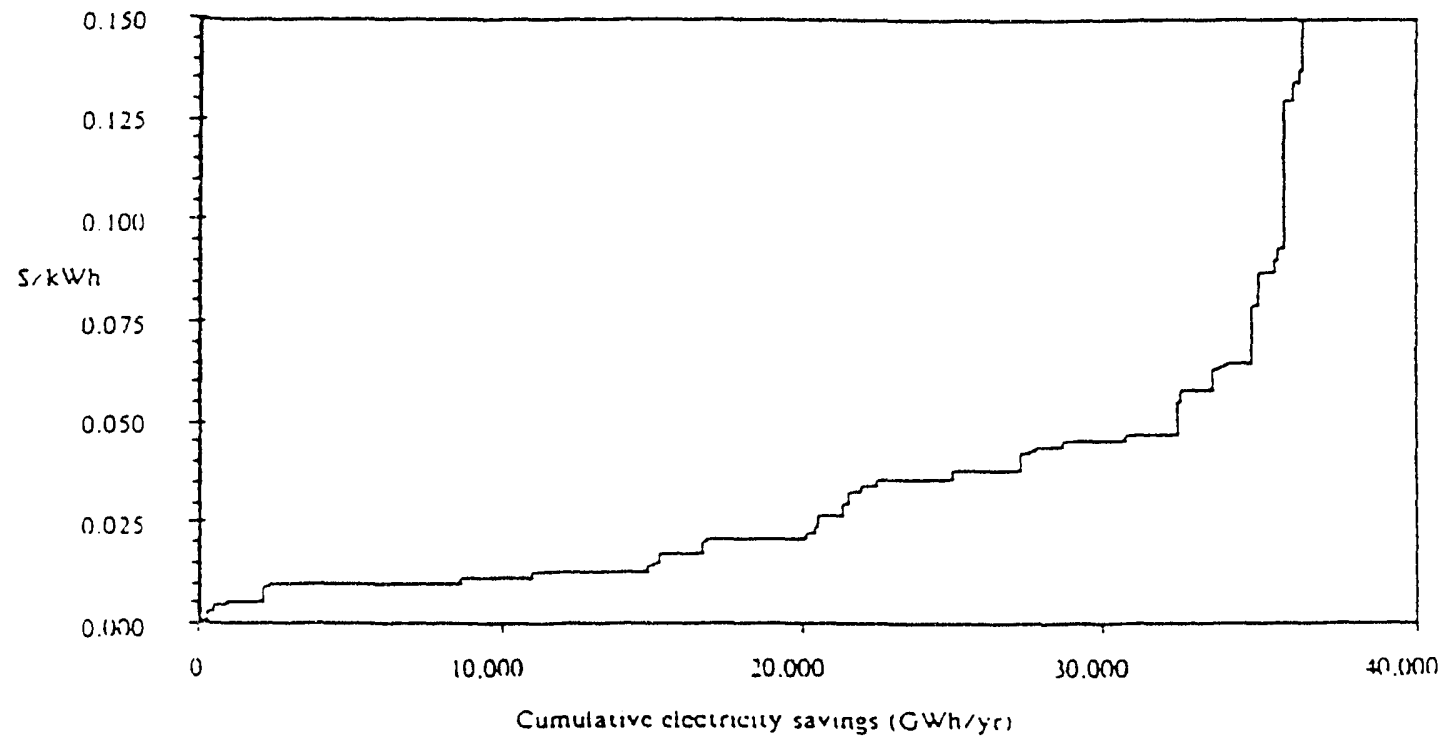

Source: Miller et al. 1989

Figure 9. Electricity conservation supply curve; New York State-6\% discount rate 
Table 9. Selected Cost-Effectiveness Calculations for the Swedish Efficiency Scenario.

\begin{tabular}{|c|c|c|}
\hline End-use technology or strategy & $\begin{array}{c}\text { Annual savings } \\
\text { (TWh) }\end{array}$ & $\begin{array}{c}\text { Cost of conserved or } \\
\text { switched electricity } \\
\text { (cents/kWh) }\end{array}$ \\
\hline \multicolumn{3}{|l|}{ Measures requiring incremental investment } \\
\hline compact fluorescents $(3000 \mathrm{~h} / \mathrm{y})$ & & 1.0 \\
\hline fluorescent systems $(2000 \mathrm{~h} / \mathrm{y})$ & & 1.6 \\
\hline Motors \& purnps, compressors, etc. & 18.5 & 1.4 \\
\hline Commercial food refrigeration & 2.4 & 2.5 \\
\hline Residential heat pumps & 5.7 & \\
\hline electric resistance home & $(2.0)$ & 6.8 \\
\hline electric boiler home & $(3.7)$ & 4.5 \\
\hline Appliances (excl. lighting) & 5.1 & 2.6 \\
\hline Subtotal & 43.7 & 1.9 \\
\hline \multicolumn{3}{|l|}{ Measures requiring little or no investment } \\
\hline New home construction & 0.6 & very low \\
\hline Miscellaneous office equipment & 6.4 & very low \\
\hline Large heat pumps & 2.0 & 0.0 \\
\hline Fuel switching for space heating & 6.9 & 0.0 \\
\hline Transmission \& distribution losses & 6.8 & $\underline{0.0}$ \\
\hline Subtotal & 22.6 & \\
\hline Total & 66.3 & 1.2 \\
\hline Residual non-monetized savings & 16.3 & $?$ \\
\hline Source: Bodlund et al. 1989 & & \\
\hline
\end{tabular}

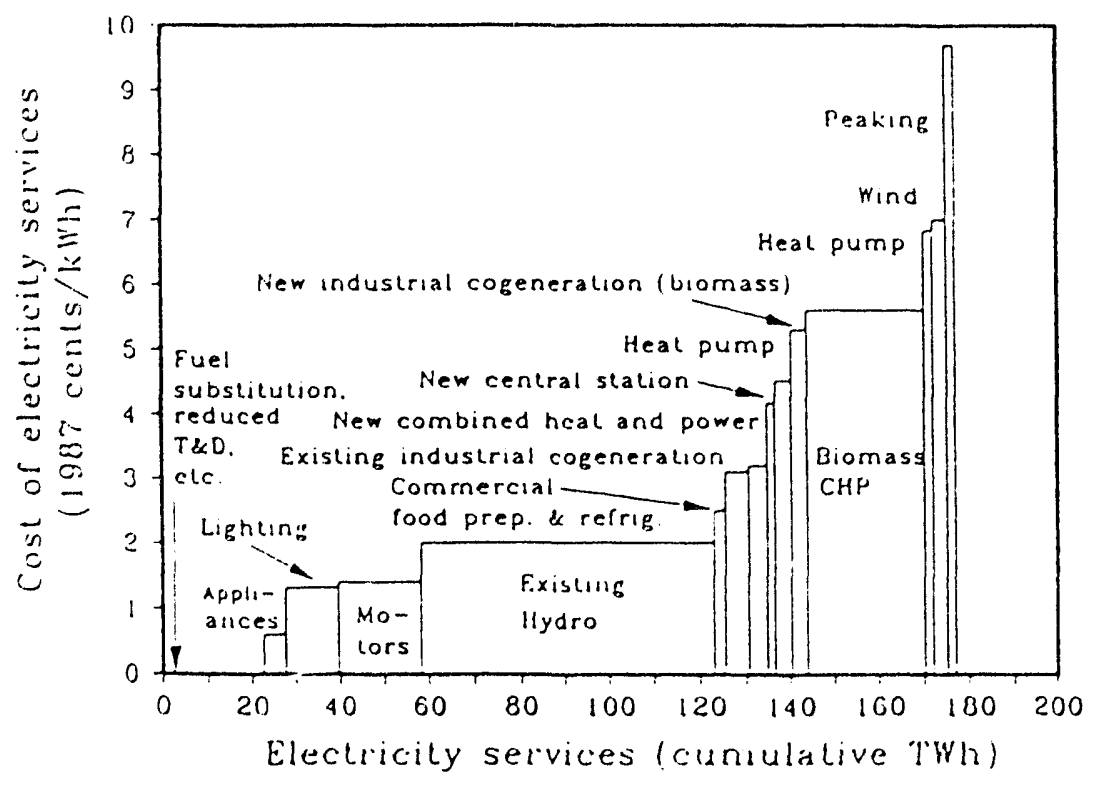

Source: Bodlund et al. 1989

Figure 10. Integrated electricity resource supply curve for Sweden 


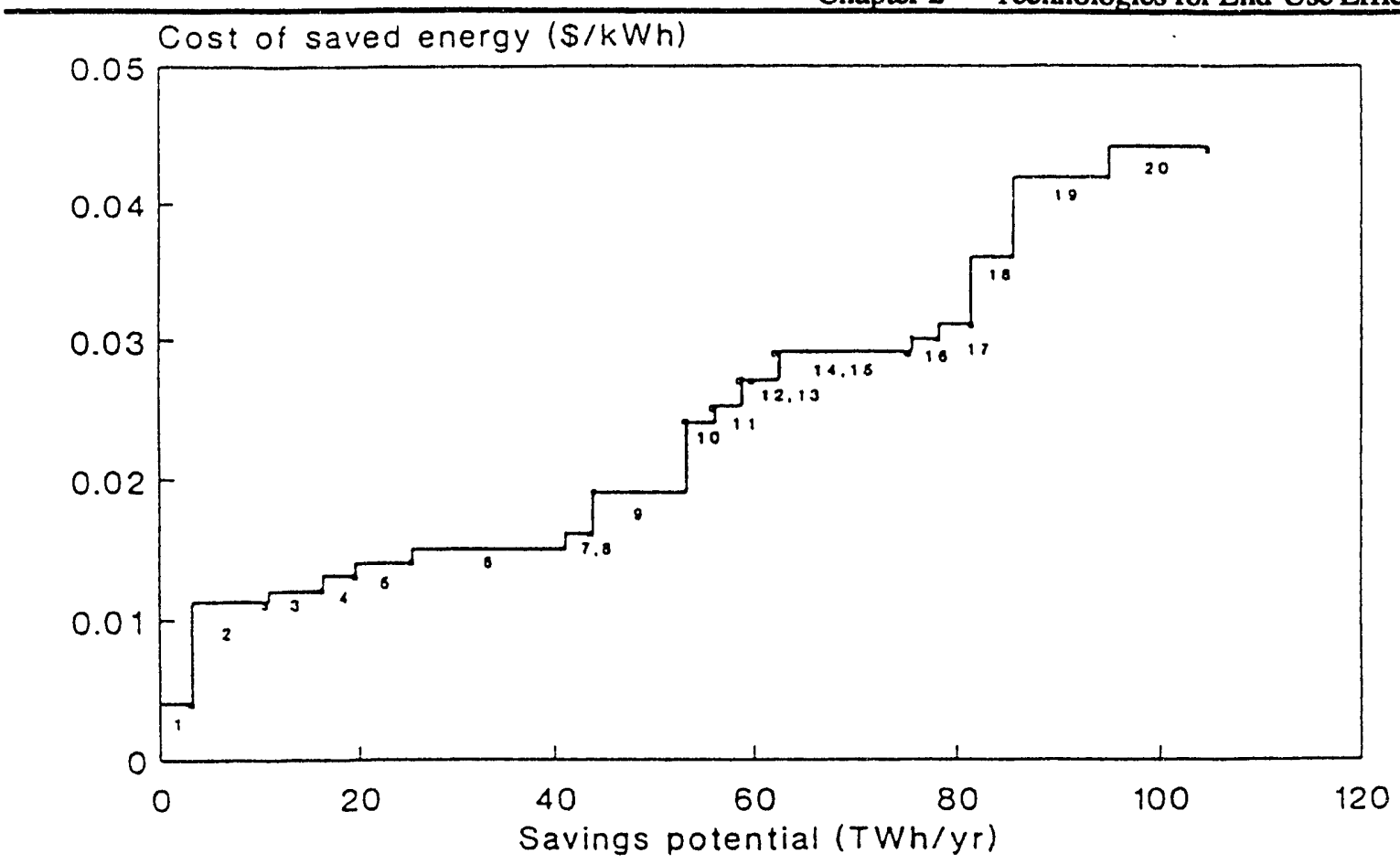

Note: Numbers in graph correspond to measures listed in Table 10

Figure 11. Electricity conservation supply curve for Brazil in 2010, improved-technology scenario

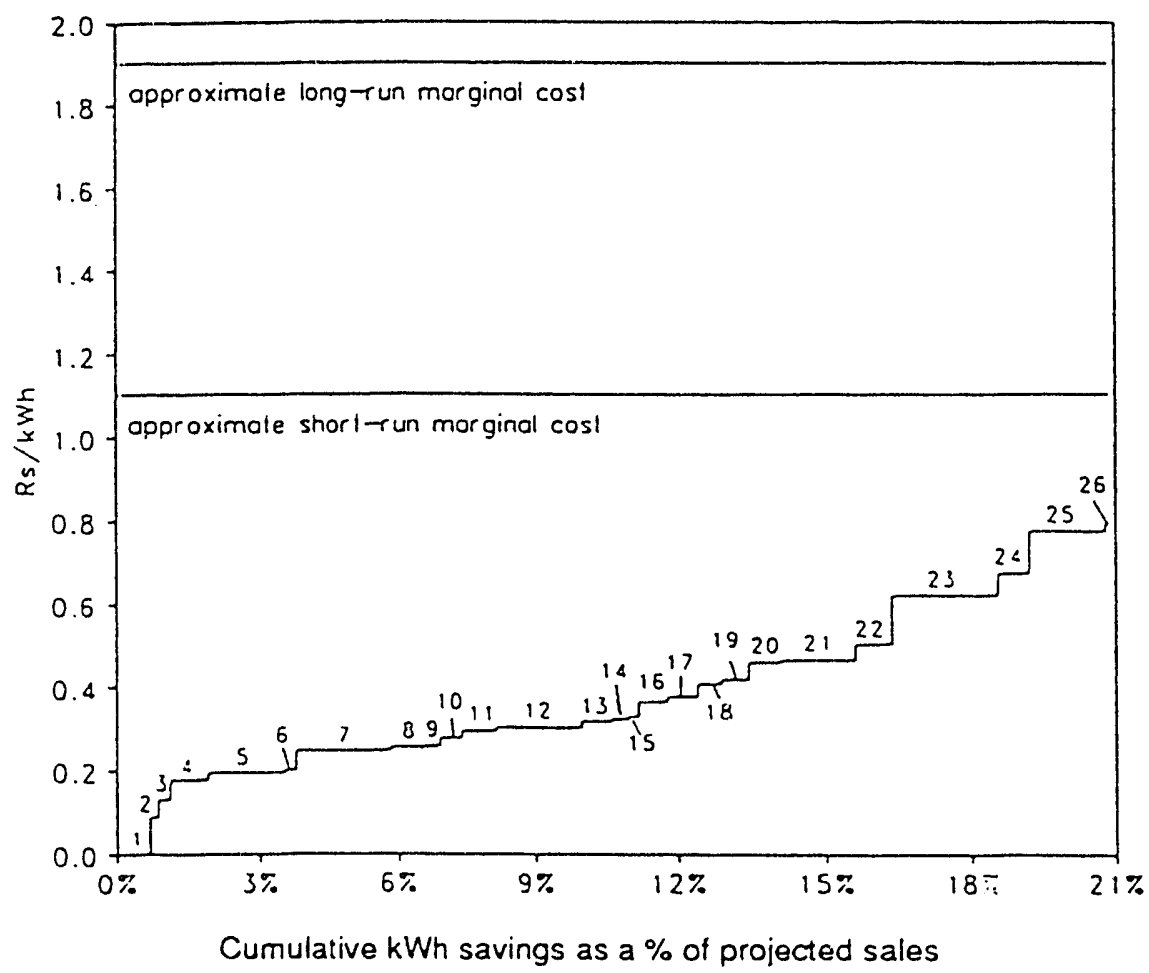

Note: Numbers in graph correspond to measures listed in Table 11. 1 Rupee (Rs.) equals U.S. \$0.05.

Source: Nadel et al., 1991b

Figure 12. Supply curve for conserved electricity in India (2005) 
Table 10. Electricity Conservation Supply Curve in 2010, Improved Technology Scenario (Brazil)

\begin{tabular}{|c|c|c|c|c|c|}
\hline Sector & & Efficiency measure & $\begin{array}{c}\text { Cost of saved } \\
\text { energya } \\
(\$ / k W h) \\
\end{array}$ & $\begin{array}{c}\text { Savings } \\
\text { potential } \\
(\mathrm{TWh} / \mathrm{yr}) \\
\end{array}$ & $\begin{array}{c}\text { Cumulative } \\
\text { savings b } \\
\text { (TWh/yr) }\end{array}$ \\
\hline COM & 1 & More efficient refrigeration & 0.004 & 3.0 & 3.0 \\
\hline $\mathbb{I N D}$ & 2 & More efficient furnaces/boilers & 0.011 & 7.5 & 10.5 \\
\hline COM & 3 & More efficient air-conditioning & 0.012 & 5.6 & 16.1 \\
\hline RES & 4 & Heat pump for water-heating & 0.013 & 3.4 & 19.5 \\
\hline IND & 5 & More efficient motors & 0.014 & 5.8 & 25.3 \\
\hline IND & 6 & Low-cost measures & 0.015 & 15.6 & 40.9 \\
\hline IND & 7 & More efficient electrochem. processes & 0.016 & 2.8 & 43.7 \\
\hline PI & 8 & Replacing incandescent lamps & 0.016 & 0.3 & 44.0 \\
\hline $\mathrm{COM}$ & 9 & More efficient fluorescent fixtures & 0.019 & 9.3 & 53.3 \\
\hline IND & 10 & More efficient lighting & 0.024 & 2.7 & 56.0 \\
\hline PI & 11 & Replacing self-ballast lamps & 0.025 & 2.6 & 58.6 \\
\hline RES & 12 & Energy-saving incandescent lamps & 0.027 & 1.1 & 59.7 \\
\hline RES & 13 & More efficient air conditioners & 0.027 & 2.4 & 62.1 \\
\hline RES & 14 & More efficient refrigerators & 0.029 & 13.1 & 75.2 \\
\hline RES & 15 & More efficient freezers & 0.030 & 2.8 & 78.0 \\
\hline PI & 16 & Replacing mercury vapor lamps & 0.029 & 3.4 & 81.4 \\
\hline RES & 17 & Power control for electric shower & 0.030 & 4.0 & 85.4 \\
\hline $\mathrm{COM}$ & 18 & Conversion to fluorescent lamps ${ }^{c}$ & 0.031 & 9.3 & 94.7 \\
\hline IND & 19 & Motor-speed controls & 0.042 & 9.9 & 104.6 \\
\hline RES & 20 & Conversion to fluorescent lamps $c$ & 0.044 & 6.5 & 111.1 \\
\hline
\end{tabular}

Source: Geller 1991

\footnotetext{
a The cost of saved energy is calculated using a $10 \%$ real discount rate.

$b^{b}$ For reference, 204 TWh of electricity were consumed in Brazil in 1988 and 469 TWh of electricity consumption is projected in 2010 in the base case.

c Cost of saved energy based on half of savings from standard and half from compact fluorescent lamps.
} 
Table 11. Cost-Effective Savings Potential for India

\begin{tabular}{|c|c|c|c|c|c|c|}
\hline & & \multirow[b]{2}{*}{$\begin{array}{c}\mathrm{CSE} \\
(\mathrm{Rs} / \mathrm{kWh}) \\
\end{array}$} & \multicolumn{2}{|c|}{$\begin{array}{c}\text { Energy } \begin{array}{c}\text { Savings } \\
\text { Possible in 2004/05 } \\
(G W h)\end{array} \\
\end{array}$} & \multicolumn{2}{|c|}{$\begin{array}{l}\text { Savings as a \% of } \\
\text { Projected } G W h \text { Sales }\end{array}$} \\
\hline & & & $\begin{array}{c}\text { Low-Case } \\
\text { Forecast } \\
\end{array}$ & $\begin{array}{c}\text { High-Case } \\
\text { Forecast } \\
\end{array}$ & Individual & Cummulative \\
\hline 1 & TLD lamp & 0.00 & 3324 & 5331 & $0.66 \%$ & $0.66 \%$ \\
\hline 2 & Centrifical. refrig. compressor & 0.09 & 872 & 1398 & 0.17 & 0.84 \\
\hline 3 & Improved arc furnaces & 0.13 & 1242 & 1998 & 0.25 & 1.09 \\
\hline 4 & Meter agricultural pumpsets & 0.18 & 3985 & 6385 & 0.80 & 1.88 \\
\hline 5 & Incand. to fluor. fixnure & 0.19 & 8227 & 13,202 & 1.64 & 3.52 \\
\hline 6 & HPSV lamp \& ballast & 0.20 & 1263 & 1989 & 0.25 & 3.78 \\
\hline 7 & Motor rewinding, etc. & 0.25 & 10214 & 16,369 & 2.04 & 5.81 \\
\hline 8 & High-efficiency motors & 0.25 & 3860 & 6186 & 0.77 & 6.58 \\
\hline 9 & Air compressor O\&M & 0.26 & 1682 & 2695 & 0.34 & 6.92 \\
\hline 10 & HVAC efficiency. improvements & 0.28 & 2465 & 3974 & 0.49 & 7.41 \\
\hline 11 & Two-speed motors & 0.29 & 3792 & 6077 & 0.76 & 8.17 \\
\hline 12 & High-efficiency. new pumpsets & 0.30 & 9086 & 14,558 & 1.81 & 9.98 \\
\hline 13 & Moderate-efficiency. refrig. & 0.32 & 3232 & 5182 & 0.65 & 10.63 \\
\hline 14 & Membrane chlor-alk process & 0.32 & 1704 & 2741 & 0.34 & 10.97 \\
\hline 15 & Room A/C EER 9 & 0.33 & 1105 & 1777 & 0.22 & 11.19 \\
\hline 16 & Circular fluorescent lamps & 0.37 & 2860 & 4589 & 0.57 & 11.76 \\
\hline 17 & Optimize industrial pumps & 0.38 & 3113 & 4995 & 0.62 & 12.38 \\
\hline 18 & Optimize industrial fans & 0.41 & 2450 & 3925 & 0.49 & 12.87 \\
\hline 19 & More efficient fan & 0.42 & 2779 & 4446 & 0.55 & 13.42 \\
\hline 20 & Improved aluminum smelters & 0.46 & 3366 & 5406 & 0.67 & 14.10 \\
\hline 21 & Electronic ballast & 0.47 & 7479 & 11,995 & 1.49 & 15.59 \\
\hline 22 & High-efficiency refrigerator & 0.50 & 3667 & 5880 & 0.73 & 16.32 \\
\hline 23 & Variable speed drives & 0.62 & 11,140 & 17,852 & 2.22 & 18.54 \\
\hline 24 & Compact fluorescent lamp & 0.67 & 3311 & 5313 & 0.66 & 19.21 \\
\hline 25 & Agrig pumpset rectification & 0.77 & 7950 & 12,738 & 1.59 & 20.79 \\
\hline 26 & Efficient evaporation cooler & 0.79 & 455 & 728 & 0.09 & 20.88 \\
\hline 26 & TOTAL & & 523,199 & 670,907 & $20.88 \%$ & $20.88 \%$ \\
\hline
\end{tabular}

Source: Nadel et al. 1991b 


\section{REFERENCES}

Abbate, G.P. 1988. "Technology Developments in Home Appliances." In Demand Side Management and Electricity End-Use Efficiency. Edited by A. de Almeida and A. H. Rosenfeld. Dorcirecht. The Netherlands: Kluwer Acadenuic Publishers.

Abel, E. 1989. "Use of Electricity in Commercial Buildings." In Electricity: Efficient EndUse and New Generation Technologies, and Their Planning Implications. Edited by T. B. Johansson, B. Bodlund and R. H. Williams. Lund, Sweden: Lund University Press.

ACEEE. 1991. The Most Energy-Efficient Appliances 1991-92. Washington, D.C.: American Council for an Energy-Efficient Economy.

AHAM. 19?1. Refrigerator, Freezer, Clothes Washer, and Room Air Conditioner Energy Efficiency and Consumption Trends. Chicago: Association of Home Appliance Manufacturers.

ARI, American Refrigeration Institut 3.1992. Personal Communication with Joe McGuire. January.

Arthur D. Little Company. 1991. Supply and Demand of Compact Fluorescent Lamps and Electronic Ballasts: Final Report to Northeast Utilities. Cambridge, MA: Arthur D. Little Company.

ASHRAE. 1990. Energy Efficient Design of New Buildings Except Low-Rise Residential Buildings (ANSI - ASHRAE IES STANDARD 90.1). Atlanta, GA: American Society of Heating, Refrigerating and Air-Conditioning Engineers.

Baldwin, Sam. 1989. "Energy-Efficient Electric Motor Drive Systems." In Electricity: Efficient End-Use and New Generation Technologies, and Their Planning
Implications. Edited by Johansson, Bodlund and Williams. Lund, Sweden: Lund University Press.

Bodlund, Birgit, Evan Mills, Tomas Karlsson and Thomas B. Johansson. 1989. "The Challenge of Choices: Technology Options for the Swedish Electricity Sector." In Electricity: Efficient End-Use and New Generation Technologies, and Their Planning Implications. Edited by T. $B$. Johansson, B. Bodlund and R. $\mathbf{H}$. WIlliams. Lund, Sweden: Lund University Press.

Brown, M.A., D.L. White and S.L. Purucker. 1987. Impact of the Hood River Conservation Project on Electricity Use for Residential Water Heating. Oak Ridge, TN: Oak Ridge National Laboratory.

Busch, J., P. DuPont and S. Chirarattananon. 1991. "Conserving Electricity for Lighting in Thai Commercial Buildings: A Review of Current Status, Potential, and Policies." Proceedings of the 1st European Conference on Energy-Efficient Lighting. E. Mills, ed. Stockholm: Swedish National Board for Industrial and Technical Development, Department of Energy Efficiency.

CEC, California Energy Commission. 1990. "Lighting Design Practice," Advanced Lighting Guidelines. Sacramento, CA: CEC.

Comnes, G. Alan and Richard Barnes. 1987. Efficient Alternatives for Electric Drives. Oak Ridge, TN: Oak Ridge National Laboratories. ORNL/iM-10415.

Davis, Barry. 1991. Personal Communication. Ottawa, Ontario, Canada: Marbek Resource Consultants.

Dreisilker, H. 1987. "Modern Rewind Methods Assure Better Rebuilt Motors." Electrical Construction and Maintenance.

EAP. 1991. Energy and Environment 1990 Annual Report. Berkeley, CA: Energy 
Analysis Program, Lawrence Berkeley Laboratory. 1991.

EIA. 1985. Characteristics of Commercial Buildings 1983. Washington, DC: Energy Information Administration, U.S. Dept. of Energy. DOE/EIA-0246 (83). July.

EIA. 1989. Housing Characteristics 1987. Washington, DC: Energy Information Administration, U.S. Dept. of Energy. DOE/EIA-0314 (87). May.

EIA. 1991a. 1991 Annual Energy Outlook. Washington, DC: Energy Information Administration, U.S. Department of Energy. DOE/EIA-0383 (91).

EIA. 1991b. Commercial Buildings Characteristics 1989. Washington, DC: Energy Information Administration, U.S. Dept. of Energy. DOE/EIA-0246 (89). June.

Eketorp, Sven. 1989. "Electrotechnologies and Steelmaking." In Electricity: Efficient End-Use and New Generation Technologies, and Their Planning Implications. Edited by T. B. Johansson, B. Bodlund and R. H. Williams. Lund, Sweden: Lund University Press.

EPRI. 1988. TAG Technical Assessment Guide; Volume 2: Electricity End Use; Part 3: Industrial Electricity Use-1987. Palo Alto, CA: Electric Power Research Institute, EPRI P-4463-SR. February.

EPRI. Forthcoming. Survey and Forecast of Marketplace Supply and Demand for Energy-Efficient Lighting Products. Prepared for EPRI, Califomia Institute for Energy Efficiency, U.S. Environmental Protection Agency - Global Change Division, and U.S. Department of Energy - Federal Energy Management Piugram by Lighting Research Institute and Plexus Research, Inc. Palo Alto: Electric Power Research Institute, TR-100288.

Faruqui, A., M. Mauldin, S. Schick, K. Seiden, and G. Wikler. 1990. Efficient Electricity
Use: Estimates of Maximum Energy Savings. Palo Alto, CA: Electric Power Research Institute. EPRI CU-6746. March.

Fickett, A.P., C.W. Gellings and A.B. Lovins . 1990. "Efficient Use of Electricity." Scientific American. September.

Gallien, John. 1990. Personal Communication. GTE Sylvania Lighting, Danvers, MA, USA.

Gamba, J.R., D. Caplin, and J. Mulckhuyse. 1986. Industrial Energy Rationalization in Developing Countries. Baltimore, MD: Johns Hopkins University Press.

Gehring, K. 1986. "The Evolution of Ventilating Heat Pump Water Heater." Presented at ACEEE 1986 Summer Study on Energy Efficiency in Buildings. Washington, DC: American Council for an Energy-Efficient Economy.

Geller, Howard S. 1985. "Progress in the Energy Efficiency of Residential Appliances and Space Conditioning Equipment." Energy Sources: Conservation and Renewables, New York, NY: American Institute of Physics.

Geller, Howard S. 1986. "Energy Efficient Appliances: 1986 Update." Presented at ACEEE 1986 Summer Study on Energy Efficiency in Buildings. Washington, DC: American Council for an Energy-Efficient Economy.

Geller, Howard S. 1988a. Commercial Building Equipment Efficiency: A State-of-the-Art Review. Washington, DC: American Council for an Energy-Efficient Economy.

Geller, Howard S. 1988b. Residential Equipmeni Efficiency: A State-of-the-Art Review. Washington, DC: American Council for an Energy-Efficient Economy.

Geller, Howard S. 1991. Efficient Electricity Use: A Development Strategy for Brazil. Washington, DC and Berkeley, CA: 
American Council for an Energy-Efficient Economy.

Geller, Howard S. and Peter M. Miller. 1988. 1988 Lighting Ballast Efficiency Standards: Analysis of Electricity and Economic Savings. Washington, DC: American Council for an Energy-Efficient Economy. August 1988.

General Electric. 1987. Lighting Application Bulletin, Specifying Light and Color. Cleveland, OH: General Electric.

General Electric. 1988. General Lighting Cost Analysis. Cleveland, OH: General Electric.

General Electric. 1990. "Selection Guide for Quality Lighting." Cleveland, $\mathrm{OH}$ : General Electric.

Gordon, Fred M., Marjorie McRae, Michael Rufo, and David Baylon. 1988. "Use of Commercial Energy Efficiency Measure Service Life Estimates in Program and Resource Planning," ACEEE 1988 Summer Study on Energy Efficiency in Buildings, Washington, DC: American Council for an Energy-Efficient Economy.

Greenberg, Steve, Jeff Harris, Hashem Akbari and Annibal de Almeida. 1988. Technology Assessment: AdjustableSpeed Motors and Motor Drives. Lawrence Berkeley Laboratory. LBL25080. March 1988.

Hunn, Bruce D., Martin L. Baughman, Scott C. Silver, Arthur H. Rosenfeld and Hashem Akbari. 1986. Technical Potential for Electrical Energy Conservation and Peak Demand Reduction in Texas Buildings. Public Utility Commission of Texas. February 1986.

Ibanez, P. 1978. "Electromechanical Energy." In Efficient Electricity Use. Edited by Smith, et al. Elmsford, NY: Pergamon Press.

IEA, International Energy Agency. 1989. Electricity End-Use Efficiency. Paris:
OECD.

IES, Mluminating Engineering Society of North America. 1985. IES Lighting Ready Reference. New York, NY: Illuminating Engineering Society of North America.

IRM, U.S. Department of Energy. 1991. "Energy Conservation and Fuzzy Logic." IRM Foreign Technology Digest. Washington, DC: U.S. DOE, March.

IRT. 1991. "Induction Lamps." The Energy Newsbrief. Vol. 6, No. 27. p. 4.

Jannuzzi, G., A. Gadgil, H. Geller and M.A. Sastry. 1991. "Energy-Efficient Lighting in Brazil and India: Potential and Issues of Technology Diffusion." Proceedings of the 1st European Conference on EnergyEfficient Lighting. E. Mills, ed. Stockholm: Swedish National Board for Industrial and Technical Development, Department of Energy Efficiency. pp. 339-356.

Johnson, Karl and Erich Unterwurzacher. 1991. "Ensuring Market Supply and Penetration of Efficient Lighting Technologies." Proceedings of the 1st European Conference on Energy-Efficient Lighting. E. Mills, ed. Stockholm: Swedish National Board for Industrial and Technical Development, Department of Energy Efficiency. pp. 249-256.

Johnston, Walt. 1991. North Carolina Industrial Extension Service, personal communication.

Koomey, Jonathan, Celina Atkinson, Alan Meier, James E. McMahon, Stan Boghosian, Barbara Atkinson, Isaac Turiel, Mark D. Levine, Bruce Nordman and Peter Chan. 1991. The Potential for Electricity Efficiency improvements in the U.S. Residential Sector. Berkeley, CA: Lawrence Berkeley Laboratory. LBL30477. July 1991.

Lebot, B. 1990. "Horizontal Axis Domestic Clothes Washers: An Alternative 
Technology That Can Reduce Residential Energy and Water Use." Presented at ACEEE 1990 Summer Study on Energy Efficiency in Buildings. Washington, DC: American Council for an Energy-Efficient Economy.

Lees, Peter. 1991. Personal Communication. GTE Sylvania, S A., Switzerland.

Levins, W.P. 1980. Energy and the Laundry Process. Oak Ridge, TN: Oak Ridge National Laboratory. ORNL/CON-41. April.

Lewis, D.C. 1983. Final Report - Closed Cycle Clothes Dryer. Washington, DC: U.S. Dept. of Energy. DOE/CE/15100-T1. June.

Lovins, A., J. Neymark, T Flanigan, P. Kieman, B. Bancroft and M. Shepard. 1989. The State of the Art: Drivepower. Snowmass, CO: Rocky Mountain Institute.

Marbek Resources Consultants Limited. 1986. Energy Efficient Fluorescent Lighting in Canadian Office Buildings: Technologies, Market Factors, and Penetration Rates; Final Report. Ottawa, Canada: Marbek Resources Consultants Limited.

Maximum Technology Inc. 1988. Personal Communication. Brisbane, CA: Maximum Technology, Inc.

McGowen, Terry. 1992. Personal Communication. Cleveland, $\mathrm{OH}$ : General Electric Lighting.

Meunier, M.Y and O.B. Kops. 1984. Energy Efficiency in the Steel Industry with Emphasis on Developing Countries. Washington, DC: World Bank. World Bank Mechnical Paper Number 22.

Meyers, S., S. Tyler, H. Geller, J. Sathaye and L. Schipper. 1990. Energy Efficiency and Household Electric Appliances in Developing and Newly Industrialized Countries. Berkeley, CA: Lawrence Berkeley Laboratory. LBL-29678.
December.

Miller, Peter M., Joseph H. Eto and Howard S. Geller. 1989. The Potential for Electricity Conservation in New York State. New York State Energy Research and Development Authority. Report \# 89-12. September 1989.

Miller, Richard and Marcia Rupnow. 1991. Survey on Variable Frequency Motor Drives. Lilbum, GA: Future Technology Surveys, Inc. Survey Report \#111.

Nadel, S., H. Geller, F. Davis and D. Goldstein. 1989. Lamp Efficiency Standards for Massachusetts: Analysis and Recommendations. Massachusetts Executive Office of Energy Resources, Washington, DC: American Council for is Energy-Efficient Economy.

Nadel, Steven, 1990a. "Efficiency Standards for Lamps, Motors and Lighting Fixtures." Presented at ACEEE Summer Study on Energy-Efficiency in Buildings Washington, DC: American Council for an Energy-Efficient Economy. pp. 7.1357.147 .

Nadel, Steven. 1990b. Memorandum: Availability of Lighting Products. New England Electric and Conservation Law Foundation, Washington, DC: American Council for an Energy-Efficient Economy.

Nadel, Steven, Barbara Atkinson and Jim McMahon. 1991a. "A Review of U.S. and Canadian Lighting Programs for the Residential, Commercial and Industrial Sectors." Proceedings of the 1st European Conference on Energy-Efficient Lighting. E. Mills, ed. Stockholm: Swedish National Board for Industrial and Technical Development, Department of Energy Efficiency. pp. 145-162.

Nadel, Steven, Virendra Kothari and S. Gopinath. 1991b. Opportunities for Improving End-Use Electricity Efficiency in India. World Bank and U.S. Agency 
for International Development. Washington, DC: American Council for an Energy-Efficient Economy.

Nadel, Steven, Michael Shepard, Steve Greenberg, Gail Katz and Anibal T. de Almeida. 1991c. Energy Efficient Motor Systems: A Handbook on Technology, Program, and Policy Opportunities. Washington, DC: American Council for an Energy-Efficient Economy.

NEMA, National Electrical Manufacturers Association. 1991. Proposal for NEMA Design E Motor Based on IEC Locked Rotor Current and Starting Torque and Higher Efficiency Limits. Washington, DC: National Electrical Manufacturers Association.

Nørgård, J.S. 1989. "Low Electricity Appliances - Options for the Future." In Electricity: Efficient End-Use and New Generation Technologies, and Their Planning Implications. Edited by T. B. Johansson, B. Bodlund and R. H. Williams. Lund, Sweden: Lund University Press.

Pedersen, P.H., J. Schjaer-Jacobsen and J.S. Norgård. 1986. "Reducing Electricity Consumption in American Type Combined Refrigerator/Freezer." Presented at 37th International Appliance Technical Conference. Purdue University.

Philips Lighting. 1988. Compact Lighting Catalog 1987/88. Netherlands: Philips Lighting.

Piette, M.A., E. Wyatt and J. Harris. 1988. Technology Assessment: Thermal Cool Storage in Commercial Buildings. Berkeley, CA: Lawrence Berkeley Laboratory. LBL-25521. January.

Schaper, C., B. Smith, P. Delany, and S. Braithwait. 1990. "High-Efficiency Heat Pumps and Gas Furnace Engineering Efficiencies from Metered Customer Homes." Presented at ACEEE 1990
Summer Study on Energy Efficiency in Buildings. Washington, DC: American Council for an Energy-Efficient Economy.

Schipper, L. and D. Hawk. 1989. More Efficient Household Electricity Use: An International Perspective. Berkeley, CA: Lawrence Berkeley Laboratory. LBL27277. May.

Seton Johnson and Odell Inc. 1987. Energy Efficiency and Motor Repair Practices in the Pacific Northwest. Portland, OR: Bonneville Power Administration.

Shepard, M., A. B. Lovins, J. Neymark, D.J. Houghton, and H.R. Heede. 1990. The State of the Art: Appliances. Snowmass, CO: Rocky Mountain Institute. August.

Streicher, A. and H. Geller. 1990. "Technologies for Increasing Electric End-Use Efficiency." Presented at PACER Conference in New Delhi.

TERI, Tata Energy Research Institute. 1990. Technical, Policy and Economic Assessments on Energy Conservation from Efficient Electric Lighting, Final Report. Government of India, New Delhi, India: Department of Power, Ministry of Energy.

Tsuchiya, H. 1988. "Electricity Conservation in Japan." In Demand-Side Management and Electricity End-Use Efficiency. Edited by A. T. de Almeida and A. H. Rosenfeld. Dordrecht, The Netherlands: Kluwer Academic Publishers.

Turiel, Isaac, Benoit Lebot, Steve Nadel, Joe Pietsch and Larry Wethje. 1990a. Electricity End Use Demand Study for Egypt. Berkeley, CA: Lawrence Berkeley Laboratory. LBL-29595.

Turiel, Isaac, Douglas Berman, Peter Chan, Terry Chan, Jonathan Koomey, Benoit Lebot, Mark D. Levine, James E. McMahon, Greg Rosenquist and Steve Stoft. 1990b. "U.S. Residential Appliance Energy Efficiency: Present Status and 
Future Directions." In Proceedings of the 1990 ACEEE Summer Study on Energy Efficiency in Buildings. Asilomar, CA: American Council for an Energy Efficient Economy. Also in: State of the Art of Energy Efficiency: Future Directions, Washington, DC and Berkeley, CA: American Council for an Energy Efficient Economy. 1991.

Turiel, Isaac and M.D. Levine. 1989. "EnergyEfficient Refrigeration and the Reduction of Chlorofluorocarbon Use." Annual Review of Energy. Vol. 14.

US DOE. 1988. Technical Support Document: Energy Conservation Standards for Consumer Products: Refrigerators, Furnaces, and Television Sets. Washington, DC: U.S. Department of Energy, Assistant Secretary, Conservation and Renewable Energy, Building Equipment Division. DOE/CE-0239. November 1988.

US DOE. 1989. Technical Support Document: Energy Conservation Standards for Consumer Products: Dishwashers, Clothes Washers, and Clothes Dryers. Washington, DC: U.S. Department of Energy. DOE/CE-0267. July.

US DOE. 1990. Technical Support Document: Energy Conservation Standards for Consumer Products: Dishwashers, Clothes Washers, and Clothes Dryers. Washington, DC: U.S. Department of Energy, Assistant Secretary, Conservation and Renewable Energy, Building Equipment Division. DOE/CE-0299P. December 1990.

Ushimaru, K. 1987. International Technology Assessment Japanese Variable Speed Heat Pump Technology. Bellevue, WA:
Energy Intemational Inc. July.

Usibelli, Anthony, Steve Greenberg, Meg Meal, Alan Mitchell, R. Johnson, Glenn Sweitzer, Francis Rubinstein and Darriush Arasteh. 1985. Commercial-Sector Conservation Technologies. Berkeley, CA: Lawrence Berkeley Laboratory. LBL18543. February 1985.

Verderber, R. and F. Rubinstein. 1983. "Lighting Controls: Survey of Market Potential." Energy. Vol. 8, No. 6. p. 433.

Washington State Energy Office. 1990. MOTORS Software Package. Olympia, WA,: Washington State Energy Office.

Weijo, R., A. Nicholls, S. Weakley, R. Eckert, D. Shankle M. Anderson, and A. Anderson. 1991. Evaluation of Near-Term Commercial Potential of Technologies Being Developed by the Office of Building Technologies, Volume II - Survey Results. Richland, WA: Pacific Northwest Laboratory. PNL-6778.

Williams, R.H, E.D Larson and M.H. Ross. 1987. "Materials, Affluence, and Industrial Energy Use." Annual Review of Energy. Vol. 12.

World Bank. 1990. Brazil Energy Strategy and Issues Study: Pricing and Investment Policy. Washington, DC: World Bank.

Xenergy Inc. 1990. An Assessment of the Potential for Electrical Energy-Efficiency Improvements in the SMUD Service Territory. Oakland, CA: Xenergy Inc. July.

Xenergy Inc. 1991. New England Electric, Energy Initiative and Design 20001991 Incentive Program Development Volume 1. Burlington, MA: Xenergy Inc. 


\section{CHAPTER 3}

\section{FACTORS LIMITING ADOPTION OF TECHNOLOGIES FOR INCREASING ELECTRICITY END-USE EFFICIENCY}

\subsection{INTRODUCTION}

The previous chapter describes the unrealized technical potential for improvements in electric end-use efficiency worldwide. Many efficiency technologies have been accepted only slowly into the market, in spite of their apparent advantages. Some of the factors limiting market acceptance result from limitations of the technologies themselves or are intrinsic to the environment in which the technology is applied. Other factors are the result of market barriers or distortions. This chapter addresses both types of factors leading to differences between actual investment decisions and the technical potential estimates.

The overriding policy challenge is to improve economic welfare by reducing the effect of market distortions where they exist and leave undisturbed those consumer choices that represent the efficient outcome from the societal perspective. Correcting true distortions will improve both enduse efficiency and economic welfare, and this chapter therefore focuses on pinpointing such distortions. The chapter also explores technological limitations as additional factors that may lead technical potential estimates to diverge from actual consumer choices. Understanding these other factors is extremely important when designing policies so that these policies do not inadvertently reduce economic welfare.

This chapter discusses factors limiting increased end-use efficiency at the consumer level, the national level, and the international level. Factors at each level are explored in turn. At the consumer level, these factors include information availability and costs, bounded rationality, capital constraints, split incentives, differences in product attributes, and variations in usage patterns. At the national level, these factors include lack of adequate institutional capability, supply-oriented centralized utilities, lack of costbased electricity prices, and the lack of energyefficient products. Internationally, these factors include lack of funding and the lack of effective collaboration between industrialized and developing countries.

\subsection{CONSUMER LEVEL FACTORS}

The most important factors affecting consumer efficiency choice are those related to availability and cost of information, bounded rationality, capital constraints, split incentives, differences in product attributes, and variations in usage patterns. The first three factors are in large part the cause of the oft-cited tendency for consumers to make decisions using short-term economic criteria. All five factors explain in some cases why the technical potential estimates diverge from actual consumer choices.

We distinguish here between explicit characterizations of consumer decision criteria and implicit discount rates. Various surveys have asked electric customers to specify the simple payback time (SFT) that they use to evaluate energy efficiency investments. The SPT is the number of years required to recoup the initial investment in an energy-efficient measure through the reduction in energy bills. Surveys that ask for this explicit characterization yield a true picture of the actual decisionmaking criteria of investors.

Implicit discount rates (or implicit SPTs), on the other hand, are inferred from actual purchasing decisions and from engineering-based cost information. For example, Meier and Whittier (1982) compare the energy use and capital cost of two otherwise identical refrigerators to estimate the implied discount rate of those who purchase the less efficient model. These calculations cannot be used to say that customers actually use such discount rates, only that the decision is the same as if customers use such discount rates.

One explicit characterization of consumer decisionmaking (i.e. a survey of the simple payback times) is summarized in Figure 13, 
which illustrates that more than three quarters of surveyed commercial customers of Potomac Electric Power Company who use an explicit payback criterion require payback times of 3 years or less before they will make investments in energy efficiency (Barker et al. 1986). Other U.S. studies find comparable results (EPRI 1988; NEEPC 1987; Peters and Gustafson 1986; Ross 1989; Schon et al. 1987) Such payback times correspond to real rates of return much higher than the social cost of capital.

The fundamental dichotomy here is between the electric customer, who often uses very short simple payback times to evaluate efficiency investments, and the electric utility, which uses discount rates corresponding to payback times of twelve years or more to evaluate supply investments. If many customers use short payback times, they will force the utility to build generating plants for which all ratepayers must pay.

If only one of the many participants in the purchase and use of energy-efficient devices uses short payback times, they can inhibit the participants from choosing more efficient technology. For instance, if tenants use two-year simple payback times due to risk aversion or cash flow constraints, many landlords will conclude that the buildings they purchase need not be exceptionally efficient. The interdependence of these factors is an important issue in almost all cases.

The use of short SPTs is a symptom of a complex set of market distortions related to information costs, bounded rationality, and capital constraints. For example, the consumers' income level affects the discount rate used to evaluate investment decisions. Because the cost of capital is high for low income consumers (or they may be unable to obtain capital at all), these consumers often apply very high discount rates. It has been shown that the discount rate applied by a consumer rises exponentially as the consumer's income decreases (Sudhakara Reddy 1990). In fact, consumer discount rates on the order of $60 \%$ are not unusual in India (Reddy
1990). Risk aversion and lack of information can also lead consumers to use short SPTs.

\subsection{Information Costs and Related Issues}

Individual consumers are faced with an array of problems associated with obtaining information about energy-efficient products. These problems include lack of information and costs associated with gathering and incorporating information.

Lack of information manifests itself in many forms (EPRI 1987). It is strongly linked to information costs, which inhibit the search for information. Designers and builders often lack current, credible information on the latest conservation technology. They may not trust energy conservation companies to deliver such information because of a perceived conflict of interest. Without the help of established, reputable energy consultants (who do not exist in many areas of the world), building purchasers have no credible way to compare the operating costs of two new buildings. Purchasers are often unable to "comparison shop" or to assess the chances of recovering their additional initial investment (due to efficiency) upon resale of the building.

Individual consumers often lack information regarding both their current electricity consumption patterns and ways to reduce this consumption. For example, a homeowner does not know the efficiency of the home's existing appliances and the monthly bill is not disaggregated so that consumption levels and trends can be monitored. In the U.S., purchasers of some major appliances (refrigerators, water heaters, air conditioners, clothes washers and dryers) have energy use labels available to them. However, even where information is available, it can be incomplete. This problem is exacerbated by the fact that energy-efficient technology is changing rapidly (Reddy 1990).

The New England Energy Policy Council (NEEPC 1987) interviewed landlords and tenants in the Boston area to assess factors inhibiting 


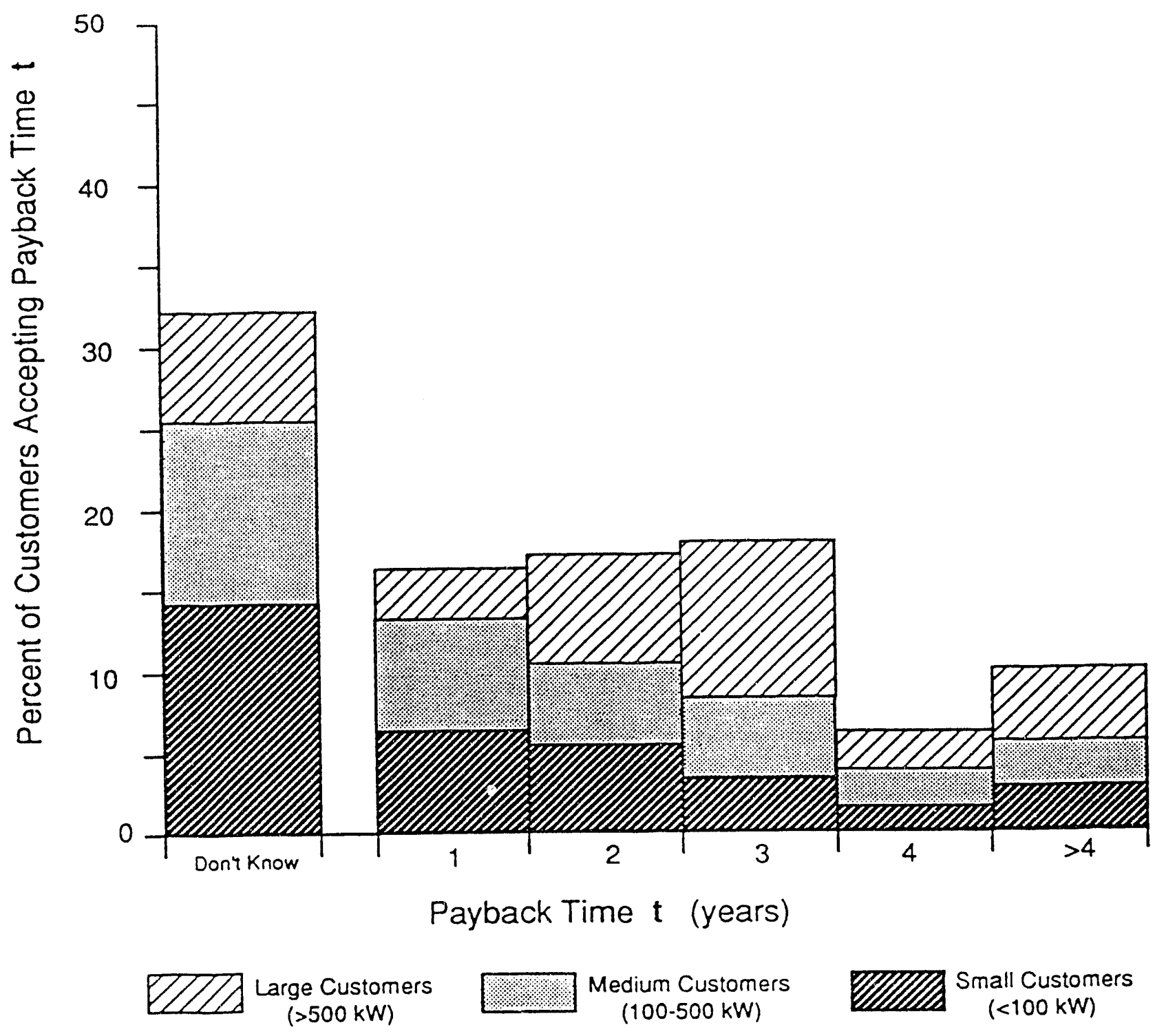

Source: Barker et al. 1986

Figure 13. Maximum acceptable payback time for investments in energy efficiency. 
efficiency improvements in the commercial sector. They found that rapid technology change does increase information costs:

"The first theme that emerged in our interviews was confusion. The pace of development in efficient energy-using and energy-conserving technologies has been accelerating in the past few years, and the people we spoke with evinced a certain bewilderment at the array of choices now being touted by vendors and the trade press " NEEPC 1987.

This rapid technological change means that both consumers and professionals will have greater difficulty gathering and filtering information about the availability and performance of technology.

Costs to obtain information inhibit the adoption of efficiency technologies just as they inhibit the adoption of other new technologies. In many cases, such costs can be reduced by centralized information and dissemination, because information is easy to replicate at low marginal cost. For example, Kempton and Layne have shown that there are large economies of scale if electric utilities calculate and deliver (in each consumer's utility bill) information on weather-normalized consumption per square foot, and the average consumption for typical buildings of the same type (Kempton and Layne 1988).

Information costs occur at every step in the process of creating a new building or product, and only sector-by-sector and country-by-country analysis can determine their importance in specific circumstances. One example of such analysis is Koomey (1990), who analyzes the cost of information associated with the design and building of new energy-efficient office buildings in the U.S. These costs include the costs of 1) collecting information about efficiency measures or the credibility and reliability of new suppliers and subcontractors, 2) developing expertise, 3 ) calculating the costs and benefits of different efficiency levels, 4) deciding how to alter established design and construction procedures,
5) demonstrating in a credible way that a new building will reduce prospective tenants' or purchasers' energy costs, 6) disseminating information about efficiency technologies, and 7) the architect/engineer incorporating new information about efficiency in day-to-day work.

Trust in the source of information also affects information costs and associated risks. The existence of a credible source of information that is perceived as unbiased will reduce information and risk costs. Conversely, the lack of such a source implies higher risk and information costs. Consulting firms meet this need in some areas, but these companies are not large enough to fully capture economies of scale, nor are they always perceived as unbiased.

Sometimes, parties to a transaction have differing access to information. Asymmetric information often arises in the sale or leasing of a building, when the developer knows more about the building than do prospective tenants or building purchasers. Without a credible, effective way of estimating building energy use before occupancy (or sale), the tenants (or the purchasers), who would pay the utility bill, are at a disadvantage in negotiations. ${ }^{1}$ They must take the developer's word that the building is more efficient, or they must hire someone they trust to analyze the building's efficiency. In the first case there is added risk; in the second, added cost.

A similar issue arises with respect to most non-energy-related aspects of purchase or lease decisions. For example, the productivity, availability, or suitability of office or industrial equipment niay be routinely overstated by sellers or lessors striving to close a deal. The same situation can arise at the consumer level in the regard to the non-energy aspects of vehicle or housing purchase decisions. However, energy use is one characteristic that can be objectively measured, whereas assessments of many of the non-energy-related characteristics of such property have large subjective components.

\footnotetext{
${ }^{1}$ Asymmetric information is not a problem for tenants if the landlord pays the utility bill.
} 
Existing institutions and professions are often not able to correct for asymmetric information by themselves. (This point also relates to Lack of Adequate Institutional Capability, below.) For instance, appraisers, upon whom banks and purchasers depend to assess the value of buildings, must be conversant with many different aspects of real estate (Pearson 1989). It is unrealistic to expect that they be expert enough in energy matters to assess operating cost benefits from specific technologies or a set of such technologies. They would be able to use information related to energy efficiency if it were supplied, but it is generally beyond their capabilities to estimate it. Even if they could estimate energy costs on a case-by-case basis, a lack of uniformity in assumptions would limit the usefulness of such estimates.

\subsection{Bounded Rationality}

Humans have limited or "bounded" rationality, since they can only process limited amounts of information (March and Simon 1959). Th: time it takes to process all inforriatiun is an information cost (described above), while humans' inability to analyze and understand every issue is an indication of bounded rationality. One indication of bounded rationality is most consumers' lack of understanding of life-cycle cost calculations. Without the ability to make such calculations, it is not possible for consumers to optimally choose the efficiency of their energy-consuming devices. Even if all the relevant input information were available to consumers, they would be unable to use the information in the requisite manner because of their bounded rationality.

\subsection{Capital Constraints}

Lack of investment capital can lead consumers to choose less energy-efficient products. It is important to recognize that the private cost of capital rather than its social cost is relevant to individual decisions. Some consumers may face a fixed budget for all their investments, including investments in both enduse efficiency and all other purposes. In these circumstances, the opportunity cost of capital for the decision-maker may far exceed the cost of capital to the economy at large. Such situations are particularly likely in developing economies where the consumer financial sector is not well developed -- if it is developed at all. In other cases, financial markets can be tapped, but the marginal source of capital may have relatively high costs. For example, many consumers in the U.S. use credit cards with real interest rates of 13 to 17 percent to finance their purchases of household durable goods. For poor Americans, who often cannot obtain credit, the incremental cost of capital to purchase more efficient products would be much higher than this.

In developing countries, capital is offered for energy supply investments at attractive interest rates by multilateral development banks and by private banks. These funders are often not interested in smaller-scale, innovative energy efficiency projects. Thus consumers often have to pay much higher interest rates (if capital is available at all) as compared to energy supply organizations.

In the energy-intensive manufacturing sector, capital constraints prevent firms from making efficiency investments that they might otherwise view as attractive (Geller et al. 1991). Ross (1986) describes how many industries divide capital investment decisions into two types: decisions directly related to manufacturing output (such as investments in new production facilities) and decisions related to marginal improvements in existing processes. The production-related decisions are usually made at the highest levels of the corporate bureaucracy, and evaluated against the cost of capital. The smaller-scale investments (such as energy efficiency projects) are usually made by engineers and managers at the plant level and are subject to "capital rationing" (only a limited amount of money is made available to these managers for such projects, and usually only short payback time investments can be funded within these capital constraints).

In some cases, it is possible to narrow the gap between private and social costs of capital either generally or in individual sectors. This can lead to greater investment in end-use efficiency 
and other attractive opportunities. Generally, financial institutions can be improved. In the residential sector, for example, energy-efficiency considerations can be "rolled-in" to mortgage financing processes or utilities can make funds for consumer energy-efficiency investments available at their own required rate of return. General improvement in financial conditions is preferable to focusing exclusively on end-use efficiency, since all productive investments of equal risk to society should have capital available at similar interest rates.

\subsection{Split Incentives}

Split incentives occur when the person who makes electric end-use investment decisions is not the person who will be financially responsible for paying the energy bills. If the developer/landlord will pay the energy bill, then the savings from any conservation investment may be negated by wasteful tenant practices. If the tenant will pay, then the developer/landlord will build an efficient building only if she thinks she can get the money back in increased rents. If the developer plans to sell the building to some currently unknown new owner, then the developer will only install efficiency if she thinks she can get her money back (plus some risk premium) in a larger selling price.

Economists argue that, in general, split incentives of this type should not cause reduced energy efficiency, because the added value of the efficiency should be capitalized in a higher selling price or be reflected in higher rents. If they are not so reflected, then it may or may not be the result of split incentives. Consider the case when the tenant pays for utilities. As discussed above, reliably determining the energy consumption of a new building before occupancy or purchase can be difficult or impossible without the existence of a standardized building energy rating system that generates consumption estimates that are easily comparable to estimates from other (both new and existing) buildings. Therefore, due to another market failure, energy efficiency will probably not be capitalized in a higher selling price or be reflected in increased rents. In this case, it is not the split incentives that cause the market failure.
In the case of the landlord paying for utilities, it is not clear how she can prevent the tenants from wasting electricity, since the users do not pay for it directly (the marginal cost of increasing energy consumption is zero). In this case, the split incentive does inhibit increased efficiency.

\subsection{Differences in product attributes}

As noted above, purchase decisions involving energy-using equipment may involve considerations other than first-cost and energy cost. The services offered by products of varying efficiency can in some cases be absolutely identical; in other cases, the services may differ in some ways. In the United States, the clearest example of the latter situation arises with respect to automobiles. Most puvate buyers of vehicles for which a range of engines is offered choose a configuration that has both higher initial and operating costs than the base model. This choice is made because consumers prefer more powerful engines. Similar, though less extreme, examples can arise with respect to electricity end-use efficiency. For example, energy-efficient lighting or appliances may have different aesthetic characteristics than standard lighting, or may be incompatible with existing fixtures.

\subsection{Variation in usage patterns}

Sometimes, costs and cost-effectiveness associated with end-use energy efficiency are calculated based on an average usage pattem that does not reflect individual use situations. This is perhaps most clear in the case of household lighting equipment, where rates of usage within a single household can vary from nearly 24 hours per day in hall or security lighting situations to only minutes per month in closets and storage areas. Capital investments in end-use efficiency may be economically justifiable in the former situation but not the latter. 


\subsection{NATIONAL LEVEL FACTORS}

National level factors limiting increased enduse efficiency include a lack of adequate institutional capability, supply-oriented centralized utilities, electricity prices not based on costs, and a lack of energy-efficient products.

\subsection{Lack of Adequate Institutional Capability}

The lack of local and national institutions and agencies that produce, gather and disseminate information, distribute financial resources, design and monitor programs and policies, and train personnel can limit adoption of end-use efficiency technologies. Wilbanks (1990b) found that many developing countries are faced with a shortage of "efficiency-oriented managers and performanceoriented staff, basic limitations in the technical capabilities of staff and research laboratories, weak linkages with both government and industry, limited financial resources, and a frequent dependence on external initiatives and resources in defining and implementing new directions for technology choices."

A strong indigenous institutional capability can play a key role in promoting improvements in electricity efficiency. National or local level institutions or agencies in developing countries will have unique insights into local development needs, indigenous resources, and cultural biases. These insights are valuable in guiding the design of successful technologies and programs.

The lack of adequate institutional capability specifically related to energy efficiency discourages international assistance institutions from funding small innovative technologies or programs, because organizations to administer and monitor the programs either do not exist or are not able to provide the needed services. Strong national institutions are also important for developing countries because industrialized countries often favor improving trade balances through exports of technologies and consulting services over improving indigenous technical capability and fostering local decision-making (Reddy 1990).

The importance of indigenous institutional capability varies by technology. Custom, sitebuilt devices (such as buildings) are heavily dependent on local capability for their successful completion, and changing the way these devices are constructed requires changes in the behavior of thousands of different participants. Massproducible devices (such as appliances or electronic equipment) are manufactured in a central location by a few relatively large businesses, making indigenous institutional capability somewhat less important in this case. It will be easier to improve the efficiency of massproducible devices than to improve that of sitebuilt devices, in either the industrialized or developing world.

Inadequate institutional capability at the national level results in information problems at the consumer level. Efficiency choices available to consumers are reduced, so that even if they want to purchase an efficient device, it is not readily available and the transactions and information costs of finding it can outweigh the expected benefits. By creating information sources that consumers trust and can understand (such as a uniform building energy rating system that calculates expected energy costs for every house being sold), a market can be created for energy-efficient choices that did not exist before. Confidence that the cost savings from efficient products will be objectively measured is needed for manufacturers to optimize the efficiency of those products.

\subsection{Supply-Oriented Centralized Utilities}

Until recently, investor-owned utilities in the U.S. were structured so that profits were directly tied to sales, providing a strong incentive for utilities to promote electricity consumption rather than conservation. Unless this link between profits and sales is broken, private utilities will lose money promoting electricity end-use efficiency, even if the efficiency costs nothing (Krause and Eto 1988). In the past few years, 
there has been a movement among utility regulatory commissions in the U.S. to assure that societally cost-effective investments by utilities in electricity end-use efficiency are also profitable to those utilities.

U.S. regulators have also begun to encourage integrated resource planning (IRP). Traditionally, utilities have focused on supplying electricity to consumers and have generally achieved this goal through a reliance on large, centralized power generation stations. IRP is based on the concept of providing energy services at lowest cost to society and accomplishes this goal through a balanced assessment of both demand-side and supply-side resources. Under this scheme, energy efficiency technologies and programs compete with supply sources to fulfill energy service requirements, thus moving the utility away from total reliance on large, centralized power stations.

In developing countries, utility reforms can help fulfill infrastructure needs because some members of the technically competent utility staffs can be trained and re-oriented from energy supply tc energy services (Reddy 1990). Other structural considerations can be important in particular situations. In some countries, utilities are prohibited from selling efficient end-use equipment or giving rebates to promote the purchase of such equipment.

\subsection{Lack of Cost-based Electricity Prices}

In most countries electricity prices do not reflect the full societal costs of generating that electricity. In some cases, particularly in developing countries, electric utility capital or operating costs are subsidized. In other cases, utility rates are set to generate sufficient revenue to cover systemwide average capital and operaing costs, which can be lower than the cost of building and operating new powerplants. Ideally, consumer: who are making energy use decisions that determine capacity needs should face rates that reflect the costs of new capacity.

Another set of issues involves the possible role of social costs that may not be properly reflected in the private marketplace, which are generally called externalities. For example, fossil fuel powerplants generate emissions of various air pollutants, and their emissions are subject to varying degrees of regulation in different countries. The costs of compliance are reflected in the cost of constructing and operating these plants. The exact monetary value of the externalities and the extent to which these externalities are internalized remains open to corisiderable debate.

In both industrialized and developing countries, electricity is improperly priced both because environmental externalities are not incorporated in prices or resource planning and because governments frequently subsidize electricity prices (such subsidies are often justified to support national development). For example, $60 \%$ of the cost of electricity is subsidized in Pakistan and 20\% is subsidized in India (OTA 1991). Such subsidies represent barriers to energy efficiency because they encourage excessive consumption, resource depletion, and environmental pollution, and result in a societal efficiency loss (Kosmo 1987).

Electricity should be priced to reflect the long-run marginal costs of production. In fact, such pricing has been a policy of the World Bank since 1977 (World Bank 1990). Table 12 shows that average electricity revenues in 11 developing countries are below long-run marginal costs (Kosmo 1987). Proper electricity prices would encourage efficiency, reduce consumption and stabilize supply, avoiding costly outages. Kosmo has estimated that large reductions in energy demand would result from long-run marginal cost pricing (Kosmo 1987). 
Table 12 Comparisons of Average Revenues and Long-Run Marginal Costs of Electricity in Selected Countries

\begin{tabular}{lcccc} 
Country & Year & $\begin{array}{r}\text { Avg. Revenues } \\
(\mathbf{d} / \mathbf{k W h})\end{array}$ & $\begin{array}{r}\text { LRMC } \\
(\mathbf{d} / \mathbf{k W h})\end{array}$ & Price/LRMC \\
\hline Bangladesh & 1984 & 5.5 .4 & 9.09 & .65 \\
Bolivia & 1982 & 3.70 & 5.85 & .63 \\
China & 1984 & 3.29 & 5.65 & .58 \\
Fthiopia & 1983 & 6.01 & 18.78 & .32 \\
India & 1981 & 3.70 & 7.00 & .52 \\
Morocco & 1983 & 8.00 & 12.70 & .63 \\
Paraguay & 1982 & 4.00 & 5.00 & .80 \\
Peru & 1983 & 5.36 & 8.40 & .45 \\
Senegal & 1981 & 11.70 & 12.72 & .82 \\
Tanzania & 1983 & 7.79 & 8.20 & .95 \\
Uganda & 1982 & 1.20 & 8.00 & .15
\end{tabular}

Source: Kosmo 1987

In 1990, the World Bank surveyed electricity tariffs in the 1980s to determine whether tariffs in developing countries were based on long run marginal costs as advocated by World Bank policy. The survey of electricity prices of over 60 developing countries found that electricity subsidies grew during the 1980s. Around 1983, electricity tariffs fell significantly and the average tariffs ivere only 55\% of the average prices in the OECD countries. The study found that existing eler:ricity prices were too low to encourage ef ricient use of electricity and that "over $60 \%$ of developing countries had no intention of basing tariffs on marginal costs in the near future" (World Bank 1990).

In the short term, increasing electricity prices to reflect full direct costs and environmental costs would hurt low-ir.ume consumers. While there may be significant long-run benefits in having electricity rices reflect costs, achieving this out sme presents considerable transitional and distributional problems. To mitigate these problems, rate increases can be phased in slowly, and price structures can be altered to include low "lifeline" rates for a "subsistence" amount of electricity use, with higher rates for electricity use above the lifeline allotment.

\subsection{Lack of Energy-Efficient Products}

Because individual consumers tend to purchase less expensive, less efficient products (see discussion in 4.1 and 4.2 , below), manufacturers have little incentive to produce and market more efficient products (Reddy 1990). Outside of the U.S., Western Europe and Japan, many energy-efficient products are not available, because they are not manufactured indigenously and are not imported. Energy-efficient products may not be manufactured domestically because manufacturers are not aware of them, cannot obtain rights to manufacture them, or do not perceive that a market for the product exists (Philips 1991). 
In some countries, energy-efficient products are not imported because of uigh import duties that, when added to the cost o1 the product, make them prohibitively expensive. For example, a $250 \%$ customs duty is applied to imports of compact fluorescent lamps (CFLs) in India, which raises their cost to about nis 400 , more than the average monthly income of Indian consumers (Gadgil et al. 1991). Also, some countries ban imports of certain products to protect domestic manufacturers. For example, energy-efficient industrial boilers may not be imported into Pakistan (Philips 1991). Lack of domestic demand, lack of competition from domestically-produced energy-efficient products, and economic and political instability are other reasons that energy-efficient products are not imported to some countries (Philips 1991).

The recent history of compact fluorescent lamp (CFL) sales in the U.S. and Westem Europe illustrates one pattem of increasing market penetration of a key end-use efficiency technology. Despite the large electricity savings that can be realized through installation of CFLs, sales were initially poor. However, as utility promotions of energy-efficient products, including CFLs, have grown in response to the recent adoption of demand-side management programs, consumers have begun to purchase CFLs. Manufacturers now estimate that future sales in the U.S. will increase dramatically, growing from about 10 million in 1988 to 72 million in 1995.

\subsection{INTERNATIONAL LEVEL FACTORS}

The adoption of efficient electricity end-use technologies and programs requires capital investments, efficiency expertise, and technological resources. In recent years, industrialized countries have developed numerous technologies that use electricity efficiently, and have experimented with various policies and programs to promote energy efficiency. Developing countries, however, have lagged in this effort due in part to the lack of international funding for initiatives to promote increased end- use efficier,cy, and the lack of collaboration with industrialized countries.

\subsection{Lack of Funding}

Intemational assistance institutions, such as the multilateral World Bank, the regional development banks (Asian Development Bank, Inter-American Development Bank, and the African Development Bank), the United Nations Development Programme (UNDP), and the bilateral U.S. Agency for International Development (U.S. AID), have historically favored the delivery of raw energy (especially electricity) over the delivery of energy services, funded construction of large, centralized energy projects, and relied upon "conventional" technologies. Goldemberg et al. (1988) estimate that between 1972 and $1980,91 \%$ of multilateral and bilateral energy assistance was for large conventional power systems, $5 \%$ was for fossil fuels recovery, $3 \%$ was for new and renewable energy sources, and $1 \%$ was for technical assistance and energy planning. Lending for enduse energy efficiency was about $1 \%$ of the World Bank's total energy lending from 1980 through 1990 (Philips 1991).

Funding for one large electricity supply project, such as a hydroelectric dam, is easier to manage and administer than funding for a number of geographically diverse, small-scale electricity efficiency projects (Reddy 1990). Because savings from electric end-use efficiency depend on the combined effect of many small measures, the emphasis on large, centralized energy projects results in inadequate funding for electricity efficiency projects. An institution or agency could combine, or "bundle" a number of small projects into one large project that is on the financial scale of international assistance institutions (OTA 1991). However, even if funding is secured, many developing countries lack the technological and managerial expertise to effectively plan and implement smaller, diverse projects (see Section 3.1).

International assistance institutions shy away from unfamiliar technologies, because the risks of these technologies are less well-known than those 
of the supply-side technologies that have been frequently funded in the past (U.S. AID 1990). This lack of familiarity prevents a balanced assessment of risks and benefits from competing demand-side and supply-side technologies.

International or bilateral funding is often structured so that project expenses involving foreign currency are covered while local project expenses are not. Thus expenditures for foreign technical assistance (such as consulting and engineering services) and foreign technologies are allowed. Little, if any, of this international aid is spent locally to develop indigenous technical capabilities or products (Goldemberg et al. 1988). Creating site-specific efficiency programs requires the use of indigenous resources in many cases, and hence these funding requirements can inhibit such programs.

\subsection{Lack of Effective Collaboration Between Industrialized and Developing Countries}

The lack of on-going, effective communication between industrialized and developing countries also has retarded the adoption of electricity efficiency technologies and programs in the developing world. Collaborative efforts between industrialized and developing countries could help to consolidate two types of information: (1) developing country conditions such as current electricity supply and end-use efficiency requirements, economic conditions, and social and cultural parameters, and (2) industrialized country resources such as existing energy efficiency technologies, potentially successful energy efficiency research, development and demonstration (RD\&D) programs, and experience with policy mechanisms (Wilbanks 1990a). To foster improved communications, it is also essential to improve national institutional capabilities (see section 3.1 ).

\subsection{CONCLUSIONS}

This chapter has explored the main factors retarding electricity efficiency improvements. Such factors can be found at the consumer level, the national level, and the international level (particularly relating to developing nations). Some of these factors reflect market distortions, while others reflect inherent problems in some technologies or their applications. Interconnections among distortions suggest that comprehensive efforts to address them may be more successful than piecemeal ones. For example, eliminating price subsidies for electricity will affect consumers' investment decisions, but if efficient products have not been brought to market in a timely fashion or if consumers are unaware of the existence of the Isw efficient products, then the new technology will be adopted much more slowly than if all these factors are addressed simultaneously. 


\section{REFERENCES}

Barker, B. S., S. H. Galginaitis, E. Rosenthal and Gikas International Inc. 1986. Summary Report: Commercial Energy Management and Decision Making in the District of Columbia. Potomac Electric Company. December 1986.

EPRI, Electric Power Research Institute. 1987. Market Research on Demand-Side Management Programs: Preferences Among Commercial Customers. EPRI. EM-5252 Research Project 2152-2. June 1987.

EPRI, Electric Power Research Institute. 1988. DSM Commercial Customer Acceptance: Vol.1: Program Planning Insights. EPRI. EM-5633, Project 2548-1. January 1988.

Gadgil, A., Rosenfeld, A., Arasteh, D., and Ward, E. 1991. "Advanced Lighting and Window Technology for Reducing Electricity Consumption and Peak Demand: Overseas Manufacturing and Marketing Opportunities." Presented at IEA/ENEL Conference on Advanced Technologies for Electric Demand-Side Management in Sorrento, Italy.

Gel_er, H.S., Hirst, E., Mills, E., Rosenfeld, A., Ross, M. 1991. Getting America Back on the Energy-Efficiency Track: NoRegrets Policies for Slowing Climate Change. American Council for an Energy-Efficient Economy. June 6, 1991.

Goldemberg, J., Johansson, T.B., Reddy, A.K.N., Williams, R.H. 1988. Energy for a Sustainable World. New Delhi: Wiley Eastern Limited.

Kempton, Willet and L. Layne. 1988. "The Consumers' Energy Information Environment." In Proceedings of the 1988 ACEEE Summer Study on Energy Efficiency in Buildings. Asilomar, CA. American Council for an Energy Efficient Economy.

Koomey, Jonathan. 1990. Energy Efficiency Choices in New Office Buildings: An Investigation of Market Failures and Corrective Policies. PhD Thesis, Energy and Resources Group, University of Califomia, Berkeley.
Kosmo, M. 1987. Money to Burn? The High Costs of Energy Subsidies. World Resources Institute.

Krause, Florentin and Joseph Eto. 1988. LeastCost Utility Planning: A Handbook for Public Utility Commissioners (v.2): The Demand Side: Conceptual and Methodological Issues. National Association of Regulatory Utility Commissioners, Washington, DC. December 1988.

March, James G. and Herbert A. Simon. 1959. Organizations. New York: John Wiley and Sons, Inc.

Meier, Alan and J. Whittier. 1982. "Purchasing Pattems of Energy-Efficient Refrigerators and Implied Consumer Discount Rates." In Proceedings of the 1982 ACEEE Santa Cruz Conference. American Council for an Energy Efficient Economy.

NEEPC, New England Energy Policy Council. 1987. Power to Spare: A Plan for Increasing New England's Competitiveness Through Energy Efficiency. Boston, MA. July 1987.

OTA, Office of Technology Assessment. 1991. Energy in Developing Countries. U.S. Congress. OTA-E-486. January 1991.

Pearson, Thomas D. 1989. "Education for Professionalism: A Common Body of Knowledge for Appraisers." The Appraisal Journal. vol. LVII, no. 1. p. 7.

Peters, Jane S. and Greg C. Gustafson. 1986. Summary Report: Non-Response Evaluation--Site Specific SponsorDesigned Program Focus Groups. Bonneville Power Administration. IEAL/PO-7. September 1986.

Philips, Michael. 1991. The Least-Cost Energy Path for Developing Countries. International Institute for Energy Conservation.

Reddy, A.K.N. 1990. Barriers to Improvements in Energy Efficiency. Indian Institute of Science, Department of Management Studies.

Ross, Marc. 1986. "Capital Budgeting Processes at Twelve Large Manufacturers." Financial Management. p. 15. 
Ross, Marc. 1989. "Improving the Efficiency of Electricity Use in Manufacturing." Science. vol. 244, no. 4902. p. 311.

Schon, Andrew, Mitchell E. Odinak, James A. Ferro and Harvey G. Michaels. 1987. Study of Energy End Uses and Conservation Potential in Selected Segments of the Commercial Class (Program G-2). Volume 1: Project Summary-Final Report. Prepared by Xenergy for The Consolidated Edison Co. of New York, Inc. July 1987.

Sudhakara Reddy, B. 1990. The Energy Sector of the Metropolis of Bangalore. Doctor of Philosophy Thesis, Indian Institute of Science.

U.S. AID, Agency for International Development. 1990. Greenhouse Gas Emissions and the Developing Countries: Strategic Options and the U.S.A.I.D. Response. U.S. Agency for International Development. July 1990.

Wilbanks, T. J. 1990a. Institutional Issues in Energy R\&D Strategies for Developing Countries. Oak Ridge National Laboratory. November 1990.

Wilbanks, T. J. 1990b. The Outlook for Electricity Efficiency Improvements in Developing Countries. Oak Ridge National Laboratory. May 1990.

World Bank. 1990. Review of Electricity Tariffs in Developing Countries. World Bank, Energy Development Division, Industry and Energy Department. 


\section{CHAPTER 4}

\section{EXPERIENCE WITH POLICIES AND PROGRAMS}

\subsection{INTRODUCTION}

Fifteen years ago, it would have been possible to discuss policies to increase electricity end-use efficiency only from a theoretical perspective. Today, there is a body of experience - primarily in industrialized countries - with policies to increase the efficiency with which electricity is used. This experience is limited in key ways. The initial efforts to foster energy conservation occurred as a result of the $1973 / 74$ oil embargo. These efforts, and their attendant policies, were focused on conserving oil and fossil fuels that could substitute for oil. In many countries where considerable oil was used to produce electricity (e.g., the United States), the major policy effort was to convert from oil to other fuels. Thus, initially little attention was paid to electricity conservation following the embargo.

By the late 1970 s and early 1980 s, electricity conservation had become more interesting in industrialized nations because of rising electricity prices, environmental concerns, and the increasing costs and risks of building new power plants. Some programs were initiated by state and national governments (e.g., appliance efficiency standards in the United States). In addition, electric utilities in the United States and later in portions of Western Europe became involved in promoting programs to assist or encourage customers to increase electricity enduse efficiently. Utilities throughout the world have years of experience in pursuing load management programs (shifting demand from one time period to another); however, it was only in the late 1970s and early 1980s that efforts were made to carry out programs that would reduce demand for baseload energy.
Thus, the primary experience in electricity end-use efficiency programs has taken place over the past ten to fifteen years. Many of the efforts began slowly, because there was little rior experience in the field and because electric utilities - as organizations experienced in production and delivery of electricity to customers - had little interest in devising ways for consumers to use and therefore purchase less electricity, particularly if utilities lose money in doing so. But as experience in these programs and policies has grown, attitudes and expertise of govermment organizations and utilities have evolved, and knowledge has been gained about what can be accomplished and how to accomplish it. A case in point is that several major utilities in the United States (e.g., the Pacific Gas and Electric Company (PG\&E) and New England Electric System (NEES)), have embraced end-use efficiency programs and are pursuing large-scale programs for a variety of reasons.

It is the purpose of this chapter to describe this experience with policies and programs, and to illustrate some of the lessons learned over the years. Most attention is necessarily given to the United States, both because of the authors' familiarity with activities in that country but also because the United States began addressing electricity conservation earlier than other nations and has more experience in putting programs into the field. We provide international examples as well, as the experiences in the United States often do not translate simply into other countries.

The policies and programs that are covered include:

- electricity pricing

- information programs 
- appliance efficiency standards

- financial incentive programs to manufacturers to produce more efficient appliances

- support for enhanced private sector involvement (energy service companies or ESCOs)

- energy standards for commercial buildings

- electric utility programs and planning processes

- research and development programs on more efficient electricity end-use technologies

Note that many of these are different ways to accomplish the same objective. Thus, when evaluating impacts of these programs and policies, the effects are not additive.

We begin with a discussion of electricity pricing because pricing issues are pervasive. We then turn to the programs described above and illustrate them largely in the context of U.S. activities. In addition to addressing experiences with these policy approaches to electricity conservation, we also provide a summary of activities that have been undertaken in developing countries.

\subsection{ELECTRICITY PRICING}

We have noted in Chapter 3 that electricity prices in many countries may not reflect the full cost of producing and distributing electricity. Because utilities in industrialized countries are generally not subsidized by their governments, they typically charge a price for electricity that is sufficient to cover costs of supplying electricity to the consumer and of building new capacity to meet growing demand. This price is between the average and the long-run marginal cost of electricity. We also noted in Chapter 3 that electricity in developing countries is often subsidized. While different analyses can be done on what the "proper" price of electricity should be, the subsidies required to keep the electric utilities in business in many developing countries attests to the low electricity prices in these countries.

There can be a number of reasons for these subsidies. Electricity prices can be used for a variety of purposes in an economy. First, they can be set to ensure the financial solvency of electric utilities. Second, prices can be set to promote efficient resource allocation. Third, they can be set to redistribute income. Fourth, energy prices can be used as a source of revenue for the government. Fifth, prices can be set to promote the consumption of specific energy products by targeted consumer groups. Sixth, energy prices can be set to promote other political or social goals - to simply keep the cost of energy low, for example (Hill 1987).

From the standpoint of economic efficiency, the first two purposes are the most in portant. Policymakers in many developing countries historically viewed electricity pricing as an important policy tool for a variety of riational objectives, emphasizing the latter four purposes at the expense of the first two. Prices historically have served an economic development objective: low electricity prices ostensibly promote the development process. Price increases can lead to protests, civil disorders, and even changes in government. Public reaction to price increases in Jamaica, Ecuador, and Guatemala illustrate this problem (Hill 1987).

Experience has shown that in many cases it is ill-advised to change prices to cost-based levels too quickly. Polish policymakers, for example, recognized that the price of electricity needed to be increased sharply and the prices of input fuels (e.g., coal) raised to border levels in the process. Increases in the price of coal in 1988 were blamed for the ensuing accelerating rate of inflation. 
Therefore, policymakers are now pushing for a gradual phasing of reforms over several years (Hill forthcoming).

Cost-based pricing of electricity includes temporal considerations. Prices that reflect changes in costs over time (peak hours, daily, and seasonal) generally lead to the most efficient use of electricity resources. Time of use rates can reduce the costs of electricity, by moving use from periods of high-cost to low-cost power. Industrial activities have been shown to be the most sensitive to time of use rates in industrialized economies. Also, interruptible and curtailable tariffs, which permit the utility to meet higher energy requirements with reduced capacity, can save substantial costs to both consumer and utility. Increasing block rates, where prices increase at high levels of electricity usage, can send price signals that are consistent with long-run marginal costs and thus discourage inefficient use of electricity. At the same time, the increasing block structure can be designed to have an initial block that is affordable to low-income users.

The World Bank has been active in promoting electricity pricing reform in developing countries (World Bank 1990). The Bank often applies considerable pressure on recipient countries to raise electricity prices if they are to receive loans for the power sector. Recent examples include Indonesia and Egypt. Both countries have not only performed analyses of electricity tariffs but have raised prices. The Bank has also noted that institutional reforms, such as changes in personnel and salary policies, bringing competition into the power sector (e.g., private power), etc. are also needed (World Bank 1990). One oft-cited example is the GovernmentInvested Enterprise Management Act in Korea, which provided incentives for managers of public enterprises to improve the performance of their firms. The legislation is credited with reducing operating costs of the Korean power monopoly by an estimated 33 percent four years after its enactment (Hill 1991).

Returning to the specific issue of electricity end-use efficiency improvements, there is no question that electricity prices are crucial to achieving such improvements. One estimate suggests a long-run price elasticity of demand for electricity can be as high as -1 , varying significantly among different countries (Kosmo 1987). This means that, if electricity prices rise on average 30 percent over the next one to two decades, total demand for electricity will fall by a comparable amount relative to what it would have been. Even if this estimate of the price elasticity is high by a factor of two, it illustrates the importance of proper electricity pricing signals to the allocation and use of the resource. The specific programs and policies described below can play a major role in increasing electricity enduse efficiency. However, proper electricity pricing will affect the nature of efficiency choices as well as create an environment in which the efficiency policies and programs can work.

Time of use rates are not in widespread practice in industrialized or developing countries. And even average prices and prices to individual customer classes are considered far from "optimal" for many utilities in industrialized countries. Promotional tariffs to promote increased use of electricity for specific uses (e.g., heat pumps or industrial development) are still found in some utilities. Declining block rates still exist in many utilities through the world. Thus, electricity price reform-affecting both the total price and the structure of electricity prices-can have a significant effect on end-use efficiency. 


\subsection{PROGRAMS IN TIIE UNITED STATES AND OTHER INDUSTRIALIZED COUNTRIES}

\subsection{Information Programs}

Information programs primarily address lack of information about specific technologies by publicizing energy conservation programs as well as helping expand and intensify the market for energy-efficient products. Many programs include both objectives by increasing the target audience's (e.g., consumers, builders and developers) awareness, acceptance, and support of particular energy conservation programs.

Two types of consumer information and marketing programs are considered in the following discussion: home energy rating systems and energy awards. The former is an example of the use of different marketing strategies in an integrated fashion to successfully promote conservation programs to several target audiences. In contrast, the latter is directed mainly to the designer/builder professional, and by itself has a more limited impact. However, when combined with other programs, such as building energy ratings, the impact of energy awards becomes more significant.

\subsubsection{Energy Rating and Labeling}

Home energy rating systems (HERS) typically certify that a home meets a specified level of energy efficiency or that it contains specific energy efficiency features. In addition to the technical rating of the program, support activities (such as program marketing and financing) are often included as part of the HERS. Home energy rating systems are often targeted to many groups: consumers, builders, the real estate community, appraisers and lenders.

The experience with implementing HERS is extensive and well-documented (Hendrickson 1988, Vine et al. 1987a, Vine et al. 1987b). In the U.S., organizations now using HERS include regional governments (e.g., Tennessee Valley Authority (TVA) and Bonneville Power Administration (BPA), national industry organizations, state and local government agencies, and utility companies. These organizations currently have 43 HERS programs in 27 states. Recently, energy rating programs have also started to be used in the commercial sector.

Home energy rating systems (HERS) are more successful, in terms of penetrations rates and improved energy efficiency, when they:

- are actively marketed

- have a comprehensive appreciation of the market

- are adaptive to the needs of particular users, and

- include user participation in the operation and revision of the program.

Where offered, the average percentage of new residential construction participating in HERS was 40 percent. Measured annual electricity savings of new homes participating in HERS and residential demonstration programs ranged from 30 to 50 percent. (Vine and Harris 1988) Energy awards were also effective in promoting energy-efficient construction, particularly when featured as part of comprehensive energy-efficiency programs.

For existing stock, the measure of the success of a HERS involves the installation of retrofits and weatherization measures This requires an authoritative rating tool that can be used to evaluate a building's current energy efficiency, as well as alternate ways of improving that energy efficiency. This rating evaluation should be capable of translation into cost-effective terms, which generally has the most significance to the homeowner. A further important key to the success of a home energy rating system involves 
the inclusion of the homeowner in the use of the tool, so that the homeowner is shown what might be done to his house, what this physically involves, what the consequences will be in terms of energy, cost and very importantly, comfort. And it is important to the success of a HERS to provide assistance to the homeowner to increase the energy-efficiency of the house. This assistance may take the form of zero- or low-cost loans, but should also include information about local sources of materials and contractors to retrofit the house.

\subsubsection{Technical Information for Non-Energy- Efficient Buildings}

Lack of information is also addressed by more specific programs and activities, such as professional guidelines, design tools, and design assistance programs.

Technical information for design practitioners and building professionals is often one of the first resources to be developed in the promotion of energy-efficient construction. One source of technical information is guidelines on designing and constructing energy-efficient buildings issued by professional organizations, often in conjunction with a code adoption process. Standards-related training, including compliance and quality control activities, not only provide specific technology-related information but also help reduce the perceived risk in implementing energy efficiency technologies by ensuring that the technologies have been designed and installed properly and that they are being operated and maintained correctly.

The available design tools are varied, including workbooks, guidebooks, calculator programs, daylighting models and microcomputer or mainframe computer software. The same tools can be used both for complying with local or state energy codes and for improved design that goes beyond standards.
In contrast to the broad and generic approach characteristic of professional guidelines and most design tools, design assistance programs are typically identified with a customized approach that is building-specific. The provision of technical assistance in designing energy-efficient buildings is one of the most common types of energy-efficiency programs offered by utilities and governmental agencies in the United States to new residential and commercial customers. As part of the design process, these design assistance programs often include consulting services and site-specific design review between energy experts and the architect and engineering team and their client.

Technical workshops and seminars are sometimes conducted, as part of energy conservation programs, to provide technical information and training to architects, engineers, building owners and managers, builders, developers, building code officials, appraisers, real estate professionals and staff of financial institutions. These training activities are important to encourage conformance with mandatory standards or voluntary guidelines. In addition to ongoing education and training activities, quality control inspections are sometimes made during the construction process and/or after the building has been completed to ensure that the building has been constructed properly and that the equipment is working as designed.

Design tools have been effective in promoting energy-efficient construction when featured as part of comprehensive energy efficiency programs. Design guidelines issued by professional organizations have also been important, over the long term, in establishing new norms of professional practice, new design guidelines, and new local and state building codes; however, more immediate, personal, and 
interactive design assistance is often needed for promoting energy-efficient construction.

Design assistance programs in the United States demonstrated that the initial reluctance of some designers to have their plans "reviewed" can be overcome when both the design firm and the client are clearly shown the benefits of designing energy-efficient buildings. Moreover, design assistance programs were most successful when energy efficiency options were introduced as early as possible in the design stage and when they did not add delays to the project design, approval, financing, or construction process. Also, these programs demonstrated that, in many cases, substantial gains can be made in energy efficiency without requiring significant cost increases or significant changes in building practices.

\subsection{Appliance Efficiency Standards}

The United States has been the leader in establishing efficiency standards for residential appliances. Appliances consumed 35 percent of total electricity in the United States in 1988.

The idea of increasing efficiency of appliances was accepted by the Congress as early as 1975, when legislation was passed calling for voluntary activities by appliance manufacturers to meet efficiency improvement targets. By 1978, when the National Energy Policy and Conservation Act (NEPCA) was placed before Congress, little progress had been made and Congress required that DOE develop mandatory energy standards based on technical feasibility and economic desirability. Over the next decade, the federal government did not promulgate appliance standards in spite of NEPCA, but many states, led by California, established standards that applied to individual states.

In 1987, Congress passed the National Appliance Energy Conservation Act (NAECA), which legislatively established stanc irds for 12 products (NAECA 1987). The legislation, which mandated levels of stringency for the standards, reflected a compromise between environmental groups and appliance manufacturers. Agreement between parties that had previously taken strong opposing positions on appliance standards was made possible by at least two factors: the proliferation of state appliance standards, with Califomia leading the way but with many other states developing their own standards, and a court ruling in 1985 which mandated strong action by DOE. The U.S. appliance manufacturers were particularly concerned about an evolving situation in which many different standards were imposed by a variety of states.

Under NAECA, manufacturers of residential appliances must meet legislatively-specified energy efficiency standards by prescribed dates. The energy efficiency or energy use for each product type is measured according to test procedures established by DOE. Standards for clothes washers, clothes dryers, and dishwashers took effect on January 1, 1988. Standards for refrigerators, freezers, room air-conditioners, and water heaters took effect January 1, 1990. The NAECA mandates periodic updates of these initial standards (Turiel et al. 1990).

Significant savings will be realized from the standards that were enacted through 1990 . The cumulative primary energy savings for the period 1990 to 2015 from these standards are estimated to be 21 Quads ( $\left.10^{15} \mathrm{Btu}\right)$ of resource energy, more than 90 percent of which is used to produce electricity. The net present benefit (calculated at a 6 percent real discount rate) of the energy savings from 1990 to 2015 is estimated to range from $\$ 34$ to $\$ 44$ billion (1987 dollars). Further savings will be realized after 2015 (McMahon et al. 1990).

The effect of these efficiency standards on a single product can be illustrated using refrigerators as an example. Figure 14 shows 
that average annual electricity consumption of new refrigerators in the U.S. grew dramatically from about $300 \mathrm{kWh}$ in the 1940 s to over 1700 $\mathrm{kWh}$ in the early $1970 \mathrm{~s}$, as the size of refrigerators increased and many features were added. Average annual consumption levels then fell to about $1450 \mathrm{kWh}$ when California announced that it would enact efficiency standards in 1978. In the 1980 s, uniform national standards were developed. The first of these standards, which took effect January 1, 1990 , requires that the most popular refrigerator (an 18 cubic foot top-freezer, automatic-defrost, refrigerator-freezer) consumes less than 960 $\mathrm{kWh} / \mathrm{year}$. This standard is estimated to reduce peak power requirements in the United States by 2.6 thousand megawatts by 2015 . The standards that will take effect January 1,1993 , require that the same refrigerator consume less than 690 $\mathrm{kWh} /$ year, for an additional peak power reduction in 2015 of 4.9 thousand megawatts. Total peak power reduction from standards is projected to be 7.5 thousand megawatts (McMahon et al. 1990).

Continued regulated improvements in appliance efficiency are expected. As described in Chapter 2, there exist a variety of technologies or design options for residential appliances that have not been incorporated into standards. Even for refrigerators, for which the new (1993) standards have recently been established, the use of vacuum insulation is estimated to result in cumulative savings (from 1993 to 2015) of additional 5.6 Quads (Turiel et al. 1990). Periodic updates of all appliance efficiency standards are underway, as DOE is required to review the standards and upgrade them if this is technically feasible and economically justified.

Worldwide, approximately 50 million refrigerators are manufactured and sold each year, requiring five to nine new $1,000 \mathrm{MW}$ power plants each year. A $30 \%$ reduction in refrigerator electricity consumption (equal to the savings from the U.S. 1993 standards relative to the existing
1990 standards) worldwide would result in a reduction in construction of about two $1,000 \mathrm{MW}$ power plants per year. At the present time only two countries, the U.S. and Canada, have extensive energy efficiency standards for residential appliances. (In Canada, two provinces, Ontario and British Columbia, have standards and the federal government is about to propose them.) The European Community is evaluating efficiency standards for several residential appliances. There are no appliance standards in developing countries, although standards have been proposed in Brazil, testing programs exist in Brazil and the Philippines, and Thailand is embarking on a variety of programs that could involve appliance testing and possibly standards.

There are several lessons that can be learned from the experience in the United States. First, political consensus on standards can take considerable time. Second, appliance test procedures, by which the performance of appliances can be measured, are a prerequisite to setting any standard, and efforts to develop and apply test procedures need to be started early. The work on test procedures as well as detailed analyses on the performance and costs of appliance efficiency measures continued, even while standards were not pursued at the federal level. Third, appliance standards are an important way of reducing electricity growth, addressing more than one-third of electricity consumption in the United States and other industrialized countries, and a large fraction of expected growth in electricity use in many developing countries. Finally, even the appliance manufacturers, who were initially strongly opposed to standards, acknowledge their effectiveness and have voiced few complaints about other unwanted effects. For example, there was considerable concern that the standards could reduce reduce consumer choice. However, in the case of refrigerators and freezers, the number of models available has risen 
(YMYg $S$ jo indino [enuure)

Sjueld IaMOd peolaseg MW OOOI

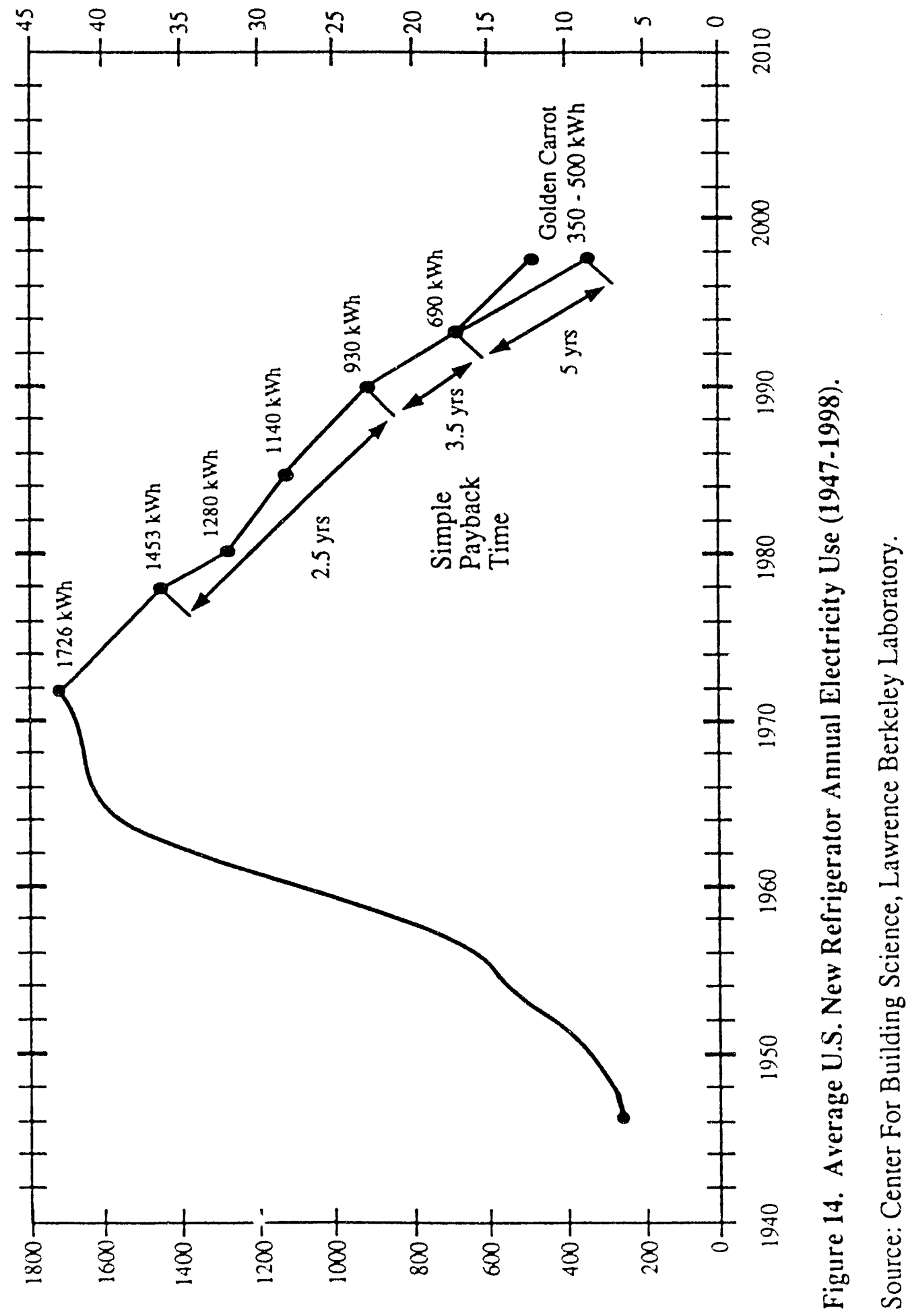

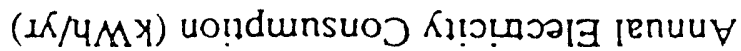


from over 1500 in 1986 to more than 2100 in 1990 (Turiel et al. 1991).

\subsection{Financial Incentives to Appliance Manufacturers}

Programs that use financial incentives, termed "Golden Carrots," are being used to encourage manufacturers to develop and produce more energy-efficient technologies. Under this approach, incentives, which can be large enough to cover the capital cost of a new product line, are provided by the government or by a consortium of utilities to a manufacturer that successfully delivers a product meeting specified energy consumption and delivery date requirements. Consumer rebates are then offered to encourage consumers to purchase the product.

In 1990, the Swedish National Energy Administration (STEV) used the Golden Carrot concept when it held a competition for refrigerator-freezer manufacturers, asking them to submit bids to design and supply a specified number of units that would consume at least $3.0 \%$ less electricity than used by the most efficient model currently on the market. Large Swedish housing-management companies endorsed the competition, implicitly indicating an interest to purchase the efficient refrigerator-freezers. Electrolux won the competition with two designs: the TR 1060-LE, a 10.25 cubic foot refrigeratorfreezer that consumes $314 \mathrm{kWh} /$ year (35\% less than the best available model) and the TR 1060SLE, with the same interior volume that consumes 212 kWh/year (McMahon 1990, Mills 1990).

A similar Golden Carrot program directed at U.S. refrigerator-freezer manufacturers is currently being developed by a consortium of utilities, government agencies, refrigerator manufacturers, and other interested parties. The utilities are seeking to pool between $\$ 20$ and $\$ 40$ million to be paid to the winning manufacturer.
Selection of the winner will be based on achievement of energy efficiency goals, earliest delivery date, and the amount of subsidies requested per unit. The consortium's goal is to encourage commercialization of refrigeratorfreezers during the 1995-1997 period that use between 350 and $500 \mathrm{kWh}$ (for an 18 cubic foot unit). This is about 30 to 45 percent less electricity than mandated by the 1993 National Appliance Standards. The units must also be CFC-free, and extra points are given for designs that use substitutes that are not HCFCs.

\subsection{Cominercial Building Energy Standards}

Buildings (including appliances within them) consume a significant share of electricity in both developed and developing countries. In 1989, they accounted for 57 percent of OECD electricity use -31 percent in the residential sector and 26 percent in the commercial sector (OECD 1991). In developing countries, buildings account for 38 percent of electricity consumption, and over the 1980s their consumption grew more than 11 percent per year (Levine et al. 1991). As developing countries raise their standards of living and services and increase urbanization, building electricity use is expected to continue to increase, especially in the commercial sector.

Since the second half of the 1970s, governments in both developed and developing countries have initiated policies to reduce energy consumption in buildings. The most common approach for this end-use sector is a building energy code or standard. Currently, there are at least 30 countries with some form of voluntary or mandatory standards for energy use in new buildings. The majority of these standards apply to new residential buildings, since this sector tends to use a higher overall percentage of energy than do commercial buildings. Because commercial buildings use so much electricity, however, a large portion of the overall electricity 
savings from building energy standards are from commerciar buildings.

A partial list of countries with voluntary or mandatory building energy standards for nonresidential buildings includes Sweden, France, Germany, the United Kingdom, the United States, New Zealand, Kuwait, Pakistan, Singapore, Jamaica, the Philinpines, and Japan. The flexibility and effectiveness of standards as a mechanism for reducing commercial energy consumption can perhaps best be demonstrated by a comparison of commercial building standards in two very different political and physical climates-Singapore and the United States.

Singapore's small size, homogeneous culmate, and strong central government produced a focused approach to building energy building energy standard development and implementation. In 1976, the Public Works Department of Singapore began a local research program on weather, construction practices, and thermal properties of building materials. This program led to the introduction of building energy standards in 1979, which focused mainly on overall thermal transfer value (OTTV) for building envelopes. A handbook was published in 1980 as an implementation guide for the standards, and in 1982 the handbook was updated to include OTTV calculations for roofs. For commercial buildings, this handbook provides requirements and guidance in five key areas: (1) lighting; (2) air-conditioning, zoning and thermal control requirements; (3) overall thermal transfer value (OTTV) for air-conditioned buildings; (4) roof insulation and roof OTTV, and (5) thermal comfort in non air-conditioned buildings (Singapore Public Works Department 1982).

In addition to these fundamental components which might serve as a basis for other hot and humid climates, several provisions of the
Singapore standard plus certain enforcement procedures set Singapore's building energy program apart. Contrary to most countries, which tend to mandate energy standards for government buildings before extending them to other sectors, the Singapore building regulations apply only to the private sector (Wong 1984).

After the 1979 energy code was developed, the Singapore government gave 200 existing buildings a two-year grace period to comply with the new regulations or they would suffer a $20 \%$ surcharge on their electricity bill. In 1984, the surcharge increased to $50 \%$. All buildings initially targeted were upgraded by 1987 (State Electricity Commission of Victoria 1991).

Most recently, changes to the 1989 building regulations include two detailed provisions which indicate the government's willingness to go beyond basic building design to limit energy use. Hotels are required to install automatic control devices in guest rooms to ensure that lighting and air-conditioning loads decrease when rooms are unoccupied. In addition, all new commercial buildings must install data logging facilities for energy auditing.

An analysis of the Singapore energy standards in 1984 by Lawrence Berkeley Laboratory (LBL) (Turiel 1984) estimated that compliance with the envelope provisions presented in the form of an overall thermal transfer value (OTTV) would save about 6 percent of total electricity over a typical commercial building of the time. Likewise, the lighting provisions were estimated to save an additional 6 percent of electricity use. While no calculation was performed on the likelv savings from the air-conditioning provision: of the standard, given that this end-use constitutes over half the total energy budget of a typical Singaporean commercial building, it is reasonable to assume potential savings in the range of 5 
percent to 10 percent, or perhaps even greater for them.

In contrast to the strict regulations and penalties set by the Singapore government to prod the private sector's commercial building stock towards energy-efficiency, the United States government has supported national consensus codes, and has given state and local govemments jurisdiction over their adoption and implementation. The first federal efforts were initiated by the National Bureau of Standards (now named the National Institute for Science and Technology) in the early 1970s and turned over to the American Society of Heating, Refrigerating, and Air-Conditioning Engineers (ASHRAE). ASHRAE published the standards in 1975 and updated them in 1980 and in 1990. The ASHRAE standards are considered industry consensus standards, and as such are widely credible among industry groups and others. All fifty states states have adopted all or part of the ASHRAE standards (OTA 1991). Energy savings estimated from the 1975 standard ranged from 10 to 60 percent; the 1980 standard increased these savings by an additional 5 to 25 percent (OTA 1991).

Even though commercial building standards are not mandatory in the U.S., the commercial sector saved about 1.7 Quads of delivered energy betwe $\cdot n$ the early 1970s and 1986 (OTA 1991). The bulk of these savings resulted from retrofits to existing buildings, because of the large fraction of existing compared with new buildings. Nonetheless, new commercial buildings that generally adhere to ASHRAE standards are considerably more energy-efficient than older ones.

A United Natio is study of energy stanciards in 15 westem European countries noted the difficulty in developing a quantitative evaluation of energy saved through voluntary or mandatory standards because of constant technological development and ongoing changes in building practice (Economic Commission for Europe 1984). Nevertheless, the report determined voluntary or mandatory standards to be "largely successful" in their purpose, and governments around the world seem to concur.

Countries on almost every continent are in various stages of developing, improving, and expanding building energy standards. Some, like India, have no building energy standards but are gathering data on commercial energy consumption patterns. Estimates from the Soviet Union suggest that 25 percent of the energy used in existing buildings could be saved, and savings up to 50 percent are possible in new buildings (Cooper and Schipper 1991).

Other countries further along in the standards development process have prepared plans, timetables, and goals for voluntary or mandatory commercial buildings standards. In Australia, the State Electricity Commission of Victoria has recommended the introduction of commercial building energy standards by 1993 , with a target energy reduction of $25 \%$ in 5 years (Consultative Forum 1991).

Countries with existing building energy standards, such as Sweden, are increasing their stringency, while others are making voluntary standards mandatory. The existing voluntary guide'ines for non-residential buildings in the Netherlands will tocome mandatory in 1992, and an update of the Federal Building code is expected in 1993 (Trines 1991).

There has long keen interest within the European Economic Community to develop a European building energy standard. The Directorate General for Energy of the European Economic Community crmmissioned studies in 1975, 1980, and 1987 (Carpentier and Uyttenbroeck 1975x; Carpentier and Uyttenbroeck 1980) regarding thermal insulation requirements in EC member states, and further 
study on the topic is underway (Kvetny 1991). On the international level, ASHRAE has proposed a new technical committee to the International Standards Organization on "Building Environment Design" (Heldenbrand 1991).

\subsection{Integrated Resource Planning and Utility Demand-Side Program Implementation}

There have been two inajor structural changes in the electric utility industry in the United States during the past decade. First, integrated resource planning (IRP) and demand-side management (DSM) programs often resulting from IRP processes have involved many utilities in programs on the customer side of the meter. Second, the introduction of competitive forces into the resource acquisition process has altered the relationship between utilities and decisions on supply choices. Both of these changes have major implications for emissions of greenhouse gases: the choice of fuel and technology for electricity supply affects emissions per unit of electricity consumed and the application of DSM/IPR processes affects the amount of electricity demanded.

We address IR? and DSM here, as we are concemed about eiectricity end-use efficiency in this report. We define and describe IRP, indicate the role that it has played in the United States to date, ieview the experience with utility DSM programs describe some of the complex factors that promote or inhibit more active roles of utilities in encouraging end-use efficiency, and speculate on the applicability of the U.S. utility experience with IRP and DSM to other regions of the world.

\subsubsection{Overview of IRP}

Integrated resource planning refers to a utility planning process that considers both supply-and demand-side resource options for meeting future customer energy service needs (Krause and Eto
1988). Under IRP, utilities must consider improvements to customer energy efficiency as resource options just as they currently consider traditional supply options. To appreciate the significance of these features of the IRP process, it is instructive to contrast them with the very different circumstances that were typical of utility planning activities until very recently.

The traditional planning process treats the demand forecast as fixed (albeit uncertain) and addresses the question of the least-cost way of creating utility-owned supply to meet the demand given reliability and other constraints on the system. Thus, environmental regulations, land acquisition requirements, likely construction delays, and numerous other factors are included in the planning process to the extent possible, but the major objective has been to meet demand at the lowest cost. The traditional planning process pays attention to demand in at least two ways: (1) the timing of demand influences decisions on the acquisition of peak, intermediate, and baseload power and (2) factors that drive up peak demand increase costs, and thus measures are to be implemented to reduce peak loads. Thus, the traditional processes did involve themselves in one type of demand-side activity: control of peak load.

IRP considers demand-side resources as equivalent to supply resources and allows for wider competition among different supply options, including generation facilities operated by non-utility firms. The utility is expected to purchase end-use efficiency rather than new supply if the cost of improved efficiency is lower than that of supply and if reliability is roughly equivalent. There are complications involved in applying this general principle. First, the comparison between supply and demand costs is not necessarily simple. Avoiding new supply means also avoiding environmental costs and reducing needs for transmission and distribution facilities. An additional kilowatt of demand 
requires more than a kilowatt of supply, as a reserve margin of 15 to 20 percent is needed to assure reliability. Second, demand-side resources are different in nature from supply. The utility typically does not own them, and acquiring them many be complicated and, at times, uncertain. Third, end-use efficiency does not deliver a product that can be sold in the traditional manner. Under traditional regulatory structures, utilities make money selling kilowatt hours to customers. IRP, particularly its demand-side component that aims at reducing sales of kilowatt hours, goes counter to these basic business objectives. ${ }^{1}$

Thus, the application of IRP raises complex issues. Indeed, IRP is by no means universally accepted by the U.S. utility industry, and within the industry, what is called IRP can vary greatly from utility to utility and state to state (Mitchell 1991). Because utilities in the United States are regulated at the state level, the specific regulatory environment and rules under which utility planning is carried out and electric rates are set has a very large impact on the nature and extent of IRP activities. IRP in the United States has resulted largely from regulations issued by these commissions directing utilities to modify their planning practices to accommodate IRP.

\subsubsection{Origins of IRP in the United States}

In many ways the evolution of IRP in the United States can be seen as the reconciliation of conflicts between utility interests (profits and reliability of service) and the broader public interest (achievement of lowest-cost electricity service). It is worth making explicit both the nature of this conflict and the ways in which it has been partially resolved.

1 Nearly 80 percent of U.S. electricity is sold by investor-owned (i.e., private) utilities that strive to earn profits for their investors.
Let us assume that measures that reduce electricity use are available at $\$ 0.02$ per kilowatt hour or $\$ 400$ per kilowatt. For example, water heater wraps for electric water heaters might cost this much, and the utility could discover that 40 percent of its customers do not have such wraps. From an overall perspective, society is better off if it pays $\$ 0.02$ for a saved kilowatt hour hy purchasing the wrap compared to an avoided supply cost in excess of this amount. However, for a variety of reasons (see Chapter 3 ) the consumer may not choose to buy such a wrap. The utility could (1) encourage the consumer to purchase the wrap (through an information campaign), (2) even more strongly encourage the purchase by visiting the house and identifying this and other opportunities for reducing waste of energy (energy audits), (3) go a step further and offer a rebate to the consumer who purchases and installs the wrap (financial incentive to consumer), (4) offer a rebate plus install or arrange installation for the customer, or (5) pay full cost of the measure and arrange installation.

Even the first of these approaches, providing information to consumers, is in conflict with the profit-making objectives of the utility. Providing literature to reduce electricity sales costs the utility money in designing, producing, and distributing this material and, more importantly, in reduced sales. Because the utility makes money on each kilowatt hour sold, reduced sales mean less profits.

Under these circumstances, one would not expect utilities to be very interested in supplying literature on electricity end-use efficiency (the first step described above), much less take more aggressive steps to acquire these resources. However, a series of events starting in the middle 1970 s and taking place throughout the 1980 s encouraged utilities to pay greater attention to DSM. Higher costs of new sources of eiectricity combined with increasing difficulties in siting and 
building new power plants meant an end to the period of declining costs and prices of electricity. Delays in power plant construction, particularly for nuclear plants, and the increasing severity of environmental regulations added to uncertainty in supply costs, and threatened to increase these costs significantly for some utilities. Regulatory hearings that assessed the prudence of utility expenditures in new power plant construction meant greater uncertainty about profits because a utility was not assured of earning full retums on investments in completed power plants. These factors made utilities more disposed to consideration of non-traditional supply-side options as well as initiation of DSM programs. At the same time, many policymakers and utility regulators became convinced of the importance of IRP and its DSM component.

At the federal level, the residential conservation service (RCS) program was created. This program, which applied to all investorowned utilities, required the utilities to audit residential buildings and to recommend weatherization measures that were cost-effective. The federal RCS program identified the list of measures to be considered. Many state regulators, taking a cue from Washington, D.C., also developed programs for utilities to implement. Some of these involved utility rebates for efficient products, others involved more extensive energy audit programs, and still others involved programs targeted to commercial buildings or industrial customers.

The response of the utility industry was far from uniform. While many utilities initiated impressive programs, a majority did very little; indeed, many continued to offer promotional rate incentives to increase sales. Often the approach taken by an individual utility depended on its individual supply-demand balance. Utilities with ample power reserves often did not create DSM programs. Even among the industry leaders there was little evidence that customer energy efficiency was considered a long-term resource alternative to new power supplies. The scale of these early programs, moreover, remained modest and contributed to the perception that these were marginal activities of much less importance than the utilities' primary business of building new power plants.

Examination of the reasons for utility indifference to the acquisition of lower-cost resource options on the customer's side of the meter led to the recognition that reducing sales through improved customer energy efficiency was rarely profitable. In other words, basic features of the current system of utility regulation created financial disincentives to utility participation in the acquisition of cost-effective customer energy efficiency.

\subsubsection{Current Status of IRP and DSM}

The extent of integrated resource planning by utilities can be measured in many ways. By the strictest of definitions, only 11 states have formal IRP regulations in place (Mitchell 1991); a looser definition would put the number of states engaged in some level of IRP at around 35. The national leaders include California, the Pacific Northwest, Wisconsin, New York, and most of the New England region.

Efforts to address the financial disincentives for utility DSM are closely linked but are often dealt with separately from formal IRP regulations. Currently, 12 states permit some form of program cost recovery between rate cases. Ten states have positive incentives for utility DSM activities (Edison Electric Institute 1990). Some 500 U.S. utilities are offering a combined total of 1400 DSM programs for their residential, commercial, and industrial customers (Blevins and Miller 1989a) Blevins and Miller 1989b).

Preliminary data collected by the U.S. Energy Information Administration 
conservatively estimate that utilities in the United States spent about $\$ 1$ billion on DSM in 1990 to reduce peak loads by nearly $18 \mathrm{GW} / \mathrm{yr}$ and save about $16 \mathrm{TWh} / \mathrm{yr}$ (Eto i991). Informal sources suggest that actual utility spending levels in 1990 were closer to $\$ 2$ billion, up from about $\$ 1.2$ billion in 1989 (EEI 1990).

The most aggressive utilities are currently spending 2 to 6 percent of operating revenues on DSM. (Typical spending levels for the most aggressive utilities in the early 1980 s were less than $1 \%$ of operating revenues.) These utilities expect DSM to reduce electricity use and peak demand by roughly 8 to 20 percent by the turn of the century (see Table 13). Moreover, these utilities expect DSM to provide a large fraction of their resource needs during the 1990s. A recent survey of 24 utility resource plans found that the surveyed utilities are planning to rely on DSM to meet 33 percent of new capacity needs and nearly 20 percent of new energy needs (Hill et al. 1991).

Recently in two regions of the United States-New England and Califormia-a series of developments that have come to be called "collaboratives" has led to an agreement among utilities and external parties (groups representing environmental and customer interests) on mechanisms for increasing DSM programs significantly and for permitzing utilities to receive greater profits for investments in DSM than for supply investments, as a means of encouraging utility involvement in DSM. This approach goes a great deal further than those typical of the 1980 s which attempted to minimize or eliminate costs to the utility stockholder of DSM programs.

The decision to allow utilities to gain larger than average profits for DSM activities has had dramatic effects to date. For example, the New England Electric System is investing 5 percent of total revenue in DSM, and expects to meet 40 percent of new load with conservation resources. Two utilities in California, Pacific Gas and Electric and Southern California Edison have recently announced plans to meet nearly $75 \%$ of their resource needs in the 1990s with DSM.

Table 13. DSM Program Expenditures and Savings Goals of Utilities Recognized as Leaders in Energy Efficiency in the United States

\begin{tabular}{|c|c|c|c|c|}
\hline \multirow[b]{2}{*}{ Utility } & \multirow[b]{2}{*}{$\begin{array}{c}1991 \\
\text { Expenditures } \\
\text { (million \$) }\end{array}$} & \multirow[b]{2}{*}{$\begin{array}{c}\text { Spending/ } \\
\text { Revenue } \\
(\%)\end{array}$} & \multicolumn{2}{|c|}{$\begin{array}{c}\text { Projected savings in } 2000 \\
\text { as a } \% \text { of demand } \\
\end{array}$} \\
\hline & & & $(G W h)$ & $(\mathbf{M W})$ \\
\hline Boston Edison & 40 & 3.3 & 7.4 & 10.5 \\
\hline Central Kaine Power & 28 & 4.1 & 2.2 & 11.8 \\
\hline New Eng ${ }_{1}$ ?nd Electric & 85 & 4.9 & 7.2 & 11.8 \\
\hline New York State E\&G & 25 & 1.9 & 9.2 & 14.5 \\
\hline Northeast Utilities & 75 & 3.3 & 11.3 & 11.5 \\
\hline Pacific Gas \& Electric & 154 & 1.7 & 7.8 & 10.9 \\
\hline Puget Sound P\&L & 35 & 3.7 & 9.4 & - \\
\hline Sacramento MUD & 42 & 6.4 & 17.7 & 19.2 \\
\hline Seattle City Light & 18 & 6.2 & 2.8 & - \\
\hline Southern California Edison & 108 & 1.4 & 17.6 & 16.7 \\
\hline Wisconsin Electric & 57 & 4.8 & 4.5 & - \\
\hline
\end{tabular}

Source: (Moskovitz et al. 1991) 
An important issue involves measurement of the impacts of DSM. Where the utility is rewarded by spending (ratepayer) money on DSM, it becomes important to establish what savings occur (Wiel 1990). For a variety of reason, evaluating the results of conservation programs is difficult and imprecise. First, it is often difficult to know what would have happened had the utility not undertaken its efforts. Second, variations in behavior can often mask the effects of conservation measures. Third, the overall effect of the DSM measures is often buried in the utility bill and cannot be separated from the bill. Fourth, some customers would have done what the utility did for them (the so-called "free-rider" effect), and it is difficult to estimate the magnitude of the effect. Some of the measures may simply not work as well as expected or intended. Thus, it is essential that utilities mounting large-scale DSM programs also develop and implement sophisticated measurement activities. This appears to be happening in the most extensive of the utility programs.

A second key issue involves cross subsidies that result from large-scale utility DSM programs. Even a program that lowers total resource costs for the service territory can (and often does) raise unit costs and prices of electricity. In this case the total "bill" to meet all demand declines, producing a net social benefit, but the price per kilowatt hour increases. Those who are not the direct beneficiaries of the utility programs pay more, thus subsidizing those who receive the DSM measures. In some cases they may pay less than they would pay if the utility had proceeded with more costly supply-side resource acquisition; in others, they pay more. To the extent that large-scale utility programs offer a broad array of DSM measures to all customers and customer classes, this problem is reduced. To date, the industrial customers have been particularly concerned about cross subsidies, either between customer classes (industrial, residential, and commercial) or within the industrial class (i.e., among different companies).

\subsubsection{Utility Demand-Side Management (DSM) Programs}

Utilities in the United States are offering many types of DSM programs. The discussion below describes the principal program types and discusses their impacts and cost effectiveness, based on Nadel (1991).

Audit Programs. U.S. utilities were required to offer households energy audits at a nominal cost during the 1980s. Six years after the program began, approximately $7 \%$ of eligible households received audits and savings averaged only $3-5 \%$ per participant. Higher levels of participation and savings resulted if utilities conducted extensive marketing, assisted with installation of conservation measures, and provided financial incentives. Audit programs for commercial and industrial customers also tend to result in limited participation and savings, but at a cost to the utility of less than $\$ 0.02 / \mathrm{kWh}$. Participation and savings can be increased with extensive marketing via personal contacts and by providing financial incentives to implement audit recommendations.

Rebate Programs. In a rebate program, the utility pays an incentive to customers who purchase specific products (e.g., efficient lamps or light fixtures) or equipment above a threshold efficiency level (e.g., high-efficiency air conditioners). Rebate programs cost utilities $\$ 0.01-0.03 / \mathrm{kWh}$ saved on average, but they generally reach a minority of customers and have not been very effective at promoting improvements involving more complex systems or processes. Both incentive level and degree of marketing and promotion affect the participation rate (see Table 14). 
Loan Programs. Utilities can finance major efficiency improvements by their customers, with the loan repaid through the traditional utility billing system. The loan can be subsidized or based on the utility's cost of capital. Experience in the United States has shown that consumers generally prefer rebates over low-interest loans.

Performance Contracting. In performance contracting, energy service companies (ESCOs) usually provide services to customers. The utility pays the ESCO based on the amount of electricity saved. In some cases, projects are solicited through competitive bidding. Performance contracting can be useful for customers who lack capital for efficiency improvements, but the utility's cost of saved energy tends to be higher than for rebate programs.

Direct Installation. If the utility arranges and pays for the installation of efficiency measures, high penetration rates and savings per customer can be realized. However, the cost to the utility (although not necessarily to society) is higher than for other types of programs. This approach is most suitable for customers that do not respond to other types of programs, such as low-income households and small business.
Comprehensive Programs. Comprehensive programs combine audits with financial incentives, technical assistance, and possibly even arranging installation. High participation and savings can result-some utilities have achieved participation rates in excess of $50 \%$ and electricity savings of $10-25 \%$ per participant for commercial and industrial sector programs. The utility's cost is typically $\$ 0.02-0.04 / \mathrm{kWh}$ saved. A number of broad lessons can be drawn from the wealth of experience with utility DSM programs in the United States.

- Different program approaches fill different niches. A utility must offer different programs to different market segments if it wants to realize a high level of overall savings.

- Marketing strategies and technical support have a large impact on program participation and savings. Personal one-on-one and community-based marketing strategies can be particularly effective. Equipment dealers, contractors, and design professionals can be important allies in promoting programs.

\section{Table 14. Results from New York State Electric and Gas Corporation's Pilot Refrigerator Rebate Program}

\begin{tabular}{|c|c|c|}
\hline \multirow[b]{2}{*}{ Treatment group } & \multicolumn{2}{|c|}{$\begin{array}{c}\text { Market share of efficient refrigerators } 1 \\
(\%)\end{array}$} \\
\hline & Pre-program & Program \\
\hline Control area & 4.7 & 14.7 \\
\hline Information and advertising area & 2.1 & 34.8 \\
\hline Information/advertising plus $\$ 35$ rebate area & 5.0 & 48.6 \\
\hline Information/advertising plus $\$ 50$ rebate area & 8.8 & 59.7 \\
\hline
\end{tabular}

${ }^{1}$ Fraction of all refrigerators sold meeting efficiency criteria.

Source: Kreitler and Davis 1987 
- Thorough program evaluation-carefully documenting program savings and cost effectiveness-is essential for gauging impacts as well as improving program performance. Not all conservation measures perform as well as initially expected.

- Programs that combine information, financial incentives, and technical assistance yield the greatest levels of participation and savings.

- Utilities can save electricity through DSM programs at a much lower cost than supplying electricity through building new power plants. Limited experience in Europe and Brazil confirms this finding.

- Utility DSM programs can only achieve a portion of the cost-effective electricity savings potential. Building codes, equipment efficiency standards, and other policies are important complements to utility DSM programs. In California, for example, standards provided about $43 \%$ and utility programs 54\% of total savings as of 1987 (CEC 1990).

\subsubsection{Significance of These Developments}

From the experience of the past ten or fifteen years, it appears that utilities could reduce electricity growth by one-half to one per cent per year through DSM programs. With a two percent baseline growth rate, this corresponds to reductions of 25 to 50 percent of demand growth. Utilities in those states where increased profits are offered have generated large programs. It is worth restating that the two large investor-owned utilities in Califomia are expecting 75 percent of their growth to be met by DSM over the next decade and the New England Electric System anticipates 40 percent of growth to be met by DSM over a longer period of time.

There is as yet only limited experience with this new phase of utility IRP and DSM, which involves increased profits and much larger-scale programs. It is too early to know whether the large-scale DSM programs will be able to meet all or most of their goals. It may take some years to sort out the programs that are most effective. It is clear, however, that changes in utility incentives in the United States have had a major impact on the involvement of utilities in DSM programs, the comparison between these programs and investments in supply options, and the implementation of the programs.

What is the relevance of the U.S. experience to the rest of the world? In one way it is enormously relevant. The decade of the 1980 s has demonstrated that utilities have the ability to deliver a large variety of DSM programs - such as improved residential insulation, more efficient lighting systems, water heater wraps, improved energy designs for commercial buildings, more efficient appliances, and advice on changes in behavior and operation and maintenance of equipment - in an effective and generally costeffective manner. The new developments in the 1990s suggest, but do not yet demonstrate, that given the right incentives utilities can deliver incse electricity efficiency improvements on a very large scale. If this turns out to be the case, then these types of programs, appropriately modified for the many different circumstances in different countries, can be a key mechanism for increasing electricity end-use efficiency, thereby cutting carbon dioxide emissions.

A major difference between the United States and most of the rest of the world concerns the business environment of the utility. In the U.S., as noted, 80 percent of electricity comes from regulated private utilities. The crucial element in causing utilities to become deeply involved in DSM has been the regulatory agency. However, most countries have nationalized utilities and it is not clear how DSM and IRP would work with a state-owned utility. It can be argued that stateowned utilities could more easily justify large- 
scale DSM on the grounds that such programs serve the public interest. The programs can thus be justified on the basis of a positive social benefit/cost ratio in the same way that other national policies are justified. On the other hand, experience in the United States has shown that some public entities providing electricity (municipal utilities, for example) have shown the least interest in providing energy efficiency to the customer.

\subsection{Private Sector Delivery of DSM Programs: The Role of Energy Service Companies}

The original concept of energy services had vendors selling the products of applied energy such as hot water, chilled air, and mechanical drive, instead of selling energy forms such as kilowatt hours of electricity, as utilities do. While this "pure" concept was rarely marketed, an industry of energy service companies (ESCOs) developed in the United States. "Shared savings" or "energy performance contracting" transactions are offered by ESCOs to overcome a number of market and institutional barriers to direct customer investment in improved end-use efficiency. ESCOs typically market an integrated service that provides three capabilities that energy users often don't have. First, ESCOs provide engineering and managerial expertise which helps customers to assess and implement optimal energy efficiency improvements. Secondly, ESCOs assume significant technical, financial, and operational risks since they usually receive a fee that is proportioned to the savings achieved over long periods of time. If there are no savings, there is no payment, and most ESCOs are willing to guarantee certain levels of savings. Finally, ESCOs often arrange project financing.

In the early 1980s, performance contracts were heavily tax-advantaged transactions, and there were a number of ESCOs that were in business to receive tax benefits, not to provide energy services. In that era, some ESCOs had a reputation of inadequate experience, qualification, and resources. With the demise of federal tax benefits in 1986, there was a shake-out in the industry. Government agencies were the primary targets of ESCO market development at that time, which resulted in the development of public sector performance contracting procurement guides. There were some analyses of institutionalizing ESCO services through utilities and public corporations. However, it was not until the development of utility competitive bidding programs that ESCOs gained systematic access to utility demand-side management (DSM) markets (Cole et al. 1988).

One of the tenets of least-cost planning is that all energy resources are evaluated on a "level playing field," i.e., no particular resource has an inherent advantage over another (Hirst et al. 1990). One of the approaches that has evolved to implement this strategy is the acquisition of new resources through competitive bidding, including DSM bidding (Cavanagh 1988). This development is significant because almost all performance contracting in utility DSM programs has been undertaken by ESCOs participating in DSM bidding programs. DSM bidding is an auction in which a utility solicits proposals from ESCOs to provide specified amounts of DSM savings in its service territory (e.g., $1000 \mathrm{~kW}$ of demand reduction) (Goldman and Wolcott 1990) (Wolcoit 1990). The proposals are evaluated and selected competitively in terms of criteria such as price, ESCO experience, and reliability of DSM savings. The utility then pays the price bid (e.g., $\$ 500 / \mathrm{kW}$ ) for DSM savings that are estimated or measured. If the bidder fails to deliver the promised amount of DSM savings on time (typically within two to three years), it forfeits a security deposit it has posted.

In terms of regulatory policy, DSM bidding has developed as either a stand-alone program or in conjunction with supply-side bidding for 
independent power resources in integrated competitive bidding auctions. Ten utilities have established ESCO subsidiaries to pursue unregulated business opportunities in the DSM market, a development that has raised concerns about utility "self-dealing:" a parent utility giving preferential treatment in a DSM bidding competition to its own subsidiary (Wolcott 1991). As of mid-1991, 14 utilities had implemented DSM bidding programs in the United States through which roughly $250 \mathrm{MW}$ of DSM has been contracted with ESCOs (Goldman and Busch 1991).

These bidding programs must be carefully structured to avoid producing socially inefficient outcomes. If the sum of payments made to ESCOs and the reductio: in electricity bills resulting from implementation of a conservation project exceeds the cost of the least-cost supplyside option (although the payment to the ESCO alone is lower than the cost of new supply), an ESCO may be able to outbid a supply-side option in a pooriy structured program.

\section{Significance of ESCOs to Electricity End-Use Efficiency}

The ESCO represents a way of tapping into the market for efficiency projects. It is in many ways the demand-side counterpart to the independent power producers, who represent a method of privatizing the power supply business. ESCOs fit particularly well in an environment in which utilities are pursuing IRP and DSM programs. Participation of ESCOs in utility demand-side programs in the United States is expected to increase significantly, leading over the next few years to contracts for several hundreds of MW of DSM per year.

Just as it is too early to know the lessons of very large-scale DSM program implementation, so is the evolution of the ESCOs in too early a stage to draw conclusions about their overall efficacy in delivering DSM. Nonetheless,
ESCOs may be a very valuable model for other nations, including developing nations. They represent a means of strengthening the private sector involvement in DSM. The adoption of the concept of ESCOs into developing nations could serve as an innovative vehicle for establishing expertise in DSM activities. It could also serve as a flexible collaboration with utilities when DSM implementation is pursued. However, experience in the United States has shown that very strong commitments to DSM by the utility is needed (including DSM bidding programs) for ESCOs involved in DSM programs to thrive.

\subsection{Research and Development}

The previous discussion focused on policies and programs to promote electric end-use efficiency that are currently being implemented and that are based on existing or soon-to-be commercialized technologies. To continue to make efficiency improvements worldwide, an essential policy is support of research and development (R\&D) efforts.

In the industrialized countries end-use efficiency R\&D occurs in both the public and the private sectors. In the United States, the R\&D on electric end-use technologies is carried out by the Department of Energy in the public sector and by the Electric Power Research Institute (EPRI) in the private sector. Some U.S. utiiities and status are also involved in this type of R\&D. For example, the Association of State Energy Research and Technology Transfer Institutions (ASERTTI) has recently been formed to enhance energy research and technology transfer on a state, regional, and interstate basis.

On-going U.S. Department of Energy (DOE) electric end-use efficiency $R \& D$ programs include contributing to the development of advanced refrigeration systems, alternatives to chlorofluorocarbons for use in refrigeration, light sources with operating efficiencies of up to 200 lumens per watt, improved electrolytic reduction 
processes, and development of automatic sensors and controls for industrial processes (DOE 1988).

Recent successes from U.S. DOE R\&D efforts in the buildings sector include development of high-efficiency compressors for residential refrigerators that are $44 \%$ more efficient than conventional compressors, supermarket refrigeration systems with multiple parallel compressors and advanced microprocessor controls that reduce energy consumption by $40 \%$, "super" windows that behave thermally as well as insulated walls in many locations, and electronic ballasts that improve fluorescent lighting efficiency by $25 \%$ (DOE 1990).

Products being developed by the Electric Power Research Institute (EPRI) include advanced heat pumps, heat and cool storage technologies, new techniques for monitoring and controlling electric loads, novel industrial electrotechnologies, and advanced techniques for modeling and predicting electricity use and customer behavior (EPRI 1989). U.S. utilities are also conducting research on heat pumps, program design and implementation, and load management.

In other industrialized countries, electric enduse efficiency $R \& D$ is performed by national governments and private industries. Heat pump R\&D illustrates the variety of efforts worldwide. For example, in Austria and Sweden R\&D programs have focused on adapting existing electrically-driven heat pump technology to a variety of heat sources, thus increasing the range of feasible applications. In Japan research is devoted to increasing the efficiency of the heat transfer between the working fluids of the heat pumps and adding chemical heat storage to increase overall operation efficiency. New heat pump compressors are being designed in the Netherlands and Sweden; R\&D efforts are focused on redesigning heat pumps to raise the output heat temperature, such as for steam generation (IEA 1989).

One area of research which has attracted little attention but is essential to addressing global electric end-use efficiency is adapting technology for use in developing countries. Because the power systems in developing countries are often unstable in various ways, efforts are often needed to permit new, efficient technologies to function well and reliably in these different environments.

\subsection{ELECTRICITY CONSERVATION PROGRAMS AND POLICIES IN DEVELOPING COUNTRIES}

\subsection{Overview}

The concept of electricity conservation is a new one for developing countries. The primary emphasis in the developing world is on new electricity supply, not conservation. This is not surprising when one considers that the per capita use of electricity is only $500 \mathrm{kWh}$ in developing countries, compared with more than $5000 \mathrm{kWh}$ for Western Europe and 10,000 for the United States (Levine et al. 1991). However, it is becoming increasingly ciear to analysts and officials in developing countries that a need for additional power and significant increases in efficiency of production, transmission, and use of electricity are compatible with each other (Goldemberg 1988). Growth in electricity consumption is especially a problem for developing nations because of the enormous capital requirements of power generation. Many developing countries currently spend more than 20 percent of the total public investment on power (Munasinghe 1990). With electricity demand growing twice as fast as GDP during the past two decades (as noted in Chapter 1), the power sector's need for capital simply cannot be met (AID 1988).

Like the industrialized countries, developing nations interested in energy efficiency initiated 
programs to reduce growth in consumption of oil and other fossil fuels long before addressing electricity conservation. For example, China was one of the first developing nations to institute wide-ranging energy conservation investments throughout the economy, beginning in eamest in 1981. However, the Chinese have not as yet begun a program to use electricity efficiently (Levine and Liu 1990). Similarly, Tunisia initiated active energy conservation programs as early as 1985 , and have continued to pursue them; however, few of Tunisia's programs encourage increases in end-use electricity efficiency (Philips 1990a).

Brazil and Pakistan were among the first to focus on electricity use. Pakistan initiated efforts partly in response to a program by the U.S. Agency for International Development (U.S. AID). Brazil began the programs on their own initiative, with little financial or technical assistance from outside. More recently, Costa Rica has become interested in establishing its electricity system, defined not only as generation, transmission, and distribution, but also as electricity end-use, as a model for other nations of improvements in economic and technical efficiency. Mexico has also become interested in electricity conservation in recent years. The Mexican electric utility, Comisión Federal de Electricidad (CFE), has created a program to promote end-use efficiency in the electricity sector. The program, titled Programa de Ahorro de Energía del Sector Eléctrico (PAESE), obtains financing through a 0.2 percent fee on all CFE investments. This amuunts to a PAESE budget of about $\$ 7$ million (U.S.) per year (Rodriguez 1991). A recent, and exciting, development has taken place in Thailand. The government has decided to initiate a large-scale utility DSM program, and has committed funds for the program over the next five years (du Pont 1991).
We review the programs in Brazil and Pakistan below, and also describe the recent developments in Thailand.

\subsection{Brazil}

Consumption of electricity in Brazil increased dramatically from about $38 \mathrm{TWh}$ in 1970 to 203 TWh in 1988 and recent official forecasts projected it to nearly double between 1988 and 2000 . To meet this demand, the nation's utilities invested about $\$ 75$ billion on new generation, transmission, and distribution facilities from 1970 to $1^{\prime}, 87$ and now find themselves with high debt service requirements and insufficient revenues to meet the projected demand for about 37,000 MW by 2000 that would cost another $\$ 75$ billion (Geller 1991).

The problem was already apparent by late 1985, when the federal government of Brazil established the Programa Nacional de Conservação de Energia Eléctrica (PROCEL), a national electricity conservation program based at the federally-owned utility, Electrobás. PROCEL promotes electric efficiency through technology $R \& D$, demonstrations, education and promotion, direct installation of conservation measures, development of standards and legislation, incentives, and joint projects with utilities and other organizations. (Geller 1991)

By early 1990 , PROCEL had dedicated $\$ 20$ million to more than 150 electric efficiency programs. Of this, about $\$ 7$ million was spent on technology R\&D and $\$ 13$ million on education, promotion, and dissemination of information. Those organizations conducting projects contributed a similar amount. Numerous electricity-conserving technologies entered the marketplace since the program began. It is estimated that, as of 1989 , the programs sponsored by PROCEL, saved between 1,070 to $2,500 \mathrm{GWh} / \mathrm{year}$, nuully from the use of more efficient refrigerators and lamps and from 
education and promotion programs. These savings translate to utility savings of \$0.6-1.3 billion, or the power provided by $280-650 \mathrm{MW}$ of installed capacity (Geller 1991).

An example of PROCEL's success is the public illumination program that has promoted the substitution of efficient mercury vapor and highpressure sodium lamps for the existing inefficient incandescent lamps. In the past, Brazilian municipalities installed some less efficient incandescent lamps for public street lights because of low electricity tariffs. Utilities, however, recover less than half the cost of providing electricity for street lighting. Thus, utilities have a strong incentive to promote and finance efficiency improvements in this area. As a result of utility programs, incandescent lamps declined from 26 percent to only 1 percent of the street lighting lamps in São Paulo State between 1981 and 1988 and street lighting electricity consumption in Brazil dropped from 4.0 percent of total electricity consumption in 1983 to 3.3 percent in 1988, despite increasing number of street lamps (Geller 1991). PROCEL has a goal of replacing all incandescent street lights in Brazil by the mid-1990s.

There have also been successful programs to improve electricity consumption in commercial buildings in Brazil. Examples include a large department store chain that has lowered ts average electricity consumption by 10 percunt since 1986 through installation of fluorescent lamps and fixtures, daylighting, thermal storage systems and air curtains; a large supermarket chain with over 600 stores that reduced the average electricity consumption per store by 35 percent between 1980 and 1988; and a São Paulo shopping center that, turough use of natural lighting and forced ventilarion, uses ij percent less power per unit of floor area than other large shopping centers in the state. Brazil's first national electricity conservation award went to Banco Itaú for its program that resulted in an average savings of 25 to 30 percent in its administrative centers and in 200 branch offices. Further improvements will be realized following the on-going installation of fluorescent fixtures and CFLs (Geller 1991).

Significant future electricity savings are expected from PROCEL programs. Savings targets established by Eletrobás indicate savings of $16.8 \mathrm{TWh}$, or 5.6 percent, of projected demand in 1995 growing to $88.1 \mathrm{TWh}$, or 14.2 percent, of projected demand in 2010. Funding for PROCEL is expected to grow, especially if a World Bank loan which has $\$ 35$ million earmarked for PROCEL is disbursed. Although approved in 1990, the loan has been delayed because of disagreements about tariff levels. The major issue regarding the continued activities and success of PROCEL is probably the level of commitment of the utilities of Brazil to the program. PROCEL has resulted from the efforts of a small number of Brazilians, who became convinced of its necessity in light of the high cost of meeting projected demand for electricity. The program appears to be institutionalized in Brazil, after six years of activity, and support is likely to continue. The key question is how much financial and political support it will receive.

\subsection{Pakistan}

Pakistan established the National Energy Conservation Centre (ENERCON) in 1986. With approximately $\$ 10$ million in technical assistance from U.S. AID, ENERCON developed and implemented programs in all economic sectors: industry, buildings, transport, and agriculture. In the industrial sector, audits that focused on lowcost measures were carried out . They identified and implemented measures to save 4 percent of electricity use witt an average payback of 6 months in 49 industrial plants. A power factor correction program was implemented in five industrial plants. It resulted in an increase in the power factor from 0.65 to 0.85 , and had an 


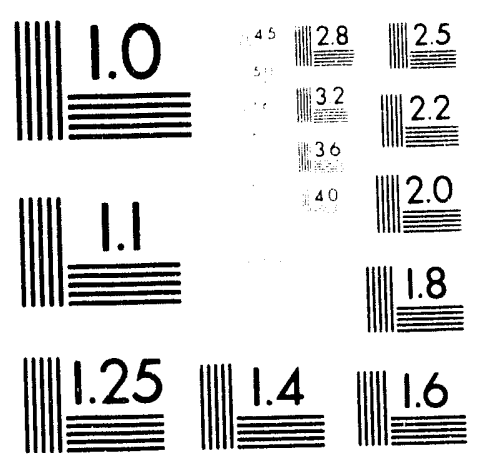



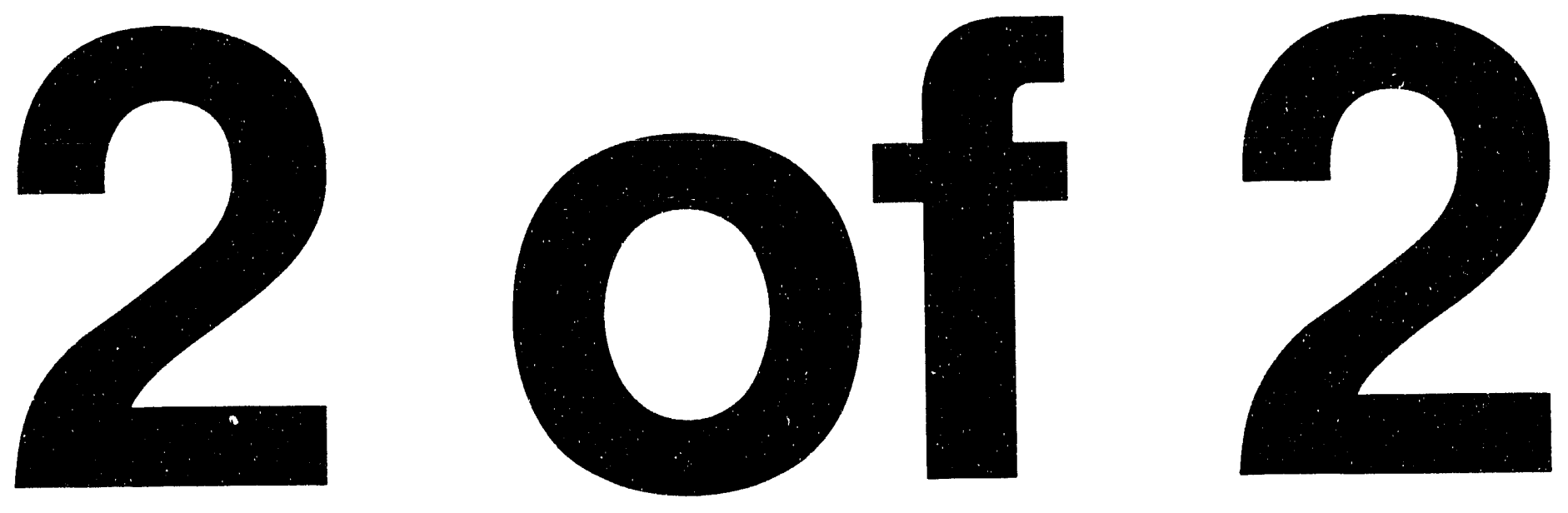
average payback of one year. Based on this pilot program, ENERCON has received a $\$ 5$ million loan from the Asian Development Bank to implement the program on a nationwide basis (Armstrong 1991).

ENERCON developed a building energy code that is estimated to reduce energy consumption by 30 percent. For commercial buildings, much of the savings will be electricity. The code has been issued for voluntary compliance as part of Pakistan's National Building Code. ENERCON has audited a number of large buildings. The audit of the 1 million square foot Aga Khan hospital in Karachi initially identified 15 percent energy savings. After carrying out a program over four years, the hospital actually reduced energy use (mostly electricity) by 20 percent. The largest savings measure was the replacement of recessed incandescent spot lights with compact fluorescent lamps.

In the agricultural sector, ENERCON developed and implemented procedures for auditing and retrofitting agricultural pumps (known as tubewells). Tubewells are the largest single end-use of electricity in Pakistan, accounting for approximately 20 percent of total electricity consumption. Forty four tubewell retrofits were conducted on a pilot basis Average savings was 29 percent, cost was less than $\$ 10$, and payback from the utility perspective (i.e., using the cost rather than selling price of electricity) was 3 months (Alanddin 1991) (Armstrong 1991).

\subsection{Thailand}

Thailand has been interested in energy and electricity conservation for a number of years. One example of this is the Thai government program that rebates up to 50 percent of the import duty for equipment that will save energy with a payback of 2 to 5 years (Philips 1990b). Another example is the development of an energy standard for new commercial buildings, which has been carried out as part of a project throughout the Association of Southeast Asian Nations (Levine 1988). These standards are expected to be implemented by several of ASEAN countries over the next several years, including Thailand.

On November 12, 1991, the National Energy Policy Committee approved a DSM plan, to be implemented by the three Thai utilities (Electric Generating Authority of Thailand, Provincial Electricity Authority, and Metropolitan Electricity Authority) working together, that will replace the need for $225 \mathrm{MW}$ of new capacity, or 5 percent of planned capacity additions over the next 5 years. This program, which has a budget of $\$ 183$ million, will be carried out over five years. The first two years will be pilot activity and the last three will be full-scale programs (Chemiack and du Pont 1991). This funding represents more thin 2 percent of utility revenues in Thailand for the third through fifth years of the program, a percentage of revenues devoted to DSM programs that is comparable to U.S. utilities that are deeply involved in DSM.

A detailed plan has been developed for the implementation of the DSM program (Cherniack and du Pont 1991). The plan allocates about 40 percent of the effort to industrial plants, 30 percent to commercial buildings, and 27 percent to residential buildings. DSM measures expected to be implemented include air conditioning and fan efficiency retrofits, encrgy-efficient designs for new commercial buildings, lighting efficiency retrofits in commercial buildings, installation of efficient motors, certification and testing of energy performance of residential appliances combined with financial incentives to manufacturers of appliances for them to upgrade appliance energy efficiency.

It is apparent that the Thai utility DSM program is strongly influenced by similar U.S. 
programs discussed above. It is of great interest that Thailand is planning to initiate a full-scale program, after just two years of pilot activity. This is an important experiment to observe, both to evaluate the applicability of the U.S.-type DSM programs to advanced developing countries (and the changes in the program that will probably be necessary for it to succeed) as well as the degree to which a national utility in a developing country can succeed in carrying out large-scale DSM.

\subsection{CONCLUSIONS}

This chapter has described programs and policies to effect end-use electricity efficiency. It is clear that these activities have had important impacts, especially in the United States. The appliance standards have resulted in large savings. The utility IRP and DSM programs have gained in importance over time, and the new developments of increasing profits to utilities who pursue such programs may expand them considerably. Commercial building standards programs have reduced electricity consumption in new buildings in the United States and other nations. New, innovative programs such as those providing financial incentives for the production of more efficient appliances hold considerable promise.

Many of these programs have spread beyond the United States. Western Europe is embarking on a variety of ventures. Increased interest in developing countries is evident. While the experience with these programs is relatively recent, they offer important ways of bringing highly efficient end-use technologies to market throughout the world. 


\section{REFERENCES}

ACEEE, American Council for an EnergyEfficient Economy. 1991. The Golden Carrot News. ACEEE. October 1991.

AID, U.S. 1988. Power Shortages in Developing Countries: Magnitude, Impacts, Solutions, and the Role of the Private Sector. U.S. Agency for International Development. March 1988.

Alanddin, Aris. 1991. 1990 Report on Pakistan Tuberwell Energy Audit and Retrofit Program.

Armstrong, J. 1991. Personal Communication. November 261991.

Blevins, R.P. and B.A. Miller. 1989a. 1987 Survey of Commercial-Sector DemandSide Management Programs. Palo Alto, CA: Electric Power Research Institute. EPRI CU-6294. 1989.

Blevins, R.P. and B.A. Miller. 1989b. 1988 Survey of Residential-Sector DemandSide Management Programs. Palo Alto, CA: Electric Power Research Institute. EPRI CU-6546. 1989.

Carpentier, G. and J. Uyttenbroeck. 1975. Comparison of Thermal Regulations in the Member Countries of the EEC. CSTC - Brussels. December 1975.

Carpentier, G. and J. Uyttenbroeck. 1980. Thermal Insulation and Ventilation in Buildings. CSTC - Brussels. 1980.

Cavanagh, R. 1988. The Role of Conservation Resources in Competitive Bidding Systems for Electricity Supply. Testimony Before the U.S. House of Representatives, Energy and Commerce Committee.
CEC. 1990. Electricity Report. California Energy Commission. P106-90-022. October 1990.

Cherniack, M. J. and P. du Pont. 1991. Demand Side Management for Thailand's Electric Power System. International Institute for Energy Conservation: Five-Year Master Plan. November 1991.

Ching, Wong Wai. 1984. "Energy Conservation in Buildings in Singapore." In Proceedings of the ASEAN Conference on Energy Conservation in Buildings.

Cole, W.J., M.J. Weedall and D.R. Wolcott. 1988. "Competitive Bidding of DemandSide Management." Presented at 1988 ACEEE Summer Study cn Energy Efficiency in Buildings Washington, DC: American Council for an Energy-Efficient Economy.

Consultative Forum. 1991. Non-Residential Building Energy Standards for Victoria's Energy Efficiency Strategy. Consultative Forum. October 1991.

Cooper, R. Caron and Lee Schipper. 1991. "The Soviet Energy Conservation Dilemma." Energy Policy.

du Pont, P. 1991. Personal Communication. November 121991.

Economic Commission for Europe. 1984. Survey of Regulations, Codes and Standards Related to Energy Use in Buildings. Economic Commission for Europe, United Nations, New York. 1984.

EEI, Edison Electric Institute. 1990. State Regulatory Developments in Integrated Resource Planning. Edison Electric Institute. September 1990. 
EPRI, Electric Power Research Institute. 1989. Research and Development Program 1989-1991. EPRI. January 1989.

Eto, Joe. 1991. Personal Communication with the U.S. Energy Information Administration.

Geller, H.S. 1991. Efficient Electricity Use: A Development Strategy for Brazil. Washington, DC and Berkeley, CA: American Council for an Energy-Efficient Economy.

Geller, Howard S. and Steven M. Nadel. 1989. "Electricity Conservation Potential vs. Achievement." Presented at NARUC Least-Cost Utility Planning in Charleston, SC.

Goldemberg, J., Johansson, T.B., Reddy, A.K.N., Williams, R.H. 1988. Energy for a Sustainable World. New Delhi: Wiley Eastern Limited.

Goldman, C.A. and J.F. Busch. 1991. "Review of Utility Experience with Demand-Side Bidding Programs." Presented at Fifth National Demand-Side Management Conference. Palo Alto, CA: EPRI.

Goldman, C.A. and D.R. Wolcott. 1990. "Demand-Side Bidding: Assessing Current Experience." Presented at 1990 ACEEE Summer Study on Energy Efficiency in Buildings. Washington, DC: American Council for an EnergyEfficient Economy.

Heldenbrand, Jim. 1991. Personal Communication: "Correspondence with Jim Heldenbrand, Manager of Standards, ASHRAE." November 12, 1991.

Hendrickson, P. 1988. "Home Energy Rating Systems: Information to Increase Efficiency." Home Energy. Nov./Dec. 1988. p. 22.
Hill, Lawrence J. 1987. Energy Price Reform in Developing Countries: Issues and Options. Oak Ridge, TN: Oak Ridge National Laboratory. ORNL-6391. August 1987.

Hill, Lawrence J. 1991. Personal Communication. November 1991.

Hill, Lawrence J. forthcoming. Energy, Economic Reform, and Capital Requirements in the Commonwealth of Independent States and Eastern Europe: Challenges and Opportunities. Oak Ridge, TN: Oak Ridge National Laboratory. ORNL-6680. Forthcoming.

Hill, Lawrence J., Eric Hirst and Martin Schweitzer. 1991. Integrating DemandSide Management Programs into the Resource Plans of U.S. Electric Utilities. Oak Ridge, TN: Oak Ridge National Laboratory, ORNL/CON-311. January 1991.

Hill, Lawrence J., E. Hearst and M. Schweitzer. 1991. Integrating Demand-Side Management Programs into the Resource Plans of U.S. Electric Utilities. Oak Ridge, TN: Oak Ridge National Laboratory. ORNL/CON-311. January.

Hirst, E. 1991. Possible Effects of Electric Utility DSM Programs, 1990 to 2010. Oak Ridge, TN: Oak Ridge National Laboratory. ORNL/CON-312. January 1991.

Hirst, E., M. Schweitzer and E. Yourstone. 1990. Key Issues in Electric Utility Integrated Resource Planning. Oak Ridge National Laboratory.

IEA, International Energy Agency. 1989. Electricity End-Use Efficiency. Faris: OECD. 
Kosmo, M. 1987. Money to Burn? The High Costs of Energy Subsidies. Washington, DC: World Resources Institute.

Krause, Florentin and Joseph Eto. 1988. LeastCost Utility Planning: A Handbook for Public Utility Commissioners (v.2): The Demand Side: Conceptual and Methodological Issues. Washington, DC: National Association of Regulatory Utility Commissioners. December 1988.

Kreitler, V.L. and T.D. Davis. 1987. HighEfficiency Refrigerator Pilot Rebate Program-Final Analysis Report. Binghampton, NY: New York State Electric and Gas Corporation. November 1987.

Kvetny, Michael. 1991. Personal Communication: "Correspondence with Michael Kvetny, COWIconsult." November 14, 1991.

L'Ecuyer, Mike. 1991. Personal Communication.

Levine, M. D. 1988. ASEAN Buildings Energy Conservation Program. Berkeley, CA: Lawrence Berkeley Laboratory. LBL26759. March 1988.

Levine, Mark D., Ashok Gadgil, Steven Meyers, Jayant Sathaye, Jack Stafurik and Tom Wilbanks. 1991. Energy Efficiency, Developing Nations, and Eastern Europe: A Report to the U.S. Working Group on Global Energy Efficiency. Washington, DC: International Institute for Energy Conservation. June 1991.

Levine, Mark D. and Xueyi Liu. 1990. Energy Conservation Programs in the Peoples Republic of China. Berkeley, CA: Lawrence Berkeley Laboratory. LBL29211. August 1990.
McMahon, J. 1990. Memo to file re: Hans Westling. "Innovative Procurement" Sweden. July $25-26,1990$.

McMahon, J. 1991. Personal Communication. November 5, 1991.

McMahon, James E., Douglas Berman, Peter Chan, Terry Chan, Jonathan Koomey, Mark D. Levine and Steve Stoft. 1990. "Impacts of U.S. Appliance Energy Performance Standards on Consumers, Manufacturers, Electric Utilities, and the Environment." In Proceedings of the 1990 ACEEE Summer Study on Energy Efficiency in Buildings. Washington, DC: American Council for an Energy Efficient Economy.

Mills, Evan. 1991. "Evaluation of European Lighting Programs: Utilities Finance Energy Efficiency." Energy Policy. vol. 19, no. 3. p. 266.

Mills, Evan, forthcoming. "Using Financial Incentives to promote Compact Fluorescent Lamps in Europe: Market Impacts and Consumer Response in 10 Countries." Energy-The International Journal.

Mills, Evan, (ed.). "Proceedings of the 1st European Conference on EnergyEfficient Lighting". Presented at $1 s t$ European Conference on EnergyEfficient Lighting in Stockholm, Sweden. Stockholm: Swedish National Board for Industrial and Technical Development.

Mills, Evan. 1990. Memo to Art Rosenfeld. August 20, 1990.

Mitchell, Cynthia. 1991. Personal Communication: "1991 IRP Śurvey Update." 
Moskovitz, S. Nadel and H. Geller. 1991. Increasing the Efficiency of Electricity Use: Barriers and Strategies. Washington, DC: American Council for an Energy-Efficient Economy. November 1991.

Munasinghe, M. 1990. Electric Power Economics. London: Butterworths.

Nadel, S. 1991. "Electric Utility Conservation Programs: A Review of the Lessons Taught by a Decade of Program Experience." In State of the Art of Energy Efficiency: Future Directions. Edited by E. Vine and D. Crawley. Washington, DC: American Council for an Energy-Efficient Economy.

NAECA. 1987. National Appliance Energy Conservation Act of 1987.

NEPCA. 1978. National Energy Policy Conservation Act of 1978.

NRDC and PG\&E. 1990. "Energy Efficiency in the National Energy Strategy: NRDC and PG\&E Find Common Ground." The Electricity Journal. Vol. 3, No. 8.

OECD, Organization of Economic Cooperation and Development. 1991. Energy Statistics of OECD Countries. Paris: OECD. 1991.

OTA, Office of Technology Assessment. 1991. Changing by Degrees: Steps to Reduce Greenhuuse Gases. OTA-O-482 Washington, DC: U.S. Government Printing Office.

Philips, M. 1990a. Energy Conservation Activities in Africa and Europe. International Institute for Energy Conservation. September 1990.
Philips, Michael. 1990b. Energy Conservation Activities in Asia. International Institute for Energy Conservation.

Rodriguez, I. 1991. Personal Communication. November 261991.

Singapore Public Works Department. 1982. Handbook on Energy Conservation in Buildings and Building Services. Development and Building Control Division, Public Works Department, Singapore. 1982.

State Electricity Commission of Vicioria. 1991. Review of Potential Standards and Consultative Processes. August 1991.

Thomas, P.C., Bhaskar Natarajan and S. Anand. 1990/91. "Energy Conservation Guidelines for Government Office Buildings in New Delhi." Energy and Buildings. Vol. 15-16.

Trines, R.L.C.J. 1991. Personal Communication: "Correspondence with R.L.C.J. Trines, Netherlands Agency for Energy and the Environment." October 29, 1991.

Turiel, Isaac. 1984. "Analysis of Energy Conservation Standards for Singapore Office Buildings." Vol. 10, No. 1.

Turiel, Isaac, Douglas Berman, Peter Chan, Terry Chan, Jonathan Koomey, Benoit Lebot, Mark D. Levine, James E. McMahon, Greg Rosenquist and Steve Stoft. 1990. "U.S. Residential Appliance Energy Efficiency: Present Status and Future Directions." In Proceedings of the 1990 ACEEE Summer Study on Energy Efficiency in Buildings. Washington, DC: American Council for an Energy Efficient Economy.

Turiel, Isaac, J. McMahon and L. Schipper. 1991. Residential Appliance Energy- 
Efficiency Standards: A Route for Sweden. Swedish Council for Building Research. May 1991.

U.S. DOE. 1988. Energy Conservation MultiYear Plan 1990-1994. Washington, DC: U.S. DOE. August 1988.

U.S. DOE. 1990. A Compendium of Energy Conservation Success Stories 90. Washington, DC: U.S. DOE. December 1990.

Vine, Edward L., Barry K. Barnes and Ron Ritschard. 1987a. Home Energy Rating Systems: Program Descriptions. Berkeley, CA: Lawrence Berkeley Laboratory. LBL-22919. February 1987.

Vine, Edward L., Barry K. Barnes and Ron Ritchard. 1987b. Implementation of Home Energy Rating Systems. Berkeley, CA: Lawrence Berkeley Laboratory. LBL-22872. February 1987.

Vine, Edward L. and Jeff Harris. 1988. Planning for an Energy-Efficient Future: The Experience with Implementing Energy Conservation Programs for New Residential and Commercial Buildings: Vol. 1. Berkeley, CA: Lawrence Berkeley Laboratory. LBL-25525. September 1988.

Wiel, S. 1990. "The Urgent Need for Verifying DSM Achievements." Presented at ACEEE 1990 Study on Energy Efficiency in Buildings. Washington, DC: American Council for an Energy Efficiency Economy.

Wolcott, D.R. 1990. "Definition, Evolution and Current Status of DSM Bidding". Presented at DSM Bidding: Challenges and Opportunities in Bala Cynwyd, Pennsylvania. Published by Synergic Resources Corporation.
Wolcott, D.R. 1991. "Performance Contracting and Demand-Side Management." In Performance Contracting for Energy and Environmental Systems.

Wong, Wai Ching. 1984. "Energy Conservation in Buildings in Singapore." Presented at Proceedings of the ASEAN Conference on Energy Conservation in Buildings.

World Bank. 1990. A Review of Regulation of the Power Sectors in the Developing Countries. Energy Series Paper No. 22. February 1990. 


\section{CHAPTER 5}

\section{CONCLUSIONS}

\subsection{IMPORTANCE OF ELECTRICITY END-USE EFFICIENCY}

Electricity generation is responsible for more than 30 percent of energy-related carbon dioxide emissions to the atmosphere. During the past twenty years, half of all increases in energyrelated carbon dioxide emissions were from electricity. There is strong reason to believe that the factors that have led in the past to electricity increasing its share of total energy demand will continue. A large fraction of growth in electricity generation will take place in the developing world.

Efforts to promote increased electricity enduse efficiency deserve serious consideration as means of reducing growth of greenhouse gas emissions. Other policy approaches that could significantly reduce growth of electricity-related emissions, without cutting growth of electricity services, are changing fuel from carbon-intensive sources and improving the thermal efficiency of converting fossil energy to electricity. These approaches also deserve serious attention, but they are not the topic of this paper.

\subsection{TECHNOLOGIES TO INCREASE ELECTRICITY END-USE EFFICIENCY}

Worldwide, industry uses about 50 percent of all electricity and buildings consume almost as much (45 percent). The largest users of electricity in buildings are air conditioning, lighting, appliances, and (in some regions) heating. The largest portion of industrial electricity is used by motors to power pumps, fans, compressors, and machine tools. Most of the remaining industrial use is in specific industrial processes in the chemical and metallurgical industries and in industrial buildings.

Technologies to significantly improve electricity efficiency exist for virually all of the buildings and industrial end-uses. Some of these technologies have already seen widespread application. For example, the average new refrigerator purchased in the United States uses half as much electricity as a comparable model purchased fifteen years ago. A typical new air conditioner uses one-third less electricity to produce the same cooling as a model purchased fifteen years ago. Heat pumps that replace electric resistance heating cut electricity use in half.

Numerous opportunities for future efficiency gains exist. Examples of more efficient technologies that have started to penetrate inarkets in many countries include compact fluorescent lamps that can replace incandescent lamps, higher-efficiency air conditioners for residential and commercial buildings, a variety of efficient appliances for residential use, fluorescent lamps with electronic ballasts and specular reflectors that can reduce electricity use by more than 50 percent, control systems in commercial buildings to reduce usage of air conditioning and lighting, efficient motors, controls for motors (such as variable speed drives) that can match the motor power to varying demands, and industrial process improvements that can reduce requirements for electricity. In addition to technology specifically aimed at increasing end-use efficiency, changes in industrial processes and in patterns of electricity usage in buildings and industry can also reduce the intensity of electricity use and thus carbon dioxide emissions. 
Estimates available today suggest that efficiency gains applied over the next fifteen to twenty years could increase efficiency of electricity use by about 30 to 40 percent at a cost of conserved electricity (evaluated at a 6 percent real discount rate) lower than current prices in industrialized countries. Current estimates of the efficiency gains for developing countries over the same time period are on the order of 20 to 30 percent. These savings are measured relative to a baseline with efficiencies fixed at today's levels and therefore include those efficiency improvements that will take place as a result of market forces. Finally, these estimates are based only on currently available technology. Continued investments in $R \& D$ are expected to lead to new, more efficient products, but many of these will require continued laboratory development, testing, and demonstrations before they are commercialized.

\subsection{FACTORS LIMITING ACCEPTANCE OF EFFICIENT TECHNOLOGIES}

While a portion of these end-use efficiency technologies will be introduced through normal market forces, there are many factors that have either limited or slowed market acceptance of efficient electricity end-use technologies. Some of the factors relate to the technology and its application. Examples include factors that affect the performance of a technology or are perceived as affecting performance (e.g., lower temperatures for clothes washing), physical barriers that impede application of the technology (e.g., difficulty in retrofitting insulation in walls of existing buildings), and instances where lower than average usage of the technology cause an unfavorable return on investment.

Other f́actors limiting acceptance of efficient technologies are market barriers and distortions. One of the most important involves the fact that the investment in efficiency is made by the enduser, who typically requires a high return on investment (a short payback period), while the investment in electricity generation is made by the electric utility, which accepts a much lower return on investment (longer payback time). If a typical consumer requires a 25 to 50 percent return on an investment in efficiency but a utility requires a 6 percent return on new supply (in constant dollars), then electricity will be produced by the utility at $\$ 0.07 / \mathrm{kWh}$ while end-use efficiency investments that save electricity at $\$ 0.02 / \mathrm{kWh}$ will be rejected.

There are other market factors that inhibit the acceptance of energy efficient technologies. High cost of credible information on efficient technologies and uncertainty about the actual savings are important factors. The difficulty of measuring electricity savings (which are obscured in utility bills) plays a role in consumers' reluctance to invest. The difficulty of finding efficient products and the time necessary to evaluate the information about the products often discourages purchase of efficient technology. Unavailability of capital or its high cost render otherwise sound investments in efficiency (and other products) unaffordable. Different parties being the beneficiary or the investor (as when a landlord pays for the efficiency measure but the tenant profits) result in rejection of energyefficient technologies.

This is a partial list of some of the factors explaining why consumers in all countries often fail to purchase products that would produce savings in electricity end-use. There are additional factors that operate especially in developing countries. Not only do many developing countries lack the trained people and industrial infrastructure for significant investments in efficiency, but the international institutions that could assist (with training or capital) have traditionally directed their efforts at electricity supply. There are often no institutions 
in developing countries for formulating or implementing policies to promote energy efficiency; if they do exist, they generally have little authority. Moreover, efficient products may not be available in developing countries. Assistance from industrialized countries that includes training programs can play a significant role in supporting developing countries to design and implement electricity end-use efficiency programs. Because a very large portion of future electricity growth is expected to take place in developing countries, attention to factors limiting the introduction of efficient technologies using electricity in these countries is important.

\subsection{EXPERIENCE WITH POLICIES}

Various policies have been carried out in different countries to stimulate adoption of technologies for increasing electricity end-use efficiency. Price reforms in countries where electricity prices are lower than costs can play an important role in promoting electricity end-use efficiency. Appliance standards have recently been adopted in the United States, and are projected to have a substantial impact on electricity growth in the residential sector. Many countries have adopted building standards. Incentives have been provided for manufacturers to produce more efficient products. In the United States and some European countries, electric utilities are carrying out large-scale demand-side management (DSM) programs. Several major U.S. utilities are planning to meet the majority of projected load growth during the 1990 s through investments in increased efficiency on the customer side of the meter. The experience with efficiency standards as well as utility DSM programs has demonstrated that these policies can be effective in promoting highly cost-effective investments in end-use efficiency; i.e., they provide energy savings at a cost well below electricity' supply from new power plants.
In recent years, utilities in some developing countries have successfully promoted electricity end-use efficiency. The Brazilian national utility has pursued DSM programs since 1985, investing about $\$ 20$ million and, by spurring investments by manufacturers and consumers, achieving savings equivalent to the output of 280 to $650 \mathrm{MW}$ of generating capacity. The national utility in Mexico now has substantial funds to pursue DSM. The government of Thailand has recently decided to have its utilities invest $\$ 183$ million (U.S.) over five years to acquire $225 \mathrm{MW}$ of savings through DSM applied to its customers.

These and other policies will be of interest to different countries depending on their particular circumstances. Many of the policies are complex, and there are many different ways in which they can be applied. In addition to policies for individual countries, consideration also needs to be given to international approaches to removing barriers to electricity end-use efficiency. In particular, developing countries may benefit from training and other types of assistance and cooperation to successfully pursue large-scale investments in end-use efficiency. Also, international lending institutions can play a significant role in promoting investments in enduse efficiency, but changes in policies and priorities of these institutions are needed for this to happen.

\subsection{SUMMARY OF FINDINGS}

The basic conclusions are:

- Half of the increases in energy-related carbon dioxide emissions in the last two decades came from electricity production. A comparable share is likely to come from electricity generation in the future.

- Increases in electricity end-use efficiency beyond those expected to occur under current 
policies can cut the growth of electricity use and associated carbon ernissions significantly.

- There has been sufficient experience with both technologies and policies to have confidence that significant increases in electricity end-use efficiency are possible in practice.

- Many end-use efficiency investments are more cost-effective than new electricity supply investments when evaluated using common criteria (e.g., using the same discount rate).

- Policies such as utility DSM programs, information and labeling programs, voluntary and mandatory appliance and building standards, and "golden carrot" financial incentives have been successful in accelerating investments in end-use efficiency. Policies that remove market distortions serve to promote both economic and end-use efficiency. Policies that try to compensate for market distortions indirectly can sometimes promote economically inefficient investments as well as economically efficient ones.

- Making these efficient electricity end-use technologies widely available in developing countries could contribute in important ways to a global effort to increase electricity end-use efficiency, thus reducing growth in electricity supply and in greenhouse gas emissions. 

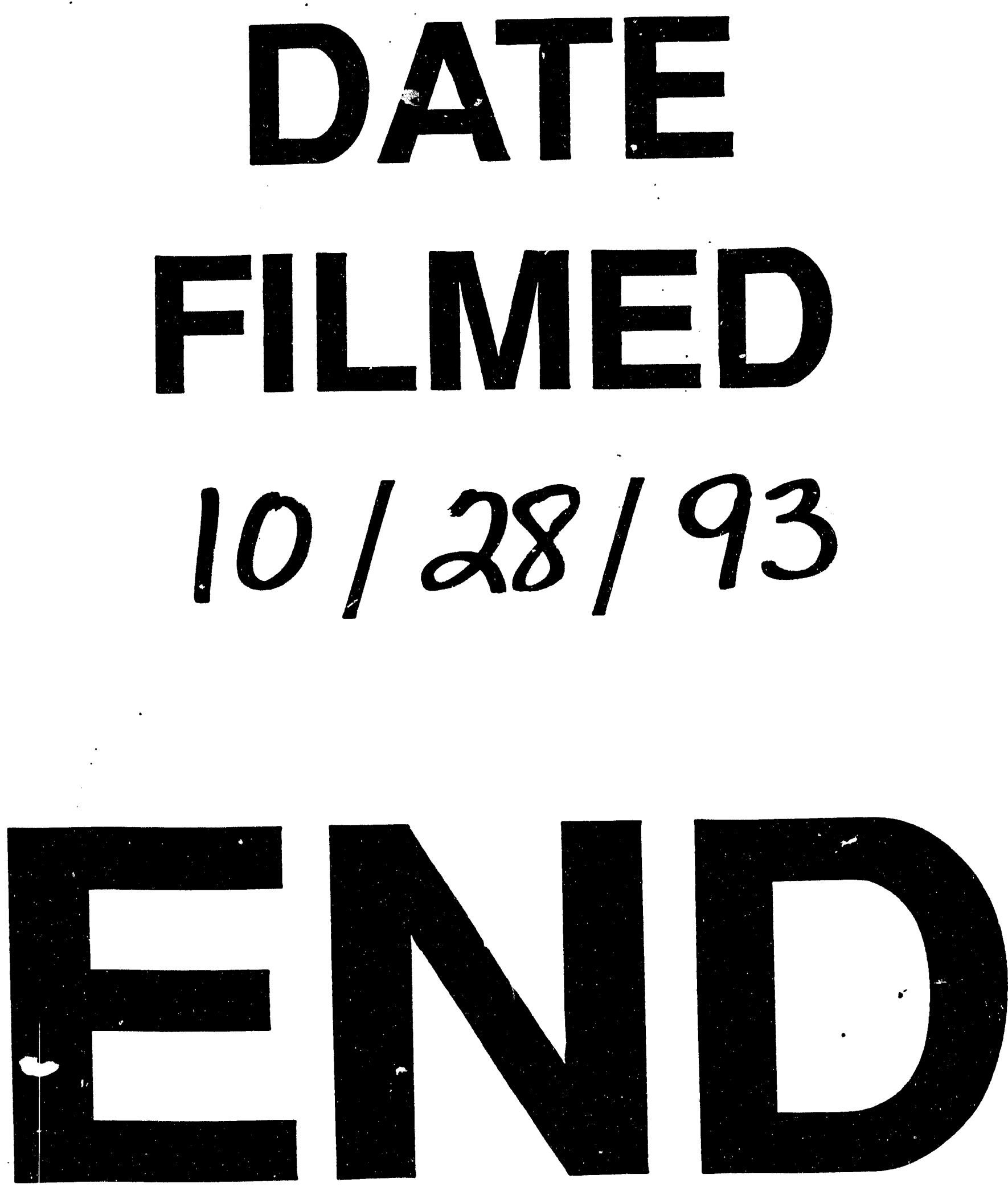
